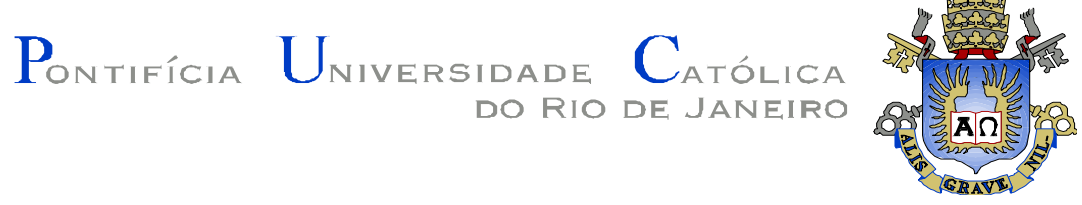

Elodie Bertrand

\title{
Anosognosia, Mood and Perspective-Taking in Mild to Moderate Alzheimer's Disease
}

Thesis presented to the Programa de Pós-graduação em Psicologia of PUC-Rio in partial fulfillment of the requirements for the degree of Doutor em Psicologia.

Advisor: Prof. Jesus Landeira-Fernandez

Co-Advisor: Prof Daniel Correa Mograbi 
Pontifícia Universidade Católica

Elodie Bertrand

\section{Anosognosia, Mood and Perspective-Taking in Mild to Moderate Alzheimer's Disease}

Thesis presented to the Programa de Pós-graduação em Psicologia of PUC-Rio in partial fulfillment of the requirements for the degree of Doutor em Psicologia. Approved by the undersigned Examination Committee.

Prof. Jesus Landeira-Fernandez

Advisor

Departamento de Psicologia - PUC-Rio

Prof. Daniel Correa Mograbi

Co-advisor

Departamento de Psicologia - PUC-Rio

Prof. Helenice Charchat Fichman

Departamento de Psicologia - PUC-Rio

Prof. Flavia Sollero de Campos Departamento de Psicologia - PUC-Rio

Prof. Jerson Laks Instituto de Psiquiatria - UFRJ

Prof. Bernardino Fernández Calvo

Departamento de Psicologia - UFPB

Prof. Monah Winograd

Vice Dean of Graduate Studies

Centro de Teologia e Ciências Humanas - PUC-Rio 
All rights reserved

\section{Elodie Bertrand}

Graduated in Psychology at the University of Strasbourg (France) in 2010 and obtained her M.Sc. Degree in Clinical and Cognitive Neuropsychology from the University of Strasbourg (France) in 2012.

Bibliographic data

Bertrand, Elodie

Anosognosia, mood and perspective-taking in mild to moderate alzheimer's disease / Elodie Bertrand; advisor: Jesus Landeira-Fernandez; co-advisor: Daniel Correa Mograbi. - 2017.

149 f. ; $30 \mathrm{~cm}$

Tese (doutorado) - Pontifícia Universidade Católica do Rio de Janeiro, Departamento de Psicologia, 2017.

Inclui bibliografia

1. Psicologia - Teses. 2. Doença de Alzheimer. 3. Consciência dos déficits. 4. Metacognição. 5. Anosognosia. 6. Humor. I. Landeira-Fernandez, Jesus. II. Mograbi, Daniel Correa. III. Pontifícia Universidade Católica do Rio de Janeiro. Departamento de Psicologia. IV. Título. 


\section{Acknowledgments}

Ao meu orientador, Professor Landeira-Fernandez, pela oportunidade e confiança em mim depositada para realizar este trabalho.

Ao meu co-orientador, Professor Daniel Mograbi. Estou profundamente grata por você ter confiado em mim e por ter me dado à oportunidade de realizar esse trabalho. Foi uma honra poder ter sido a sua primeira aluna de doutorado. Obrigada por ter me passado sua paixão pela pesquisa. Obrigada também pela qualidade da sua orientação, pelos seus conselhos e seu apoio ao longo dessa jornada.

I am grateful to Professor Robin Morris for having provided the major theoretical framework on which this work has been built. Thank you for your collaboration.

Aos Professores Jerson Laks e Marcia Dourado, pela colaboração e por ter me abrindo as portas do Centro da Doença do Alzheimer no IPUB (UFRJ).

I would like to thank Professor Stephanie Cosentino for kindly welcoming me in her lab. Thank you for having always your door open, our exchanges have usefully nourished this work.

A very special thanks to my labmates at the Taub Institute: Silvia, Martina, Preeti and Sara, for their friendship. Our personal and professional discussions made this work richer.

A CAPES, pelo apoio financeiro.

Aos meus colegas na PUC-Rio e todos os membros do Mograbilab. Ticiana, obrigada pela ajuda com a coleta de dados. Rodrigo, obrigada pelo seu apoio e sua amizade na reta final desse trabalho. Carol, a minha grande amiga, estou grata por ter tido você de meu lado, que seja no Brasil ou um pouquinho mais longe.

A todos os funcionários do Departamento de Psicologia, especialmente Marcelina e Vera, pela grande ajuda.

A todos os participantes dessa pesquisa, especialmente a todos os pacientes e seus cuidadores. Estou muito grata por ter aprendido tanto trabalhando com vocês.

Aos meus sogros, Angela, Paulo José e Denise, às minhas cunhadas, Paula e Carolina, aos meus concunhados, Joel e Romulo, e a Catarina e Marco. Obrigada por ter me acolhido no Brasil com tanto carinho. 
A mes parents, Christine et Marcel, à qui je dois tout et plus encore. Ainsi qu'à ma sœur, Adeline, mon beau-frère, Antonio et mon neveu, Alessio. Merci pour votre amour et votre soutien par-delà les frontières.

A ma mamie, Théodora (in memoriam), pour son soutien et son amour inconditionel.

Ao meu marido, Felipe, pelo amor, carinho e apoio sem limites e sem fronteiras, em todos os momentos dessa jornada. Obrigada por tudo. 


\section{Abstract}

Bertrand, Elodie; Landeira-Fernandez, Jesus (Advisor); Mograbi, Daniel Correa (Co-advisor). Anosognosia, Mood and Perspective-Taking in Mild to Moderate Alzheimer's Disease. Rio de Janeiro, 2017. 149p. Tese de Doutorado - Departamento de Psicologia, Pontifícia Universidade Católica do Rio de Janeiro.

Lack of awareness about cognitive deficits or illness, also named anosognosia, is a common feature of Alzheimer's disease (AD). However, there is variability in the presentation and severity of anosognosia in patients with AD. Based on the Cognitive Awareness Model (CAM), this thesis aims to explore experimentally two factors which could possibly influence the awareness of cognitive abilities in $\mathrm{AD}$, namely current mood state and the perspective through which the information is presented. The first section of this thesis explores the impact of mood state on awareness of deficits. As it has been suggested in the CAM that emotional biases could influence the access to personal memories, consequently leading to anosognosia, a systematic literature review was conducted to understand better the mood-congruent memory effect in healthy adults (Article 1). Then, we present an experimental study investigating this hypothesis in AD (Article 2). In this study, negative and neutral mood states were experimentally induced using four Success-Failure Manipulation (SFM) tasks, two based on reaction time tasks and the other on memory tasks. The results showed an improvement of awareness of symptoms after negative mood induction, but only when the task used in the SFM was memory-based. The second section of this work investigates if the perspective through which the information is presented (self vs. other) has an influence on metacognitive abilities of patients with AD. Indeed, a literature review highlighted that studies exploring the impact of perspective taking on metacognition with different neurologic and psychiatric populations showed that patients are able to recognize deficits in others, despite lack of awareness of their own difficulties (Article 3). Then, an experimental study was conducted by asking AD patients and controls to evaluate their own performance on four different tasks, as well as the performance of a well-known person (caregiver/spouse/friend) (Article 4). Our findings highlight that overall both groups made higher overestimation when evaluating the performance of a well-known person. However, AD patients tended to 
overestimate more the performance compared to controls but only in the memory experiment. In summary, results of these studies give experimental support to three aspects suggested by the CAM as factors influencing awareness of deficits. First, the findings on the relationship between mood and awareness support the idea of emotional biases in memory as a partial explanation for anosognosia. Second, the results showing that AD patients appraise the evaluation of selfperformance differently than the evaluation of a well-known person's performance support the inclusion of different memory records for self- and otherinformation in the reformulated version of the CAM. Third, by presenting differences in results depending on the type of task used in the SFM (reaction time vs. memory), our findings reinforce the concept that awareness is multidimensional, on which is based the modular aspect of the CAM.

\section{Keywords}

Alzheimer's Disease; Awareness of Deficits; Metacognition; Anosognosia; Mood; Mood-Congruent Memory; Perspective-Taking. 


\section{Resumo}

Bertrand, Elodie; Landeira-Fernandez, Jesus (Orientador); Mograbi, Daniel Correa (Co-orientador). Anosognosia, humor e tomada de perspectiva na Doença de Alzheimer leve a moderada. Rio de Janeiro, 2017. 149p. Tese de Doutorado - Departamento de Psicologia, Pontifícia Universidade Católica do Rio de Janeiro.

A falta de consciência dos déficits cognitivos ou da doença (ou anosognosia) é uma característica frequente na doença de Alzheimer (DA). No entanto, existe uma variabilidade na apresentação e na severidade da anosognosia em pacientes com DA. Com base no "Cognitive Awareness Model" (CAM), esta tese tem como objetivo explorar experimentalmente dois fatores que podem possivelmente influenciar a consciência das habilidades cognitivas, a saber, o estado de humor atual e a perspectiva através da qual a informação é apresentada, na DA. A primeira parte desta tese explora o impacto do estado de humor na consciência dos déficits. Como sugerido no CAM que vieses emocionais podem influenciar o acesso para memórias pessoais, consequentemente levando a anosognosia, uma revisão sistemática da literatura foi conduzida para entender melhor o efeito de memória congruente ao humor em adultos saudáveis (Article 1). Em seguida, apresentamos um estudo experimental investigando esta hipótese na DA (Article 2). Nesse estudo, estados de humor negativos e neutros foram experimentalmente induzidos usando quatro tarefas de "Success-Failure Manipulation" (SFM), duas tarefas com base no tempo de reação e duas com base na memória. Os resultados mostraram um aumento da consciência dos sintomas após a indução de humor negativo, mas somente quando a tarefa usada no SFM era com base na memória. A segunda parte deste trabalho investiga se a perspectiva através qual a informação é apresentada (auto vs. outro) influencia as habilidades metacognitivas de pacientes com DA. De fato, uma revisão da literatura destacou que estudos explorando o impacto da tomada de perspectiva na metacognição com diferentes populações neurológicas e psiquiátricas mostraram que os pacientes são capazes de reconhecer déficits em outros, apesar da apresentar uma falta de consciência das suas próprias dificuldades (Article 3). Em seguida, um estudo experimental foi conduzido pedindo para pacientes com DA e controles avaliar o seu próprio desempenho em quatro diferentes tarefas, assim 
como avaliar o desempenho de uma pessoa conhecida (cuidador/esposo/amigo) (Article 4). Nossos resultados destacam que, em geral ambos os grupos superestimaram mais quando avaliavam o desempenho de uma pessoa conhecida. No entanto, pacientes com DA tenderam a superestimar mais o desempenho em comparação com controles, mas somente no experimento envolvendo tarefas de memória. Em resumo, os resultados destes estudos dão suporte experimental a três aspectos sugeridos pelo CAM como fatores influenciando a consciência de déficits. Em primeiro lugar, as achados sobre a relação entre humor e consciência apoiam à ideia de vieses emocionais na memória como uma explicação parcial para anosognosia. Em segundo lugar, os resultados mostrando que os pacientes com DA avaliam o próprio desempenho de uma forma diferente em comparação a avaliação do desempenho de uma pessoa conhecida apoiam à inclusão de diferentes registros de memória para informações pessoais e para informações sobre os outros na versão reformulada do CAM. Em terceiro lugar, nossos achados mostrando diferenças nos resultados dependendo do tipo de tarefa usado no SFM (tempo de reação vs. memória) reforçam o conceito de uma consciência dos déficits como sendo multidimensional, conceito que está na base do aspecto modular do CAM.

\section{Palavras-chave}

Doença de Alzheimer; Consciência dos déficits; Metacognição; Anosognosia; Humor; Memória congruente ao humor; Tomada de perspectiva. 


\section{Table of contents}

I. Theoretical background .............................. 14

1. Alzheimer's disease.............................. 14

2. Unawareness of impairments in AD ................... 15

3. Cognitive Awareness Model......................... 17

4. Awareness and mood................................. 19

5. Awareness, self and other........................... 21

II. Objectives......................................... 23

III. Articles section.................................. 24

- Article 1: Mood-Congruent Memory in Healthy Adults: A Systematic Review................. 25

- Article 2: Mood-congruent recollection and anosognosia in Alzheimer's disease............... 66

- Article 3: Metacognition and perspective-taking in Alzheimer's disease: a mini-review.................. 89

- Article 4: Metacognition and perspective taking in Alzheimer's Disease............................ 108

IV. General discussion.................................... 130

V. References............................................. 135 


\section{List of figures}

\section{THEORETICAL BACKGROUND}

Figure 1 - Cognitive Awareness Model (CAM)

\section{ARTICLE 1}

Figure 1 - Studies included in the final review

\section{ARTICLE 2}

Figure 1 - Awareness of symptoms during experiment 1

Figure 2 - Awareness of symptoms during experiment 2

\section{ARTICLE 3}

Figure 1 - Cognitive Awareness Model (CAM)

\section{ARTICLE 4}

Figure 1 - Bar graph of the mean with standard deviation of the OJD per condition during Experiment 1 (reaction time).

a) AD, b) Controls

Figure 2 - Bar graph of the mean with standard deviation of the OJD per condition during Experiment 2 (memory).

a) $A D$, b) Controls 


\section{List of tables}

\section{ARTICLE 1}

Table 1 - Quality assessment criteria for included studies

Table 2 - Characteristics of the studies reviewed

\section{ARTICLE 2}

Table 1 - Sample characteristics

Table 2 - Anosognosia questionnaire

Table 3 - Self-reported emotion before and after the SFM for the success and failure condition in Experiment 1 (reaction time)

Table 4 - Self-reported emotion before and after the SFM for the success and failure condition in Experiment 2 (memory)

\section{ARTICLE 4}

Table 1 - Sample characteristics

Table 2 - Performance and awareness of performance (OJD) during Experiment 1 (reaction time) for success and failure conditions in the both groups

Table 3 - Performance and awareness of performance (OJD) during Experiment 2 (memory) for success and failure conditions in the both groups 


\section{List of abbreviations}

ACMS Autobiographical Conceptual Memory System

AD

Alzheimer's disease

AES

Apathy Evaluation Scale

AQ-D

Anosognosia Questionnaire-Dementia

BPSD

Behavioral and psychological symptoms of dementia

CAM

Cognitive Awareness Model

CCMs

Cognitive Comparator Mechanisms

CDA

Center for Alzheimer's disease and Related Disorders

CDM Context-dependent memory

DMN Default Mode Network

DSM Diagnostic and Statistical Manual of Mental Disorders

EEG Electroencephalography

fMRI Functional Magnetic Resonance Imaging

FTD

Fronto-temporal dementia

GDS

Geriatric Depression Scale

GMS

Generic Memory System

IPUB-UFRJ Institute of Psychiatry of the Federal University of Rio de Janeiro

MAS Metacognitive Awareness System

MCM Mood-congruent memory

MDM Mood-dependent memory

MIP Mood induction procedure

MMSE Mini-Mental State Examination

NINCDS- National Institute of Neurological and Communicative Diseases

ADRDA and Stroke/Alzheimer's Disease and Related Disorders Association

OJD Objective-Judgement Discrepancy

PDB Personal Database

PwD People with dementia

SFM Success-failure manipulation 


\section{THEORETICAL BACKGROUND}

\section{Alzheimer's disease}

Alzheimer's disease $(A D)$ is the most common form of dementia in older adults, representing 60 to $80 \%$ of all dementia cases (ALZHEIMER'S ASSOCIATION, 2015). With a global aging population, the number of people with dementia (PwD), especially $A D$, is increasing. According to the Alzheimer's Disease International (ALZHEIMER'S DISEASE INTERNATIONAL, 2015), 46.8 million people are currently living with dementia, and studies suggest that this number will increase in the near future, with estimations of double the number of people who are affected by dementia by 2030 (WIMO; JONSSON; WINBLAD, 2006).

The clinical presentation of $A D$ is centered on progressive cognitive decline, with the key feature being impaired acquisition and retrieval of information (LOEWENSTEIN, 2013). This initial deficit in episodic memory is thought to be the result of early pathological changes involving the hippocampus and adjacent cortical areas (APOSTOLOVA; THOMPSON, 2008; BRAAK; BRAAK, 1996). With the progression of the disease, other cognitive domains are affected and impairment such as aphasia, apraxia and agnosia are reported (LOEWENSTEIN, 2013). Additionally, with AD neuropathology spreading to the frontal cortex, executive functioning is also compromised (COLLETTE; VAN DER LINDEN, 2004; COLLETTE; VAN DER LINDEN; SALMON, 1999).

In addition to the characteristic cognitive deficits, behavioral and psychological symptoms of dementia (BPSD) are an integral part of $A D$ (CEREJEIRA; LAGARTO; MUKAETOVA-LADINSKA, 2012; ZHAO et al., 2016). BPSD are a widespread series of non-cognitive symptoms, including apathy, aggression, delusions, psychosis, hallucinations anxiety, irritability, depression and sleep disorders (VAN DER LINDE et al., 2014). The presence of BPSD has important negative consequences on $A D$ 
patients and their caregivers. For instance, BPSD result in premature institutionalization, increased cost of care and diminished quality of life for both patients and caregivers (BLACK; ALMEIDA, 2004; FEAST et al., 2016; SCARMEAS et al., 2007; SCHALLER et al., 2015). BPSD have also been shown to be correlated with another significant characteristic of $A D$, namely, unawareness of cognitive deficits (MOGRABI et al., 2015).

\section{Unawareness of impairments in $A D$}

Lack of awareness for cognitive and/or behavioral deficits, also termed anosognosia, is a common characteristic in AD (MORRIS; HANNESDOTTIR, 2004; MORRIS; MOGRABI, 2013). There is variability in the presentation and severity of anosognosia in patients with $A D$, with unawareness ranging from slight minimization to complete denial of the condition (CLARE et al., 2005) When explored in large samples, the prevalence of impaired awareness in AD have consistently been reported to be above 30\% (MOGRABI et al., 2012a; STARKSTEIN et al., 2006, 2007). However, these estimations range widely, from $20 \%$ to $81 \%$ depending on the studies (MIGLIORELLI et al., 1995; MOGRABI et al., 2012a). These variations certainly reflect differences in the criteria used to define awareness, the disease severity of the sample and also the method of assessing awareness (CLARE et al., 2005; MORRIS; HANNESDOTTIR, 2004). In the literature, three main methods of awareness assessment are described: clinician rating scales, discrepancy between patient and informant report, discrepancy between patient evaluation and actual performance on a specific task. The multidimensional aspect of awareness also contributes to variations in its prevalence in dementia. Indeed, the degree of unawareness in AD varies considerably, ranging from slight minimization to complete denial of problems (CLARE et al., 2005). Another striking feature of awareness is that it can vary according to its object. For example, some studies (KOTLER-COPE; CAMP, 1995; VASTERLING et al., 1995a) suggested 
that patients with $A D$ present better awareness of behavioral difficulties relative to cognition.

Anosognosia has major psychosocial implications on three spheres (BERTRAND; LANDEIRA-FERNANDEZ; MOGRABI, 2013). First, lack of awareness regarding cognitive and behavioral disturbances influences negatively the course of the illness (SPALLETTA et al., 2012). Indeed, AD patients with anosognosia are more likely to present a poorer quality of life, to engage in high risk situation, such as driving, and to refuse treatment (ARLT et al., 2008; HURT et al., 2010; SELTZER et al., 1997). Second, because anosognosia leads to an increased need for family support, studies conducted over the last 20 years have clearly demonstrated a link between the presence of anosognosia and an increased caregiver burden (CLARE et al., 2011; RYMER et al., 2002; TURRÓ-GARRIGA et al., 2013). Finally, unawareness of deficits amplifies the cost of dementia for the society, through earlier institutionalization, increased need of care for AD patients and their caregivers (BERTRAND; LANDEIRA-FERNANDEZ; MOGRABI, 2013; STEFANACCI, 2011; WIMO et al., 2013; ZHU et al., 2015)

In the literature, anosognosia is used as a synonym of deficits in metacognition. However, it is important to highlight that the two terms rely on different theoretical frameworks (SOUCHAY, 2007). Metacognition, defined as the knowledge and reflective capacities one has concerning one's own cognitive functioning (FLAVELL, 1979), is based on the functioning of awareness in the normal population. By contrast, the concept of anosognosia focuses on deficits in awareness in clinical populations and it was described in the context of various neurological and psychiatric conditions, such as dementia, traumatic brain injury, hemiplegia due to stroke and schizophrenia (MOGRABI; BROWN; MORRIS, 2009; STUSS, 1991; STUSS et al., 2005). Additionally, "denial of deficits" can also be found in the literature, though its use usually refers to the psychological defense mechanism in place when patients avoid confronting their impairments (MCGLYNN; SCHACTER, 1989). Note that in the present work, we will use the terms "deficits in metacognition", 
"anosognosia" and "unawareness of deficits" interchangeably to refer to a symptom primarily caused by a neurocognitive disturbance.

\section{Cognitive Awareness Model}

As described above, anosognosia is considered a multidimensional phenomenon. The Cognitive Awareness Model (CAM; AGNEW; MORRIS, 1998; MORRIS; HANNESDOTTIR, 2004; MORRIS; MOGRABI, 2013) (see Figure 1) is a theoretical model of anosognosia, which tries to encompass this heterogeneity. According to this model, each individual constantly evaluates his own performance on everyday tasks by comparing it to his expected performance, with comparisons operating on different levels.

Through perceptual processes, the incoming information about performance is initially processed locally, in domain-specific modules, before being monitored at a more central level by the Cognitive Comparator Mechanisms (CCMs). This multi-level monitoring helps to explain domain-specific anosognosia, such as anosognosia for hemiplegia. CCMs compare this incoming information to the individual's self-knowledge, stored in the Personal Database (PDB). Indeed, the PDB contains semanticized representations of personal ability, as being part of an individual's self-concept and is updated when the comparator mechanisms detect a mismatch between the two sources of data, current and expected performance. The PDB is also based on the materiel stored in another memory record, the Autobiographical Conceptual Memory System (ACMS), which contains lifetime knowledge concerning experienced events in relation to the self. If the individual presents longterm memory deficits, as it is the case in AD, the ACMS and PDB cannot be used by the comparator mechanisms and the PDB fails to be updated due to impairment in consolidation. This long-term memory failure would lead to a mnemonic anosognosia (HANNESDOTTIR; MORRIS, 2007; MOGRABI; BROWN; MORRIS, 2009). It should be noted that in the last version of the CAM (MORRIS; MOGRABI, 2013), a third memory record is 
also described, the Generic Memory System (GMS), which stores other types of material, especially non-self information. This idea is supported by recent neuroimaging findings highlighting different pattern of activation during self-reflective processing than during other referential processes (FEYERS et al., 2010; VAN DER MEER et al., 2010). This distinction between self and other-memory records and its experimental and clinical implication will be explored in more detail later in the present work.

In addition to its role in updating the PDB, the output of the comparison is also feeding into the Metacognitive Awareness System (MAS), which is the mechanism necessary to provide awareness regarding the individual's ability. Impairment at the MAS level would prevent the result of the comparison between current and expected performance to be registered consciously, causing a primary anosognosia. Based on clinical observations and on experimental findings highlighting that unaware patients may present signs of acknowledgement of cognitive deficits despite no explicit recognition (for review see MOGRABI; MORRIS, 2013), the model predicts a parallel route for the comparison output, bypassing awareness provided by the MAS. This "implicit awareness" may allow modulation of the individual's affect and behavior, even in absence of explicit awareness. The relationship between awareness and affect is discussed further in the next section. 
Figure 1-Cognitive Awareness Model (CAM)

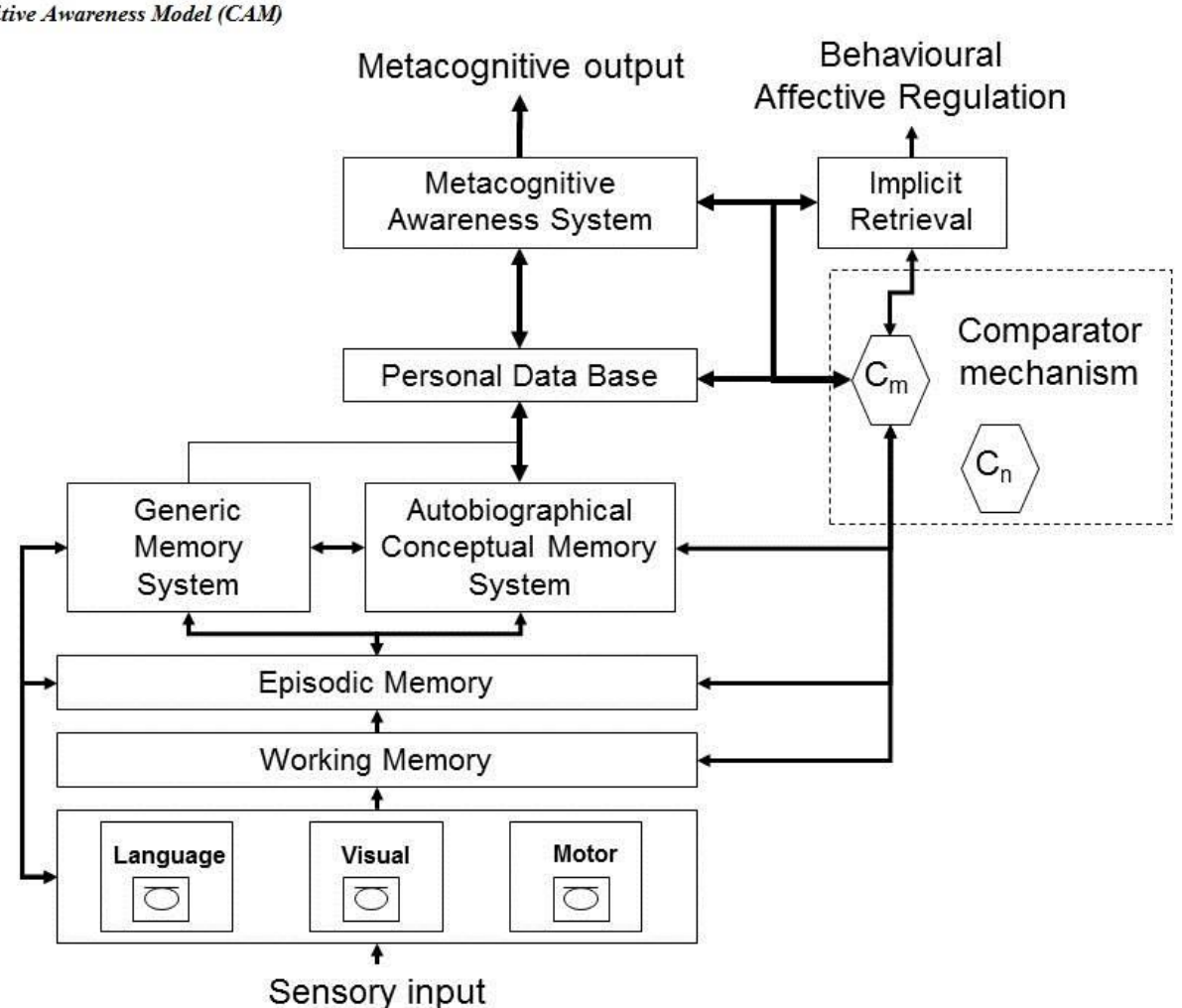

Reprinted from Cortex, Vol. 49, Issue 6, Morris, R.G., \& Mograbi, D.C., "Anosognosia, autobiographical memory and self knowledge in Alzheimer's disease", pp. 1553-1565, Copyright 2013, with permission from Elsevier.

\section{Awareness and mood}

An important aspect of awareness in dementia is its relation with mood state. Indeed, many studies exploring the clinical correlates of anosognosia in $A D$ highlighted a negative association between depression and anosognosia, with increased depression associated with more awareness (CLARE et al., 2012a; HARWOOD; SULTZER; WHEATLEY, 2000; STARKSTEIN et al., 1997). However, some studies were not able to find this relationship (LOPEZ et al., 1994; MANGONE et al., 1991; ZANETTI et al., 1999). These discrepant results can be explained by methodological differences, such as the sample size or the criteria used to define depression. The type of measurement used to assess depression (clinician, caregiver or self-rating) can also affect the results, considering that, as suggested by Agnew and Morris (AGNEW; MORRIS, 1998), AD patients who are unaware of their cognitive deficits may also lack awareness regarding depressive symptoms. Nevertheless, the few studies 
exploring specifically unawareness for mood disturbance showed mixed results, with one indicating that patients with $A D$ present better awareness of depression relative to cognition (VASTERLING et al., 1995a) and another study highlighting that $A D$ patients demonstrate difficulties to recognize their own depressive symptoms, leading the authors to propose the term "affective anosognosia" (VERHÜLSDONK et al., 2013). In conclusion, while the relationship between awareness of deficits and mood is well established, the direction of causality is still debated in the literature.

Additionally, another question regarding the relation between awareness and mood has recently been explored: are AD patients presenting appropriate emotional responses, despite lack of awareness of their performances? Using computerized tasks permitting to match error rates between groups, Mograbi, Brown, Salas, and Morris (MOGRABI et al., 2012b) investigated emotional reactivity to failure experience in $A D$ patients and age-matched controls. The results indicated that, in a failure situation, patients with $A D$ exhibited a similar level of emotional reactivity as did controls, despite unawareness of their performance. The authors interpreted these results as the evidence of implicit awareness, which has been defined as the indirect manifestation of some degree of knowledge about a deficit even without verbal acknowledgment of this deficit (MOGRABI; MORRIS, 2013). Using a modified emotional Stroop test including memory-related words (e.g. remember, forgetful), Martyr and colleagues (MARTYR et al., 2011) also highlighted the preservation of implicit awareness in PwD. For instance, they showed that PwD presented an increased reaction time for condition-related words, which was comparable to the caregivers' results. However, this effect was not correlated with the participants' level of explicit awareness (measured by clinician rating based on extensive interviews with patients and caregivers).

Furthermore, in this context, it is worth mentioning the well-explored relationship between mood and memory. Indeed, as mentioned above, the pronounced memory deficits characteristic of $A D$ could partly explain the 
lack of awareness for cognitive deficit. The phenomena of mooddependent memory (MDM) and mood-congruent memory (MCM) are the most explored effects of mood on memory in the literature. MDM is defined as the memory improvement when the individual's mood is similar at the moment of encoding and retrieval (BOWER, 1981; EICH; METCALFE, 1989), whereas MCM refers to the recovery enhancement of material for which the emotional valence is the same as the individual's current mood state (BOWER, 1981). In the CAM, the authors already suggested that emotional biases, namely the MCM and MDM effects, could affect the access to memories stored in PDB and consequently could impair awareness. Despite numerous studies showing changes in emotional processes in AD (ERGIS; PIOLINO; MURE, 2003; FERNÁNDEZMARTÍNEZ et al., 2008; SHAJI; BOSE; KURIAKOSE, 2009), we are not aware of any research exploring these phenomena in $A D$ patients.

\section{Awareness, self and other}

The distinction between self- and other-awareness seems an important feature of metacognition, with behavioral evidence from different clinical groups showing that metacognitive abilities can vary according to the perspective through which the information is presented. For instance, in anosognosia for hemiplegia, it has been highlighted that sessions of video self-observation could improve the awareness for motor deficits after stroke (BESHARATI et al., 2015; FOTOPOULOU et al., 2009). Similarly, a couple of studies pointed to awareness enhancement in psychotic patients after seeing videos of themselves during an acute psychotic episode (DAVID; CHIS STER; ZAVAREI, 2012; DAVIDOFF et al., 1998; VIKRAM et al., 2008). In addition, findings suggest that unaware individuals (e.g. unawareness of motor deficits or of psychotic symptoms) may be able to acknowledge deficits in others (GARRETT et al., 2011; RAMACHANDRAN; ROGERS-RAMACHANDRAN, 1996).

In the context of dementia, studies exploring the capacity of AD patients to evaluate another individual's performances showed mixed results, which 
can be partly explained by methodological differences. Indeed, in Duke and colleagues (DUKE et al., 2002), AD patients were asked to estimate the performance of a well-known and an unknown person, based on normative data. Results showed that $A D$ patients were more accurate when estimating their spouses (well-known person) but overestimated the fictional patient (unknown person). In contrary, AD patients were able to recognize deficits and give appropriate advice to a fictional individual described in a vignette (CLARE et al., 2012b). Finally, when asked to judge the level of difficulty of a cognitive task for themselves and for someone else their own age, AD patients predicted that others would find the task as difficult as they themselves did, despite their cognitive deficits (MOGRABI et al., 2014a). In conclusion, the different methodological features in these studies do not permit to generalize the results and further research is needed to better understand the difference between self- vs other-evaluation in AD.

Regarding theoretical implications of the experimental results, the notion of a distinction between self vs. other processing has been incorporated in the reformulated CAM (MORRIS; MOGRABI, 2013), with the inclusion of distinct memory systems for the storage of self and non-self information (i.e. PDB and ACMS for self-information and GMS for non-self information). 


\section{OBJECTIVES}

On the basis of the theoretical background presented above, the present thesis will be composed of two literature reviews, with the following objectives:

- To provide a review of the literature regarding the phenomena of MDM and MCM in healthy subjects;

- To identify the published studies exploring the distinction between self- and other-awareness in different clinical populations, including AD.

We also propose two experimental studies, with the following objectives:

- To explore the impact of the current mood state (experimentally induced) on the level of awareness of AD patients;

- To investigate the dissociation between self and non-self evaluation in patients with $A D$. 
III. ARTICLES SECTION 


\section{ARTICLE 1}

Bertrand, E., Morris, R. G., Landeira-Fernandez, J., \& Mograbi, D. C. Mood-Congruent Memory in Healthy Adults: A Systematic Review. (Manuscript submitted for publication) 


\section{ABSTRACT}

Mood-congruent memory ( $\mathrm{MCM}$ ) is defined as the facilitation to remember emotional material when the emotional valence of this material is congruent with current mood. This phenomenon has important clinical implications, especially because of its involvement in mood disorders, such as depression. The present systematic review discusses the factors contributing to the occurrence of MCM in healthy adults and its theoretical and clinical implications. We argue that characteristics of the material used in the memory task (e.g. structure, valence intensity, self vs otherreference) and characteristics of the subjects (e.g. personality, physiological arousal) are factors likely to modulate the presence of MCM. Ultimately, there is a need for further research investigating the phenomenon in more ecological settings and exploring the neuroanatomical correlates underlying the effect of MCM.

Key words: emotion, mood, cognition, memory, mood-congruent memory 


\section{Introduction}

During the last two decades, numerous studies explored the influence of emotional state on cognitive processes (EICH et al., 2000). However, the relationship between mood and cognition, and in particular between mood and memory, has been discussed for centuries. Already in the eighteenth century, the French thinker Voltaire had written: "We retain by heart despite yourself and that is why we say "remember by heart", because what touches the heart is engraved in the memory" (1764, p.150). Throughout the twentieth century, cognitive science demonstrated a link between memory and emotions through a variety of ideas, amongst them, the concept of Mood-Congruent Memory (MCM) (BLANEY, 1986; BOWER, 1981).

MCM is the phenomenon through which the recovery of emotional material is facilitated when the emotional valence of this material is congruent with current mood (BOWER, 1981). For example, when feeling sad, it is easier to retrieve stimuli with a negative emotional valence. Thereby, this effect is important because of the likely involvement in the genesis of emotional disorders, such as depression. Indeed, cognitive theories of depression support the hypothesis that MCM may be a critical factor for vulnerability to depression and also for the maintenance of depressive symptoms (TEASDALE, 1983; VAN WINGEN et al., 2010; WATKINS, 2002), for example through the rumination of negative information which involves a process akin to MCM (NOLEN-HOEKSEMA, 1991, 2000).

MCM is distinct from Mood-Dependent Memory (MDM), which in turn is part of the global phenomenon of State-Dependent Memory (SDM) in which memory is enhanced if the state at encoding and retrieval of information is generally the same $(\mathrm{EICH}, 1980)$. In the case of SDM, the state represents the physiological, internal environment of the subject and can be psychopharmacological (DARLEY et al., 1974; DUKA; WEISSENBORN; DIENES, 2001), or emotional, which is the case in MDM (BOWER, 1981; EICH; METCALFE, 1989; NUTT; LAM, 2011). Therefore, MDM is defined as the ability to increase the recall of any type of material, 
when the subject's emotional state is the same at the time of encoding and at the time of retrieval, regardless of the content of the material.

This work focuses on the exploration of MCM, an effect for which results are variable, but this variability is likely to be in part due to methodological differences between studies rather than weak statistical properties of the effect (BARRY; NAUS; REHM, 2004; ELLWART; RINCK; BECKER, 2003; WATKINS, 2002). Indeed, researchers have used different experimental procedures, with variations of type of task (e.g. explicit memory, implicit memory) and mood induction procedure (e.g. hypnosis, viewing videos, listening to music, reading sentences with emotional valence). These variations in experimental procedures make the generalization of results difficult. The MCM studies may be tapping into different contextual memory phenomena, depending on how different memory systems are being utilized. Consequently, we perceived a need to conduct a systematic review of the literature concerning this phenomenon in order to understand better the mechanisms of MCM.

The purpose of the current article is to present a systematic review of the literature on MCM in healthy adults. This will allow to: 1 - clarify the characteristics of this phenomenon; 2 - explain the contribution of the factors behind the variation in findings; and 3 - explore the possible implications of this mechanism in the case of depression. In addition, by identifying methodological limitations in the existing literature, this work aims to provide guidelines to improve the design of future studies in this area.

\section{Method}

\subsection{Literature search}

Searches were conducted in PubMed and PsycINFO databases and updated until January 06, 2016. We used combinations of the following keywords: 'context' OR 'state' OR 'mood'; 'dependent' OR 'congruent'; and 'memory' OR 'learning' OR 'retrieval' OR 'encoding' OR 'bias'. We employed filters to restrict the search to articles only involving human 
adults and published in English. No limit of time period was applied to this search. An a priori decision was made to search only published work and to control for publication bias in a posterior analysis.

\subsection{Inclusion/exclusion criteria}

Original articles found had their titles and abstracts screened, and were only included if they included healthy subjects and explored the impact of emotional state on retrieval of emotional material. In addition, articles regarding clinical populations, such as major depressive disorder or anxiety disorder, were excluded, as well as articles involving studies with animals and those exploring mathematical models. Furthermore, reviews and case reports were not analysed in this systematic review.

Whenever possible, eligible studies were retrieved in full text for screening (using the same criteria used to screen the abstracts). Finally, references of the articles selected were checked for additional relevant articles.

\subsection{Quality assessment}

E.B. performed the quality assessment of included studies. A quality assessment form was devised which focused on sampling, measurement of outcomes and analysis (Table 1). In accordance with the Cochrane Collaboration recommendations (HIGGINS; GREEN, 2008), an overall score was not generated, with a risk of bias judgment of "yes", "no" or "unclear" being given instead for individual domains. If a study received more than two "no" or three "unclear" judgments, the study was considered as having poor quality and was excluded from the review. 
Table 1. Quality assessment criteria for included studies

\begin{tabular}{ll|l}
\hline & & $\begin{array}{l}\text { Judgment } \\
\text { (yes/no/unclear) }\end{array}$ \\
\hline & $\begin{array}{l}\text { Was the study design appropriate to } \\
\text { answer the research question? }\end{array}$ & \\
Sampling & Was the sampling method appropriate? & \\
& $\begin{array}{l}\text { If applicable, was the control group } \\
\text { comparable to the experimental group? }\end{array}$ & \\
Measurement & Were potential confounding variables & \\
& measured? & \\
\hline Analysis & Was the analysis appropriate? & \\
\hline
\end{tabular}

\section{Results}

The search generated a list of five hundred and sixty-eight articles. Only 34 articles met the inclusion criteria. An additional 22 articles were identified for the review by scanning the reference lists of these studies. Out of the 56 resulting articles, 41 were selected after application of the qualitative assessment, with a total of 68 studies being included (see Figure 1 and Table 2, for a summary). 
Figure 1. Studies included in the final review

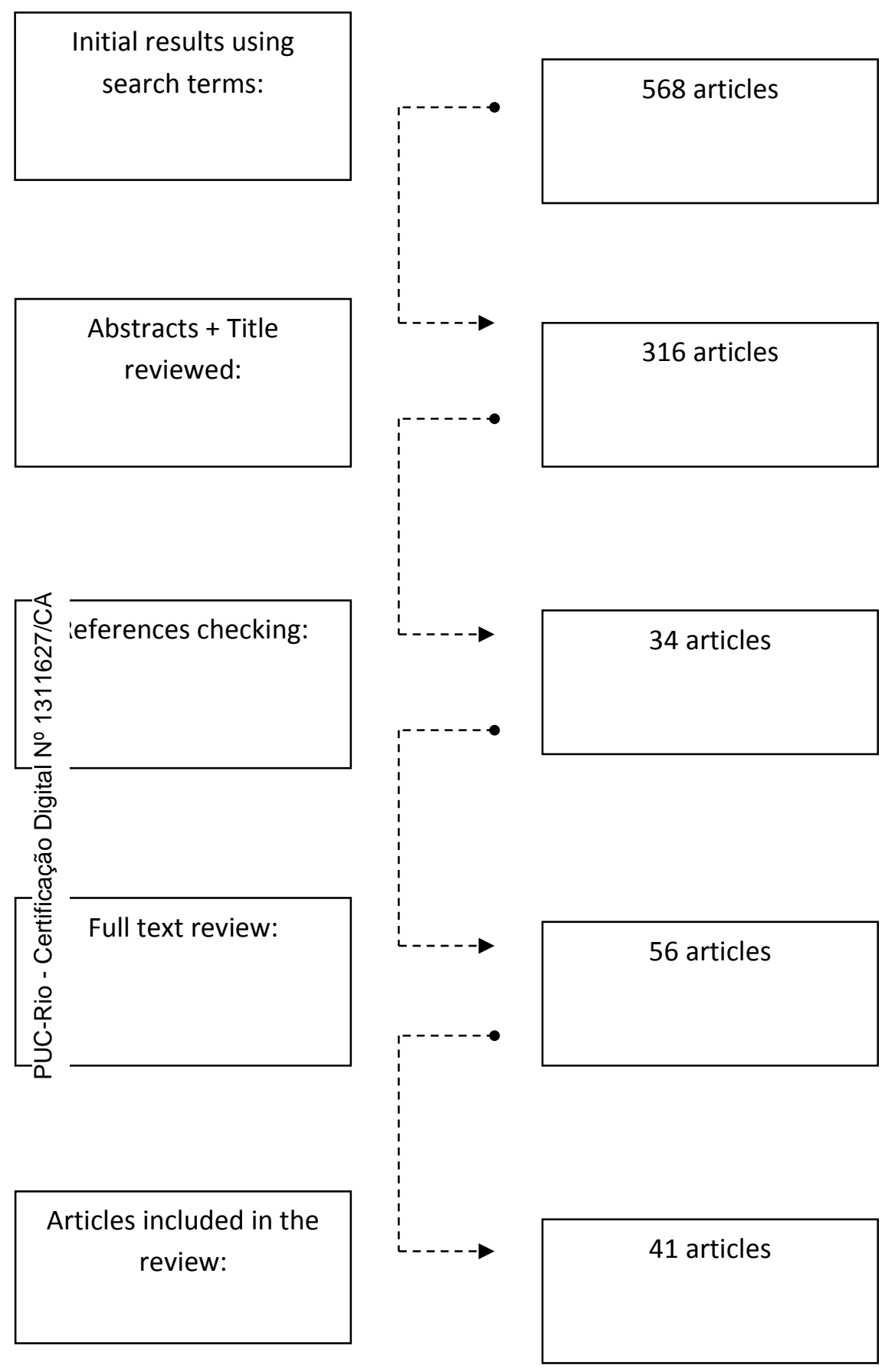

- Removal of duplicates

- Removal of papers in languages other than English

252 papers removed

- Review of title and abstract

- Application of exclusion and inclusion criteria

282 papers excluded

- Check of references for additional relevant articles

- Addition of 22 articles

- Application of the quality assessment

- 7 articles unable to obtain the full text

- 8 articles studying only MoodDependent Memory 
Table 2. Characteristics of the studies reviewed 


\begin{tabular}{|c|c|c|c|c|c|c|c|}
\hline $\begin{array}{l}\text { Authors } \\
\text { (Year) }\end{array}$ & $\begin{array}{c}\mathrm{N}^{\circ} \\
\text { subjects }\end{array}$ & Subjects' age & $\begin{array}{c}\text { MIP } \\
\text { (Type of MIP) }\end{array}$ & $\begin{array}{l}\text { Evaluation of } \\
\text { mood }\end{array}$ & Memory task & $\begin{array}{c}\text { Memory task } \\
\text { material }\end{array}$ & $\begin{array}{c}\text { MCM } \\
\text { demonstrated }\end{array}$ \\
\hline \multirow{2}{*}{\multicolumn{8}{|c|}{ 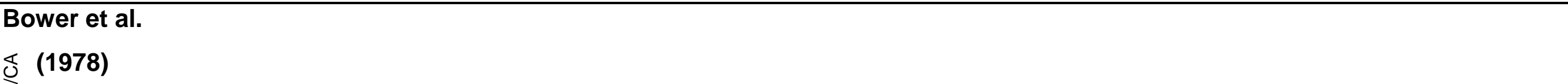 }} \\
\hline & & & & & & & \\
\hline $\operatorname{Exp} 1$ & 10 & undergraduates & Yes (hypnosis) & self reported & explicit retrieval & word list & No \\
\hline $\operatorname{Exp} 2$ & 16 & undergraduates & Yes (hypnosis) & self reported & explicit retrieval & word list & No \\
\hline Exp 3 & 24 & students & Yes (hypnosis) & self reported & explicit retrieval & word list & No \\
\hline 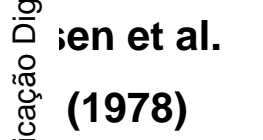 & & & & & & & \\
\hline Exp 2 & 47 & students & Yes (success or failure & None & explicit retrieval & word list & Yes \\
\hline. & & & to a game) & & & & \\
\hline 仓ે asdale et & 43 & students & Yes (Velten procedure) & self reported & autobiographical & neutral word & Yes \\
\hline al. & & & & & memory & cues & \\
\hline \multicolumn{8}{|l|}{$(1980)$} \\
\hline \multirow{2}{*}{\multicolumn{8}{|c|}{$\begin{array}{c}\text { Bower et al. } \\
\text { (1981) }\end{array}$}} \\
\hline & & & & & & & \\
\hline $\operatorname{Exp} 1$ & 16 & undergraduates & Yes (hypnosis) & observation & explicit retrieval & story & Yes \\
\hline $\operatorname{Exp} 2$ & 16 & adults & Yes (hypnosis) & None & explicit retrieval & story & No \\
\hline Exp 3 & 32 & undergraduates & Yes (hypnosis) & None & explicit retrieval & story & Yes \\
\hline $\operatorname{Exp} 4$ & 16 & undergraduates & Yes (hypnosis) & self reported & explicit retrieval & story & No \\
\hline $\operatorname{Exp} 5$ & 16 & undergraduates & Yes (hypnosis) & self reported & explicit retrieval & story & Yes \\
\hline
\end{tabular}


(1982)

\begin{tabular}{|c|c|c|c|c|c|c|c|}
\hline $\operatorname{Exp} 1$ & 30 & undergraduates & $\begin{array}{l}\text { Yes (Velten } \\
\text { procedure) }\end{array}$ & self reported & $\begin{array}{c}\text { autobiographical } \\
\text { memory }\end{array}$ & none & Yes \\
\hline Exp 2 & 97 & undergraduates & $\begin{array}{c}\text { Yes / No (Velten } \\
\text { procedure) }\end{array}$ & self reported & $\begin{array}{c}\text { autobiographical } \\
\text { memory }\end{array}$ & list of activities & Yes \\
\hline 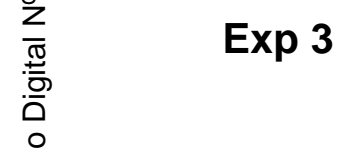 & 50 & undergraduates & $\begin{array}{l}\text { Yes (Velten } \\
\text { procedure) }\end{array}$ & None & $\begin{array}{c}\text { autobiographical } \\
\text { memory }\end{array}$ & list of activities & No \\
\hline 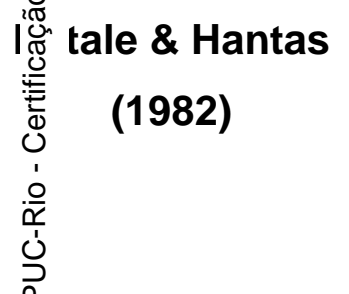 & 54 & 17 to 32 & $\begin{array}{l}\text { Yes (hypnosis + } \\
\text { Velten procedure) }\end{array}$ & $\begin{array}{l}\text { self reported + } \\
\text { psychomotor }\end{array}$ & $\begin{array}{c}\text { autobiographical } \\
\text { memory + explicit } \\
\text { retrieval }\end{array}$ & $\begin{array}{l}\text { none / word } \\
\text { list } \\
\text { (personality } \\
\text { traits) }\end{array}$ & Yes \\
\hline $\begin{array}{c}\text { Teasdale \& } \\
\text { Russell } \\
\text { (1983) }\end{array}$ & 32 & $\begin{array}{c}\text { mean age }= \\
20,4\end{array}$ & $\begin{array}{l}\text { Yes (Velten } \\
\text { procedure) }\end{array}$ & $\begin{array}{l}\text { self reported + } \\
\text { psychomotor }\end{array}$ & explicit retrieval & word list & Yes \\
\hline $\begin{array}{c}\text { Gilligan \& } \\
\text { Bower } \\
\text { (1983) }\end{array}$ & 16 & adults & Yes (hypnosis) & None & $\begin{array}{c}\text { autobiographical } \\
\text { memory + explicit } \\
\text { retrieval }\end{array}$ & phrases & No/Yes \\
\hline $\begin{array}{c}\text { Mecklenbräuker } \\
\text { \& Hager } \\
\text { (1984) }\end{array}$ & 64 & 18 to 32 & $\begin{array}{l}\text { Yes (Velten } \\
\text { procedure) }\end{array}$ & self reported & explicit retrieval & story & No \\
\hline
\end{tabular}




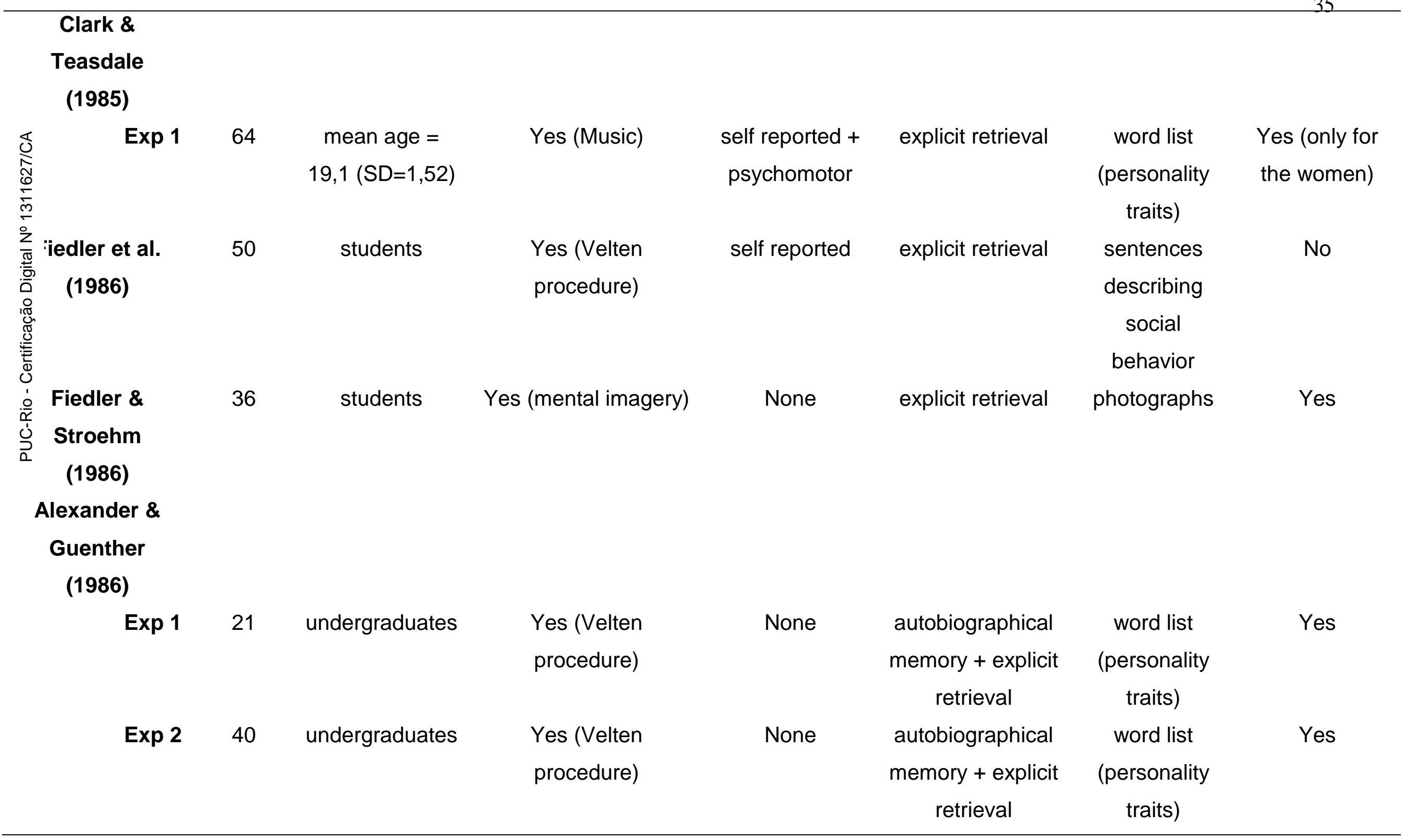


(1988)

\begin{tabular}{|c|c|c|c|c|c|c|c|}
\hline Exp 1 & 26 & students & Simulating mood & Self reported & explicit retrieval & word list & Yes \\
\hline \multicolumn{8}{|l|}{$\begin{array}{l}\text { 太ิ Salovey \& } \\
\frac{0}{\mathrm{~m}} \text { inger (1989) }\end{array}$} \\
\hline 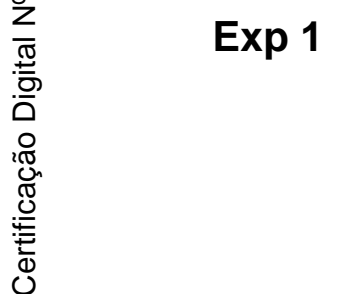 & 60 & undergraduates & $\begin{array}{c}\text { Yes (self-generated } \\
\text { imagery) }\end{array}$ & self reported & $\begin{array}{c}\text { autobiographical } \\
\text { memory } \\
\text { (childhood } \\
\text { memories) }\end{array}$ & none & No \\
\hline Exp 2 & 36 & undergraduates & $\begin{array}{c}\text { Yes (self-generated } \\
\text { imagery) }\end{array}$ & self reported & $\begin{array}{c}\text { autobiographical } \\
\text { memory ("last } \\
\text { week" memories) }\end{array}$ & none & Yes \\
\hline Exp 3 & 66 & undergraduates & $\begin{array}{c}\text { Yes (self-generated } \\
\text { imagery) }\end{array}$ & self reported & $\begin{array}{l}\text { autobiographical } \\
\text { memory } \\
\text { (childhood + } \\
\text { recent memories) }\end{array}$ & none & Yes \\
\hline $\begin{array}{l}\text { Lewis \& Williams } \\
\qquad(1989)\end{array}$ & 28 & students & Yes (Hypnosis) & None & explicit retrieval & word list & Yes \\
\hline \multicolumn{8}{|l|}{$\begin{array}{c}\text { Bower \& Mayer } \\
\text { (1989) }\end{array}$} \\
\hline Exp 1 & 48 & students & Yes (Hypnosis) & self reported & explicit retrieval & word list & Yes \\
\hline Exp 3 & 24 & students & Yes (Hypnosis) & self reported & explicit retrieval & word list & Yes \\
\hline
\end{tabular}




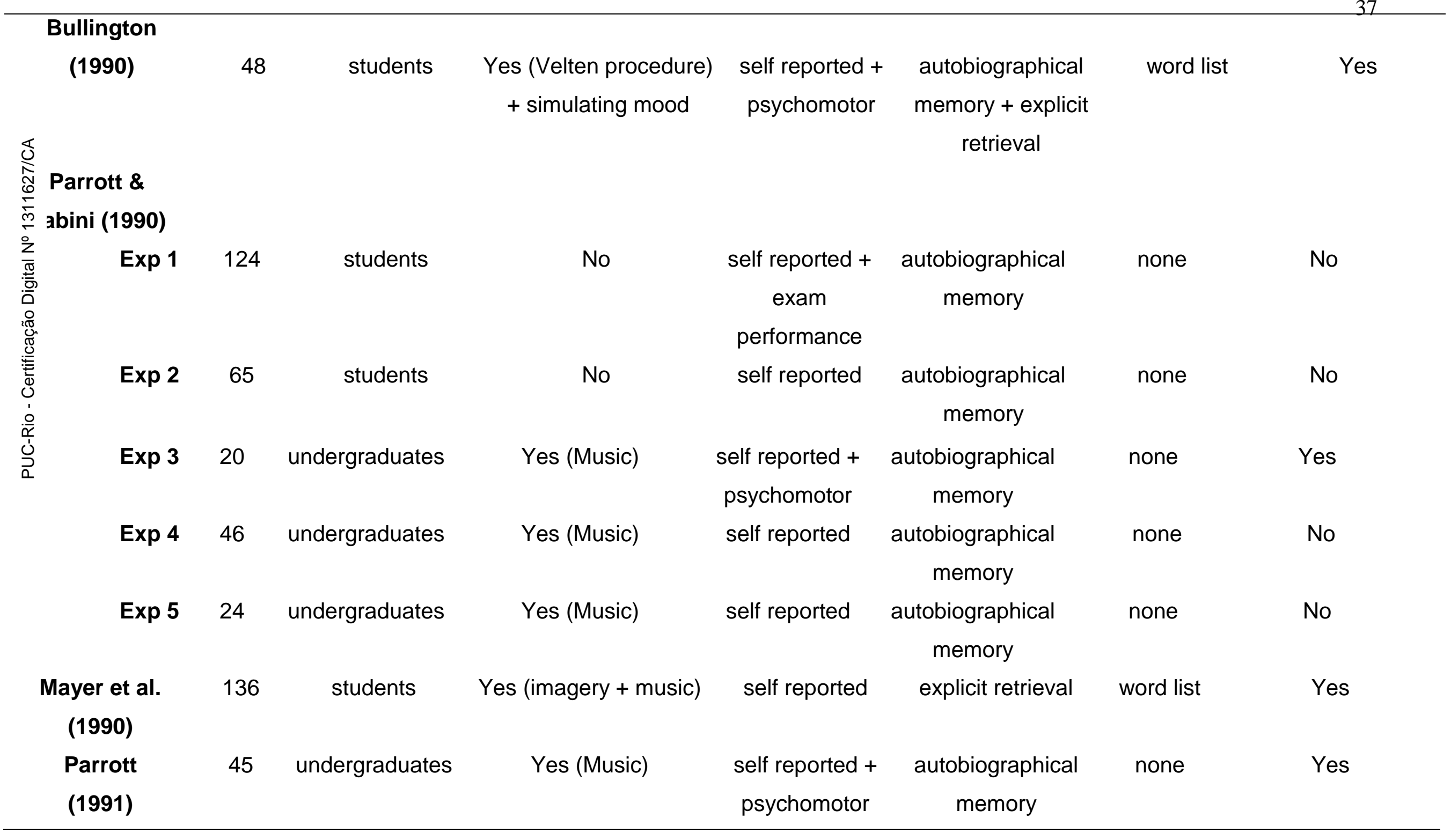


Rinck et al.

(1992)

\begin{tabular}{|c|c|c|c|c|c|c|c|}
\hline Exp 1 & 48 & undergraduates & $\begin{array}{c}\text { Yes (suggestion } \\
\text { technique) }\end{array}$ & self reported & explicit retrieval & word list & Yes \\
\hline Exp 2 & 48 & undergraduates & $\begin{array}{c}\text { Yes (suggestion } \\
\text { technique) }\end{array}$ & self reported & explicit retrieval & word list & Yes \\
\hline 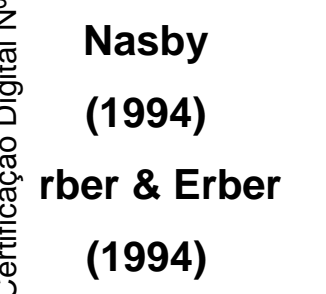 & 84 & undergraduates & Yes (Velten procedure) & $\begin{array}{l}\text { self reported + } \\
\text { psychomotor }\end{array}$ & explicit retrieval & word list & Yes \\
\hline Exp 2 & 64 & undergraduates & $\begin{array}{c}\text { Yes (memory elicitation } \\
\text { instructions) }\end{array}$ & & $\begin{array}{c}\text { autobiographical } \\
\text { memory }\end{array}$ & none & Yes \\
\hline $\begin{array}{l}\text { Bradley et al. } \\
\qquad(1994)\end{array}$ & 53 & students & No & self reported & $\begin{array}{c}\text { implicit retrieval + } \\
\text { explicit retrieval }\end{array}$ & word list & Yes \\
\hline \multicolumn{8}{|l|}{$\begin{array}{c}\text { Mayer et al. } \\
\text { (1995) }\end{array}$} \\
\hline Exp 1 & 200 & students & No & self reported & implicit retrieval & & Yes \\
\hline Exp 2 & 223 & students & No & self reported & implicit retrieval & & Yes \\
\hline Exp 3 & 193 & students & No & self reported & implicit retrieval & & Yes \\
\hline
\end{tabular}




\section{Boden \&}

\section{Baumeister}

(1997)

\begin{tabular}{|c|c|c|c|c|c|c|c|}
\hline $\operatorname{Exp} 1$ & 60 & undergraduates & Yes (Video tape) & None & $\begin{array}{c}\text { autobiographical } \\
\text { memory }\end{array}$ & none & Yes \\
\hline $\begin{array}{c}\text { Exp } 2 \\
\text { arner \& Ellis } \\
\text { (1998) }\end{array}$ & 17 & undergraduates & Yes (Video tape) & None & $\begin{array}{c}\text { autobiographical } \\
\text { memory }\end{array}$ & none & No \\
\hline $\operatorname{Exp} 1$ & 40 & undergraduates & $\begin{array}{l}\text { Yes (Reading } \\
\text { statements) }\end{array}$ & self reported & explicit retrieval & word list & Yes \\
\hline Exp 2 & 72 & undergraduates & $\begin{array}{l}\text { Yes (Reading } \\
\text { statements) }\end{array}$ & self reported & explicit retrieval & word list & Yes \\
\hline \multicolumn{8}{|l|}{$\begin{array}{l}\text { Rusting } \\
\text { (1999) }\end{array}$} \\
\hline $\operatorname{Exp} 1$ & 142 & students & No & self reported & $\begin{array}{c}\text { explicit retrieval + } \\
\text { implicit retrieval }\end{array}$ & $\begin{array}{c}\text { word list } \\
\text { (homophones) }\end{array}$ & Yes \\
\hline Exp 2 & 79 & undergraduates & Yes (music + imagery) & self reported & $\begin{array}{c}\text { explicit retrieval + } \\
\text { implicit retrieval }\end{array}$ & $\begin{array}{c}\text { word list } \\
\text { (homophones) }\end{array}$ & Yes \\
\hline $\begin{array}{c}\text { Eich \& } \\
\text { Macaulay } \\
(2000)\end{array}$ & 48 & undergraduates & Simulating mood & self reported & $\begin{array}{c}\text { autobiographical } \\
\text { memory }\end{array}$ & $\begin{array}{l}\text { neutral word } \\
\text { cues }\end{array}$ & Yes \\
\hline
\end{tabular}




\begin{tabular}{|c|c|c|c|c|c|c|c|}
\hline $\begin{array}{l}\text { Maccallum et al. } \\
\qquad(2000)\end{array}$ & 24 & $\begin{array}{c}\text { mean age }= \\
20,17 \\
(S D=5,50)\end{array}$ & Yes (hypnosis) & $\begin{array}{l}\text { self reported + } \\
\text { psychomotor }\end{array}$ & $\begin{array}{c}\text { autobiographical } \\
\text { memory }\end{array}$ & $\begin{array}{l}\text { emotional } \\
\text { word cues }\end{array}$ & $\begin{array}{l}40 \\
\text { Yes }\end{array}$ \\
\hline \multicolumn{8}{|l|}{ 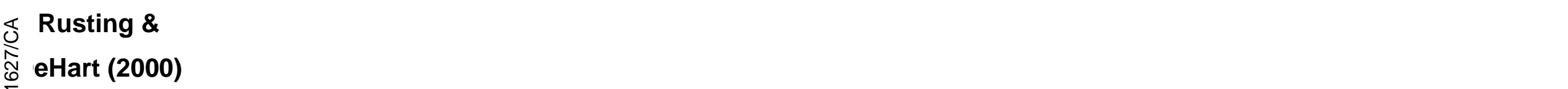 } \\
\hline Exp 1 & 59 & students & Yes (imagery) & self reported & $\begin{array}{c}\text { autobiographical } \\
\text { memory }\end{array}$ & none & Yes \\
\hline Exp 2 & 60 & students & Yes (imagery) & self reported & explicit retrieval & word list & Yes \\
\hline 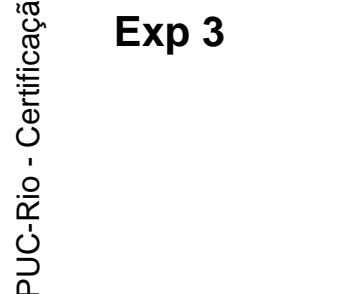 & 60 & students & $\begin{array}{c}\text { Yes (idiographic } \\
\text { negative mood } \\
\text { induction / remember } \\
\text { past experiences) }\end{array}$ & self reported & explicit retrieval & word list & Yes \\
\hline Exp 4 & 117 & undergraduates & No & self reported & $\begin{array}{c}\text { autobiographical } \\
\text { memory }\end{array}$ & none & Yes \\
\hline \multicolumn{8}{|l|}{$\begin{array}{l}\text { Fiedler et al. } \\
\text { (2001) }\end{array}$} \\
\hline $\operatorname{Exp} 1$ & 57 & students & Yes (Video tape) & self reported & explicit retrieval & $\begin{array}{c}\text { word list } \\
\text { (synonymous) }\end{array}$ & Yes \\
\hline Exp 2 & 80 & students & Yes (Video tape) & self reported & explicit retrieval & $\begin{array}{c}\text { word list } \\
\text { (synonymous) }\end{array}$ & Yes \\
\hline $\begin{array}{l}\text { Klaassen et al. } \\
\qquad(2002)\end{array}$ & 27 & $\begin{array}{c}18 \text { to } 61 \\
(30,9)\end{array}$ & Yes (pharmaceutical) & self reported & explicit retrieval & word list & Yes \\
\hline
\end{tabular}




\begin{tabular}{|c|c|c|c|c|c|c|c|}
\hline $\begin{array}{l}\text { Lewis et al. } \\
\text { (2005) }\end{array}$ & 18 & $\begin{array}{c}\text { mean age }= \\
29\end{array}$ & $\begin{array}{c}\text { Yes (Music + emotional } \\
\text { faces) }\end{array}$ & $\begin{array}{l}\text { self reported + } \\
\text { physiological }\end{array}$ & explicit retrieval & word list & Yes \\
\hline $\begin{array}{l}\text { Miranda \& } \\
\text { ک ihlstrom } \\
\text { ড̂ (2005) }\end{array}$ & 86 & 17 to 35 & Yes (Music) & self reported & $\begin{array}{c}\text { autobiographical } \\
\text { memory }\end{array}$ & word & Yes \\
\hline 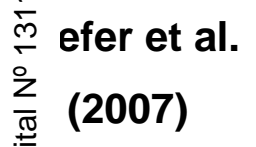 & 38 & $\begin{array}{c}\text { mean age }= \\
26\end{array}$ & Yes (Music) & self reported & explicit retrieval & word list & Yes \\
\hline 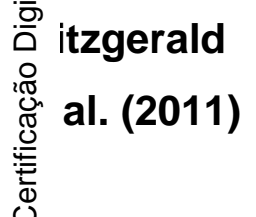 & 24 & $\begin{array}{c}\text { mean age }= \\
22,8 \\
(\mathrm{SD}=3,7)\end{array}$ & Yes (Video tape) & self reported & explicit retrieval & word list & Yes \\
\hline 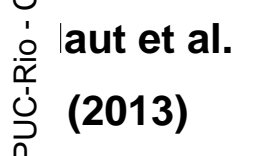 & 71 & $\begin{array}{l}\text { mean age }= \\
22(S D=2,5)\end{array}$ & No (n/a) & self reported & explicit retrieval & word list & Yes \\
\hline $\begin{array}{l}\text { Loeffler et } \\
\text { al. (2013) }\end{array}$ & 55 & $\begin{array}{c}\text { mean age }= \\
25,3(18 \text { to } \\
45)\end{array}$ & No (n/a) & psychophysiological & explicit retrieval & word list & Yes \\
\hline
\end{tabular}




\subsection{Sample characteristics}

The total sample sizes ranged from 10 (BOWER; GILLIGAN; MONTEIRO, 1981) to 223 subjects (MAYER; MCCORMICK; STRONG, 1995). The samples in the studies were primarily of undergraduate students. In nine articles, more detailed sample characteristics were provided, and mean age in these studies ranged from 20.17 ( $S D=5.50$ ) (MACCALLUM et al., 2000) to 30.9 ( $S D=10.9$ ) years (KLAASSEN et al., 2002).

\subsection{Type of mood manipulation}

Studies can be divided into different groups based on the type of mood used to explore the effect of memory congruency to the emotional state. Indeed, most studies used a Mood Induction Procedure (MIP), while a smaller fraction of the studies are based on the "natural" mood of the subjects or simulation of a specific mood state.

\subsubsection{Natural mood}

Ten studies (BLAUT et al., 2013; BRADLEY; MOGG; WILLIAMS, 1994; LOEFFLER; MYRTEK; PEPER, 2013; MAYER; MCCORMICK; STRONG, 1995, Experiment 1, Experiment 2, Experiment 3; PARROTT; SABINI, 1990, Experiment 1, Experiment 2; RUSTING, 1999, Experiment 1; RUSTING; DEHART, 2000, Experiment 4) used the current natural emotional state of the subjects, that is, subjects' mood was not induced using a MIP. In all studies, the mood state was self-rated by the subjects and their degree of current positive or negative affect could then be linked to the extent of mood congruent material retrieval or otherwise.

Some studies used naturally occurring mood to explore differences within subjects but without manipulating their emotional state. For example, Parrott and Sabini (1990, Experiment 1) evaluated the subjects after they received their exam results, assuming that the grade would affect the students' mood. The same group also used the weather as a mood influencer: one group of subjects was evaluated on a sunny day and the 
other on a cloudy day (PARROTT; SABINI, 1990, Experiment 2), assuming that this type of context would influence the subjects' mood. These two studies were not able to demonstrate a mood congruency effect on memory, when evaluating this effect on retrieval of autobiographical memories.

Rusting and DeHart (2000, Study 4) also used the natural context in order to measure differences of emotional state. They tested the subjects on the first day of classes, assuming that the subjects would be in a positive or neutral mood, or in another moment of the semester before an important examination, which was considered as the negative mood condition. In contrast with Parrott and Sabini (1990), these authors were able to show an effect of MCM for the recall of personal events.

One study (LOEFFLER; MYRTEK; PEPER, 2013) explored MCM in everyday life, outside the laboratory and without manipulating subjects' mood. The subjects were asked to rate their mood every 10-20 minutes and when they were in a positive or a negative state, a memory task was done. This study was able to demonstrate an MCM effect in daily life.

\subsubsection{Simulated mood}

Three studies (BULLINGTON, 1990; EICH; MACAULAY, 2000; PERRIG; PERRIG, 1988) used mood simulation, asking subjects to behave as if they were in a specific emotional state (positive or negative) without really experiencing this emotion. An MCM effect was demonstrated for autobiographical memory (PERRIG; PERRIG, 1988) and for explicit retrieval of a word list (EICH; MACAULAY, 2000). Bullington (1990) employed simulated mood to explore the effect of demand characteristics on MCM for autobiographical memory. For one group, the emotional state was experimentally manipulated, while the other group was asked to simulate a specific mood. In this study, the author demonstrated an MCM effect for the group who received a MIP but there was no effect in the "simulation" group. 


\subsubsection{Induced mood}

The majority of the studies (55 of 68) used a MIP to explore the MCM effect. Different methodologies have been used to induce specific emotional states, with the most commonly used procedures being the Velten technique and hypnosis.

The Velten procedure consists of reading a series of self-referent statements that are designed to elicit a particular mood state. This MIP was used in twelve studies. Only three studies using this MIP were not able to demonstrate a MCM effect, one evaluating autobiographical memory (SNYDER; WHITE, 1982, Experiment 3) and two exploring explicit retrieval of verbal material (FIEDLER; STROEHM, 1986; MECKLENBRAUKER; HAGER, 1984).

Natale and Hantas (1982) combined the Velten procedure with hypnosis and showed a MCM effect in an autobiographical memory task and also in an explicit retrieval task for emotionally toned words. In one article, a modified version of the Velten procedure was used (VARNER; ELLIS, 1998). The two studies described in this article demonstrated a MCM effect evaluating explicit memory for a word list on immediate and delayed free recall.

Hypnosis was used as a MIP in thirteen studies. Only one study used this MIP to explore the MCM effect in autobiographical memory (MACCALLUM et al., 2000) and the results demonstrated a significant advantage for mood congruent memories. The other studies using hypnosis explored the explicit retrieval for verbal material (emotional phrases or words with emotional connotation, stories with positive or negative characters). Five studies (BOWER; GILLIGAN; MONTEIRO, 1981, Experiment 2, Experiment 4; BOWER; MONTEIRO; GILLIGAN, 1978, Experiment 1 Experiment 2, Experiment 3) did not indicate a significant MCM effect, in contrast with others, which were able to show this effect (BOWER; GILLIGAN; MONTEIRO, 1981, Experiment 1, Experiment 3, Experiment 5; BOWER; MAYER, 1989, Experiment 1, Experiment 3; GILLIGAN; BOWER, 1983; LEWIS; WILLIAMS, 1989). 
Similar to the hypnosis technique, Rinck, Glowalla and Schneider (1992) used a suggestion technique, with the difference that this MIP permits the recruitment of non-hypnotizable subjects. In the three studies described in this article, the authors showed a MCM effect for explicit retrieval of a word list.

Five studies (BODEN; BAUMEISTER, 1997, Experiment 1, Experiment 2; FIEDLER et al., 2001, Experiment 1, Experiment 2; FITZGERALD et al., 2011) used film clips (happy, sad or neutral) to induce a specific mood state. From these studies, three evaluated explicit memory for words, and all were able to show a MCM effect (FIEDLER et al., 2001, Experiment 1, Experiment 2; FITZGERALD et al., 2011). Two studies using film clips as a MIP explored MCM on autobiographical memory. Boden and Baumeister (1997, Experiment 1) demonstrated a MCM effect but they were not able to replicate this result in a complementary study (BODEN; BAUMEISTER, 1997, Experiment 2).

Rusting and DeHart (2000, Experiment 1, Experiment 2) used mental imagery to induce negative mood and were able to demonstrate a MCM effect on autobiographical memory retrieval and explicit memory (free recall of a word list). Fiedler and Stroehm (1986) explored the MCM effect by employing the same MIP and also showed a significant effect using visual material (photographs). Also using imagery to induce a positive or a negative mood state, Salovey and Singer (1989) revealed a MCM effect for the retrieval of recent and remote autobiographical memories. The mental imagery technique has also been combined with music listening (MAYER et al., 1990; RUSTING, 1999, Experiment 2), leading to a MCM effect for explicit retrieval of a list of emotionally toned words.

Music has also been combined with a procedure in which the subjects were asked to look at pictures showing emotional faces (LEWIS et al., 2005) and this study was successful to show a MCM effect for explicit retrieval of a word list. Seven studies (CLARK; TEASDALE, 1985, Experiment 1; KIEFER et al., 2007; MIRANDA; KIHLSTROM, 2005; PARROTT, 1991; PARROTT; SABINI, 1990, Experiment 3, Experiment 4, 
Experiment 5) used music listening alone to induce a specific mood state. Five of these studies evaluated autobiographical memory (MIRANDA; KIHLSTROM, 2005; PARROTT, 1991; PARROTT; SABINI, 1990, Experiment 3, Experiment 4, Experiment 5). Parrott and Sabini (PARROTT; SABINI, 1990, Experiment 4, Experiment 5) did not demonstrate any MCM effect on autobiographical memory, contrary to the three other studies using the same MIP (MIRANDA; KIHLSTROM, 2005; PARROTT, 1991; PARROTT; SABINI, 1990, Experiment 3). The difference between the studies that have shown an effect and those that have not is that, in the former, subjects were asked to modify their mood according to the music, while in the latter, this was not explicitly asked. Two of the studies using music listening as a MIP showed a MCM effect for the retrieval of a list of emotional words (CLARK; TEASDALE, 1985; KIEFER et al., 2007).

Isen, Shalker, Clark and Karp (1978, Study 2) employed a success-failure manipulation, assuming that the outcome of a game (involving victory or defeat) would influence the subjects' mood (positive or negative mood). The results demonstrated an effect only for positive mood on the recall of positive words.

Klaassen et al. (2002) were the only authors to use a pharmaceutical procedure to induce mood, the "tryptophan (TRP) depletion method" (YOUNG et al., 1985). This method consists of an ingestion of an amino acid mixture without tryptophan, which reduces the production of serotonin in the brain, inducing symptoms of depression. On this study, the recall of positive words was impaired by the TRP depletion, demonstrating a MCM effect.

\subsection{Mood evaluation}

The studies differed on the methodology used to evaluate the current mood of the subjects. Thirteen studies did not measure the current emotional state of the subjects (see Table 1). 


\subsubsection{Self reported measures}

Mood state was most commonly measured through self-report questionnaires. Various instruments were used in the studies selected for the review (Likert scale, Beck Depression Inventory). Forty-two studies (out of sixty-eight) employed only a self-report measure for the evaluation of the subjects' current mood and thirty-two of them demonstrated a MCM effect.

\subsubsection{Behavioral measures}

Some behavioral measures evaluated by psychomotor tasks have been shown to reflect the emotional state of healthy or clinical subjects (BURDICK et al., 2009; JOHNSON, 1937; NELSON; CHARNEY, 1981). The most common tasks are speed writing, letter cancelation and counting. Eight studies combined self-report methods with behavioral measures and all were able to show a MCM effect (BULLINGTON, 1990; CLARK; TEASDALE, 1985, Experiment 1; MACCALLUM et al., 2000; NASBY, 1994; NATALE; HANTAS, 1982; PARROTT, 1991; PARROTT; SABINI, 1990, Experiment 3; TEASDALE; RUSSELL, 1983).

\subsubsection{Physiological measures}

Numerous studies explored the correlation between mood and heart rate variability and supported the use of physiological measures to evaluate emotional state (CACIOPPO et al., 2000; EKMAN; LEVENSON; FRIESEN, 1983; RAINVILLE et al., 2006). Two studies employed physiological measures (heart rate) to evaluate the emotional state of the subjects. All studies (LEWIS et al., 2005; LOEFFLER; MYRTEK; PEPER, 2013) demonstrated a MCM effect for explicit memory of verbal material (word list). 


\subsection{Type of retrieval}

The studies selected for this systematic review evaluated the mood congruency effect on different forms of memory retrieval. Most studies (65/68) explored explicit retrieval and only six used implicit retrieval tasks.

\subsubsection{Explicit retrieval}

Verbal material is the most commonly used in these studies, with only a few authors employing visual material.

Verbal material. Forty-three studies employed verbal material. Most studies (35/43) used word lists, with a positive or negative valence. In Natale and Hantas (1982), Clark and Teasdale (1985, Experiment 1) and Alexander and Guenther (1986), the words employed were related to positive or negative personality traits. All these studies were able to demonstrate a MCM effect.

Another paradigm used was logical memory (story recall). In Bower et al. (1981), subjects were asked to read a story containing information about a sad character and others about a happy character, and to retrieve as much details as they could remember in a delayed free recall. Three of the five studies in that paper were able to demonstrate a MCM effect. Mecklenbräuker and Hager (1984) employed a revised version of the story used by Bower et al. (1981) and also showed a MCM effect. These two articles differed, among other things, on the MIP applied, with hypnosis being used in Bower et al. (1981) and the Velten procedure in Mecklenbrauker \& Hager (1984).

Gilligan and Bower (1983) used happy and sad phrases that the subjects needed to recall in a free-recall and then in a cued-recall task and the authors were able to demonstrate a significant advantage for moodcongruent phrases. Fiedler, Pampe and Scherf (1986) employed sentences describing an individual with regard to six categories of social behavior, with each description having a positive or negative valence. With 
this procedure, the authors did not demonstrate any MCM effect for the free recall of these sentences. This result can be explained by the lack of a negative mood condition, considering that the authors only compared the effect of positive induced emotional state with a neutral condition.

Visual material. Only one study used pictures to explore the MCM effect. Fielder and Stroehm (1986) used photographs showing either pleasant or unpleasant scenes, some of the pictures organized in thematic categories and other pictures consisting of "isolated" pictures, not belonging to a thematic group. The authors demonstrated an advantage of moodcongruent material in a free recall task (identifying the pictures with key words), but only for isolated pictures; those depicting material, which were part of a thematic category, did not show this effect. With this study, the authors highlighted the influence of the structure of the stimuli in MCM.

Autobiographical memory. Twenty-one studies explored MCM on autobiographical retrieval, and seventeen studies showed an effect. The most common measure for autobiographical retrieval was a free recall task. This procedure was used in nineteen studies, six of which were not able to demonstrate a MCM effect. In four articles (EICH; MACAULAY, 2000; MACCALLUM et al., 2000; MIRANDA; KIHLSTROM, 2005; TEASDALE; TAYLOR; FOGARTY, 1980), word cues (neutral or emotional) were employed to help subjects recollect specific events and all these studies demonstrated a MCM effect.

Snyder and White (1982, Experiment 2, Experiment 3) asked the subjects to indicate, for various types of activity (positive or negative), the frequency with which the event had occurred during the week before the testing session. Using this procedure, the experiment demonstrated a MCM effect on the retrieval of autobiographical memories. 


\subsubsection{Implicit measures}

Six studies explored the MCM effect for implicit material (BRADLEY; MOGG; WILLIAMS, 1994; MAYER; MCCORMICK; STRONG, 1995, Experiment 1, Experiment 2, Experiment 3; RUSTING, 1999, Experiment 1, Experiment 2). Despite differences in the type of mood analyzed or in the tasks used, all these studies were able to demonstrate a MCM effect.

Using a primed lexical decision task with subjects in a natural mood state, Bradley et al. (1994) demonstrated an MCM effect for subliminally primed and unprimed words but not for supraliminally primed words. Mayer et al. (1995) also explored this effect using the natural mood of the subjects but applying a category-retrieval and an association-retrieval test; in the category-retrieval task, the subjects were asked to list a member of the key category that began with a specific letter (ex.: Key category Weather, specific letter - C... clear, cloudy, cold); in the associationretrieval task, the aim was to free-associate to a key word using a pair of letters (ex: Marriage, $d / / \ldots$ divorce/love). Using this procedure, the authors were able, in the three studies presented, to demonstrate that implicit retrieval was congruent with the current mood of the subjects.

In Study 1, Rusting (1999) also explored the effect with the natural mood of subjects but using a homophone task. The subjects were asked to spell each word they heard, with homophones being either positive/neutral or negative/neutral. For this task, implicit effects congruent with their current emotional state were observed. In Study 2 with the same task, the author employed a combination of music and imagery to put the subjects in a specific mood. This experiment also showed a MCM effect.

\section{Discussion}

The present paper reviewed a subset of the published researches on mood-congruent memory in healthy subjects. Our review shows that most of the studies were able to demonstrate an MCM effect, independently from the type of mood manipulation and from the type of retrieval, suggesting the influence of other factors for the occurrence of the effect. 
Indeed, some authors already explored several variables that could mediate the phenomenon of mood-congruent memory. Those factors may concern characteristics of the experiment (e.g. experimental instructions, structure of the information) or characteristics of the subjects themselves (e.g. personality, level of arousal).

\subsection{Factors which may influence the occurrence of MCM}

The type of the structure of the information to be remembered was proposed by Fiedler and Stroehm (1986) as a factor mediating the MCM effect. The authors explored this hypothesis using visual material. They presented isolated pictures and pictures organized by thematic categories to the subjects and were able to show an advantage of mood-congruent material but only for isolated pictures, the effect disappeared for the categorical information.

Rinck et al., (1992, Exp 1) investigated the influence of the valence intensity of the words on MCM effect and showed a mood-congruent learning for the strongly toned words and a mood-incongruent learning of the slightly toned words. The findings were explained by the authors based on the ease of valence determinations, which propose that the ratings of slightly mood-congruent words were facilitated and the ratings of slightly mood-incongruent words were rendered more difficult. In a second experiment (RINCK; GLOWALLA; SCHNEIDER, 1992, Experiment 2), the findings supported this explanation, showing that the subjects took longer to rate the valence of a slightly mood-incongruent words than a slightly mood-congruent words, increasing the time of processing and facilitating the recall.

Nasby (1994) has pointed out two moderators of the MCM effect: selflother-reference at the moment of the encoding ("Does the following adjective describe you?" vs. "Does the following adjective describe your mother?") and the affirmative/non-affirmative judgment about the information to be remembered. Indeed, this author showed that when in a positive mood, subjects recall better the affirmatively rated positive words 
for both self- and other-reference conditions, but, when in a negative mood, the advantage for affirmatively rated congruent words was present only in the self-reference condition. For the non-affirmative rated words, no mood-congruent effect was observed. The author replicated his findings in another study (NASBY, 1996), showing additionally that in an experimenter-reference condition, there is no mood-congruent effect.

Several authors explored the experimenter's demands hypothesis, which propose that the MCM effect was due to subjects believing that the experimenter was seeking such a pattern of results (SNYDER; WHITE, 1982). To tests this hypothesis, Snyder and White (1982, Exp 3) used an ineffective mood induction (using the Velten procedure with affectively neutral statements) and they were not able to evidence a MCM effect, failing to provide evidences supporting the demand hypothesis. Alexander and Guenther (1986, Exp 2) addressed the same question but using another methodology, in which subjects in the "compatible condition" were told that after the mood induction people tend to recall information compatible with the current mood, and subjects in the "incompatible condition" were told that the mood induction can advantage incompatible recall. They reported results that argue against the experiment's demands hypothesis. Indeed, when asked to report autobiographical events, subjects showed a MCM effect in both compatible and incompatible conditions. Bullington (1990) also explored demand effects, using a "simulated mood" condition and the results did not support the demand hypothesis. In summary, most of the studies argued against the demands hypothesis as a main factor explaining the presence of $M C M$, but as observed in other types of research into emotion, demand effects may play a role depending on the study design.

Some authors tested another factor likely to moderate the MCM effect, named the subject compliance hypothesis, which argues that it is the subjects' effort to maintain the induced mood that creates the mood congruent recall. Mayer et al. (1990) manipulated the instruction about the mood induction (e.g. condition 2: "the music may or may not cause your mood to change", condition 3: "get into the music and allow your mood to 
change or stay the same"). The mood congruency effect was unaffected by the manipulation of the instruction, arguing against the subject compliance hypothesis. Parrott (1991) also explored the same hypothesis and showed that, even after telling the subjects they can stop maintaining the induced mood, they still presented a mood congruent recall of autobiographical memories, which is opposed to the subject compliance hypothesis.

Bower and Mayer (1989, Exp 3) studied the effect of the type of memory instructions, manipulating the attention and learning strategy of the subjects. In one condition, they asked the subjects to concentrate on learning mood congruent words, and in the other condition, the instruction was to pay more attention in learning mood incongruent words. The incongruent learning condition cancelled the MCM effect showed in the congruent condition, by increasing the quantity of mood incongruent words recalled. The authors interpreted these results as an evidence of the implication of attention and learning processes in MCM effect. Based on the cognitive theories of depression, which argue that attentional bias for negative information is a characteristic of the mood disorder, Blaut et al. (2013) also explored the effect of attention processes on the presence of a MCM effect. They showed that, after an attentional training focusing on neutral words, the subjects did not show a better recall for negative words in comparisons to the subjects who did not receive the attentional training. These results support the implication of attentional bias in the occurrence of MCM effect.

Fiedler and Stroehm (1986) were interested in the effect of arousal as a moderator of the MCM effect. Using a pharmacological treatment to increase the autonomic arousal, they showed that the evaluation of the emotionally toned stimulus differed regarding the condition. However, there were no significant differences on the recall performance between the pharmacologically increased arousal group and the relaxation group, failing to demonstrate an effect of autonomic arousal on mood-congruent recall. In order to compare the effect of cognitive activation and of autonomic arousal on MCM, Varner and Ellis (1998) compared the recall 
of negative and organizational words in four conditions: negative mood induction, organizational schema induction, physiological arousal induction and neutral condition. The authors concluded that physiological arousal does not seem to have an influence on the occurrence of MCM, contrary to the cognitive activity of the emotional state. In a more recent study, Loeffler et al. (2013) explored the effect of psychophysiological arousal on MCM in the context of daily life and showed contradictory results. Indeed, in the case of a negative situation, physiological arousal seemed to be a necessary condition for the occurrence of MCM and, in the absence of physiological arousal, the recall of incongruent memories tended to be better. However, this is not the case in a positive context, where physiological arousal did seem to influence the recall.

Several studies demonstrated that the subject's personality can be a moderator in the occurrence of mood-congruent or mood-incongruent effect. Boden and Baumeister (1997) compared the speed of recall of happy memories in a group of repressors (subjects who are less affected by negative stimuli) and a group of non-repressors, in order to explore the impact of this specific personality trait on MCM. The authors showed that the repressor subjects were quicker to recall happy memories when in a negative mood compared to non-repressors. Rusting (1999) revealed significant interactions between personality traits of the subjects and the effects of mood on memory, showing for example, that extraversion was related to a better recall of positive memories and neuroticism to a better recall of negative memories. Rusting and DeHart (2000) manipulated the use of mood-regulation strategies and confirmed the relation between personality and MCM, showing that the score on the Negative Mood Regulation Scale, which measures the individuals' beliefs about their capacity to regulate negative mood, influenced the effects of moodregulation strategies on $\mathrm{MCM}$.

To summarize, the studies reported evidences for several mediators of MCM occurrence. The structure and the valence intensity of the material to be remembered seem to influence the MCM effect, just as the self vs other-reference of that material; a mood-congruent effect is more probable 
with more structured, intense and self-oriented material. Regarding the characteristics of the subjects that can mediate the MCM, personality and attention processes are factors likely to modulate the presence of the MCM. In relation to physiological arousal, the results are contradictory but, in real life settings, a greater psychophysiological arousal appears necessary to generate $\mathrm{MCM}$ for negative events. Neither the experimenter's demands nor the subject compliance hypotheses were able to explain the occurrence of a MCM effect.

\subsection{MCM models}

The associative network theory suggested by Bower (1981) is the most cited model proposed to explain the mood-congruent phenomenon. This model considers that the memory can be represented by a network, in which every concept forms a node linked to other nodes of associated concepts. For example, the concept of a specific emotion is linked to the physiological reactions, behaviors, words and events associated with this specific emotional state. When a concept/node is activated, this activation spreads into the network activating associated concepts/nodes. According to this view, when someone is in a positive emotional state, the node "happy" will be activated and this activation will spread to associated nodes, such as positive autobiographical memories, facilitating the recall of these memories. This model explains, for example, that valence intensity of the material is a mediator of MCM. Indeed, Bower et al. (1981) proposed that the activation of the node needs to reach a threshold in order to spread to associated nodes, which would explain why intensely toned mood-congruent words are better recalled than slightly toned words. The network model also allows explaining the influence of attentional processes on the occurrence of MCM. For Bower et al. (1981), when an emotional node is activated, people should be more attentive to moodcongruent information that are already activated by the spread of the activation in the network. 
Nevertheless, some studies demonstrated a mood-incongruent effect (LOEFFLER; MYRTEK; PEPER, 2013; PARROTT; SABINI, 1990; RUSTING; DEHART, 2000) and also asymmetrical results when comparing the effects of positive and negative moods (ISEN et al., 1978; MAYER et al., 1990). These results cannot be explained exclusively by Bower's network theory and the concept of mood regulation was then proposed to explain the occurrence of these phenomena. The mood regulation hypothesis proposes that people try to regulate their mood by recalling material incongruent with their current mood state, especially when in a negative mood (BOWER; GILLIGAN; MONTEIRO, 1981; ISEN, 1985; SINGER; SALOVEY, 1988).

According to Isen (1984) and to Salovey and Singer (1989), the asymmetry in the finding about positive and negative mood states can be explained by a combination of the network theory and the mood regulation concept. In fact, these authors suggested that the neurophysiological activation of the network may lead to a mood-congruent effect, which can be diminished or cancelled by the implementation of mood-regulation strategies, where the mood-regulation serves to diminish the negative mood state. Unfortunately, most of the studies do not compare positive, negative and neutral emotional states, which may complicate the interpretation of the results and may be seen as a limitation of the field of study.

\subsection{Mood-congruent learning / Mood-congruent retrieval}

The MCM process can be divided into two processes: mood-congruent learning / mood-congruent recall. The mood-congruent-learning (or moodcongruent judgment/encoding) corresponds to the effect of the mood at the moment of encoding (or learning), while the mood-congruent-recall (or mood-congruent retrieval) corresponds to the exploration of mood influence at the moment of recall. Only fourteen studies out of sixty-eight considered this difference when exploring the MCM effect. Indeed, seven studies explored only the MC-learning effect (BOWER; GILLIGAN; 
MONTEIRO, 1981, Exp 1 and Exp 5; GILLIGAN; BOWER, 1983; LEWIS; WILLIAMS, 1989; NASBY, 1994; PERRIG; PERRIG, 1988; RINCK; GLOWALLA; SCHNEIDER, 1992) and seven explored specifically MCretrieval (BOWER; GILLIGAN; MONTEIRO, 1981, Exp 2 and Exp 4; CLARK; TEASDALE, 1985; FIEDLER et al., 2001; FIEDLER; STROEHM, 1986; TEASDALE; RUSSELL, 1983; VARNER; ELLIS, 1998). All the studies exploring MC-learning were able to demonstrate an effect, but two studies about MC-retrieval (BOWER; GILLIGAN; MONTEIRO, 1981, Exp 2 and Exp 4) were not. This result suggests that the current mood at the moment of the retrieval may have a minimal role in the MCM phenomenon, comparing to the mood during encoding. This support Ellis and Moore's comments (1999), who affirmed that the results regarding the MC-retrieval phenomenon are less conclusive than MC-learning results. These authors also suggested that the results from the studies exploring MCM as a unique process may be biased, especially in the case of autobiographical memory, where the event is always associated with the mood state at the moment of the event, which is also the moment of encoding. Studies exploring the neural basis of the phenomenon may help to understand the role of MC learning and MC retrieval in the MCM effect.

\subsection{Neural basis of MCM}

Studies exploring the neurophysiological correlates of MCM may help to discover if MCM reflects memory processes during memory encoding or response biases at the moment of the retrieval. However, in our review, only three out of sixty-eight studies explored the neural basis of the MCM effect.

Kiefer et al. (2007) used electroencephalography (EEG) to explore the patterns of neural response during the encoding phase of MCM. The results showed that, depending on the current mood state, positive and negative words seem to be processed in different ways. This suggests that MCM effect is not only a retrieval bias but that it already originates at the time of encoding. As the source analysis pointed that structures commonly associated with semantic knowledge (parahippocampal cortex, perirhinal cortex, fusiform gyrus) had different activations depending on mood and 
valence of the words, the authors also suggested an influence of the semantic processes in the MCM effect. Lewis et al. (2005) explored the neural networks underlying the MCM effect using functional magnetic resonance imaging (fMRI). The framework of this study is the Bower's model (1981) and one of the aims of the authors was to observe neural activity corresponding to the nodes of Bower's model. The results showed that the structures activated for mood congruent encoding are the same activated for mood congruent retrieval: the subgenual cingulate for positive words and the right parietal lateral orbitofrontal cortex for negative words, which are structures known to be involved in emotional processing. The authors interpreted these results as a demonstration of the associative model. Also using fMRI, Fitzgerald et al. (2011) showed an implication of frontal structures in the MCM learning, with activation of the left medialand inferior-frontal gyri during mood incongruent memory and with activation the left orbito-frontal cortex during mood congruent memory.

In summary, the few studies exploring the neural correlates of MCM highlighted that the origin of the phenomenon begins during encoding and that frontal structures seem to be implicated in the MCM phenomenon. The results also support Bower's associative model. Nevertheless, these studies were not able to demonstrate a clear pattern of activations and more studies in this field are needed in order to understand the neural mechanisms underlying the MCM effect.

\subsection{Limitations}

Some limitations to a direct interpretation of data from the MCM literature should be considered. First, the age of the subjects could have influenced the results. In fact, most of the subjects are undergraduates. This could limit the possibility to generalize results to the rest of the population. Another limitation associated with this review lies in the heterogeneity of the methodologies used across studies (e.g., explicit memory vs. implicit memory, different types of MIP, and different types of material for the memory task). This latter factor affects reliability of comparisons between 
different studies. However, those limitations seem intrinsic to the field of research and, as discussed in the next part of this review, further studies are needed in order to understand better the mechanism underlying the MCM effect.

\subsection{Conclusions and future directions}

Mood congruent memory seems to be a strong phenomenon; however, the factors mediating the occurrence of the effect remain unclear. Characteristics of the material used in the memory task (e.g. structure, valence intensity, self vs other-reference) and characteristics of the subjects (e.g. personality, physiological arousal) are factors likely to modulate the presence of MCM. Bower's associative network theory combined to the mood regulation concept seem to provide the best available framework to explain the effect, with initial support for this from neuroimaging studies. Authors who explored the neural correlates of MCM also showed the implication of frontal structures and gave leads regarding the mood-congruent learning vs. mood-congruent recall question. Indeed, the formation of MCM seems to have already its initial stages during the encoding phase.

However, the generalization of these results is limited because of the limited age range of the studies' subjects and also because of the heterogeneity of methodologies used across studies. Therefore, more studies using systematic designs and different age groups are needed to be able to generalize the findings regarding MCM.

It is also important to have more studies controlling objectively the efficacy of the mood induction procedure, using physiological measures of the emotional state. Indeed, only two studies in this review ensured objectively that the subjects reached the specific mood state, which is the first requirement to be able to interpret the results.

Other studies exploring the neural correlates of the MCM are also needed in order to understand the mechanism underlying the mood-congruent and 
mood-incongruent effects. As it was the case with previous EEG and fMRI studies, this kind of research may help answer different theoretical questions about MCM and elaborate an actualized model of the phenomenon.

The exploration of MCM in ecological settings, comparable to Loeffler et al. (2013), may be useful to understand the impact of mood on memory in daily life and the relation of this phenomenon in the case of mood disorders. Indeed, some cognitive theories of depression postulate that mood-congruent phenomena may be crucial for developing depression and may contribute to the maintenance of depressive symptoms (BECK, 1976; MATHEWS; MACLEOD, 2005; VAN WINGEN et al., 2010). The relation of $\mathrm{MCM}$ with mood disorder is a main clinical aspect supporting the importance of expanding research on MCM.

\section{Acknowledgments}

The authors acknowledge financial support from the Capes Foundation, Ministry of Education of Brazil.

\section{REFERENCES}

ALEXANDER, L.; GUENTHER, R. K. The effect of mood and demand on memory. British Journal of Psychology, v. 77, n. 3, p. 343-350, 1986.

BARRY, E. S.; NAUS, M. J.; REHM, L. P. Depression and implicit memory: Understanding mood congruent memory bias. Cognitive Therapy and Research, v. 28, n. 3, p. 387-414, 2004.

BECK, A. T. Cognitive therapy and the emotional disorders. New York: International Universities Press, 1976.

BLANEY, P. H. Affect and memory: a review. Psychological bulletin, v. 99, n. 2, p. 229-246, 1986.

BLAUT, A. et al. Are attentional bias and memory bias for negative words causally related? Journal of Behavior Therapy and Experimental Psychiatry, v. 44, n. 3, p. 293-299, 2013. 
BODEN, J. M.; BAUMEISTER, R. F. Repressive coping: distraction using pleasant thoughts and memories. Journal of personality and social psychology, v. 73, n. 1, p. 45-62, 1997.

BOWER, G. H. Mood and memory. The American psychologist, v. 36, n. 2, p. 129-148, 1981.

BOWER, G. H.; GILLIGAN, S. G.; MONTEIRO, K. P. Selectivity of learning caused by affective states. Journal of Experimental Psychology: General, v. 110, n. 4, p. 451-473, 1981.

BOWER, G. H.; MAYER, J. D. In search of mood-dependent retrieval. Journal of Social Behavior and Personality, v. 4, n. 2, p. 121-156, 1989.

BOWER, G. H.; MONTEIRO, K. P.; GILLIGAN, S. G. Emotional mood as a context for learning and recall. Journal of Verbal Learning and Verbal Behavior, v. 17, n. 5, p. 573-585, 1978.

BRADLEY, B. P.; MOGG, K.; WILLIAMS, R. Implicit and explicit memory for emotional information in non-clinical subjects. Behaviour research and therapy, v. 32, n. 1, p. 65-78, 1994.

BULLINGTON, J. C. Mood congruent memory: A replication of symmetrical effects for both positive and negative moods. Journal of Social Behavior and Personality, v. 5, n. 4, p. 123-134, 1990.

BURDICK, K. E. et al. Attention and psychomotor functioning in bipolar depression. Psychiatry Research, v. 166, n. 2-3, p. 192-200, 2009.

CACIOPPO, J. T. et al. The psychophysiology of emotion. 2. ed. New York: Guilford Press, 2000.

CLARK, D. M.; TEASDALE, J. D. Constraints on the effects of mood on memory. Journal of Personality and Social Psychology, v. 48, n. 6, p. 1595-1608, 1985.

DARLEY, C. F. et al. The nature of storage deficits and state-dependent retrieval under marihuana. Psychopharmacologia, v. 37, n. 4, p. 139149, 1974.

DUKA, T.; WEISSENBORN, R.; DIENES, Z. State-dependent effects of alcohol on recollective experience, familiarity and awareness of memories. Psychopharmacology, v. 153, n. 3, p. 295-306, 2001.

$\mathrm{EICH}, \mathrm{E}$. et al. Cognition and Emotion. New York: Oxford University Press, 2000.

EICH, E.; MACAULAY, D. Are real moods required to reveal moodcongruent and mood-dependent memory? Psychological science: a 
journal of the American Psychological Society / APS, v. 11, n. 3, p. 244-248, 2000.

EICH, E.; METCALFE, J. Mood dependent memory for internal versus external events. Journal of Experimental Psychology: Learning, Memory, and Cognition, v. 15, n. 3, p. 443-455, 1989.

$\mathrm{EICH}, \mathrm{J}$. E. The cue-dependent nature of state-dependent retrieval. Memory \& Cognition, v. 8, n. 2, p. 157-173, 1980.

EKMAN, P.; LEVENSON, R. W.; FRIESEN, W. V. Autonomic nervous system activity distinguishes among emotions. Science, v. 221, n. 4616, p. 1208-1210, 1983.

ELLIS, H. C.; MOORE, B. A. M. Mood and Memory. In: DALGLEISH, T.; POWER, M. J. (Eds.). . Handbook of Cognition and Emotion. Chichester, UK: John Wiley \& Sons, Ltd, 1999. p. 191-210.

ELLWART, T.; RINCK, M.; BECKER, E. S. Selective memory and memory deficits in depressed inpatients. Depression and anxiety, v. 17, n. 4, p. 197-206, 2003.

FIEDLER, K. et al. Is Mood Congruency an Effect of Genuine Memory or Response Bias? Journal of Experimental Social Psychology, v. 37, n. 3, p. 201-214, 2001.

FIEDLER, K.; PAMPE, H.; SCHERF, U. Mood and memory for tightly organized social information. European Journal of Social Psychology, v. 16, n. 2, p. 149-164, 1986.

FIEDLER, K.; STROEHM, W. What kind of mood influences what kind of memory: the role of arousal and information structure. Memory \& cognition, v. 14, n. 2, p. 181-188, 1986.

FITZGERALD, D. A. et al. How mood challenges emotional memory formation: An fMRI investigation. Neurolmage, v. 56, n. 3, p. 1783-1790, 2011.

GILLIGAN, S. G.; BOWER, G. H. Reminding and mood-congruent memory. Bulletin of the Psychonomic Society, v. 21, n. 6, p. 431-434, 1983.

HIGGINS, J. P.; GREEN, S. (EDS.). Cochrane Handbook for Systematic Reviews of Interventions. Chichester, UK: John Wiley \& Sons, Ltd, 2008.

ISEN, A. M. Toward understanding the role of affect in cognition. In: SCRULL, T. K.; WYER, R. S. (Eds.). . Handbook of social cognition. Hillsdale, NJ: Lawrence Erlbaum Associates, Inc, 1984. v. 3p. 179-236. 
ISEN, A. M. Asymmetry of happiness and sadness in effects on memory in normal college students: Comment on Hasher, Rose, Zacks, Sanft, and Doren. Journal of Experimental Psychology: General, v. 114, n. 3, p. 388-391, 1985.

ISEN, A M. et al. Affect, accessibility of material in memory, and behavior: a cognitive loop? Journal of personality and social psychology, v. 36, n. 1, p. 1-12, 1978.

JOHNSON, W. B. Euphoric and Depressed Moods in Normal Subjects*. Journal of Personality, v. 6, n. 2, p. 79-98, 1937.

KIEFER, M. et al. Mood states modulate activity in semantic brain areas during emotional word encoding. Cerebral Cortex, v. 17, n. 7, p. 1516-30, 2007.

KLAASSEN, T. et al. Mood congruent memory bias induced by tryptophan depletion. Psychological medicine, v. 32, n. 1, p. 167-172, 2002.

LEWIS, P. A. et al. Brain mechanisms for mood congruent memory facilitation. Neurolmage, v. 25, n. 4, p. 1214-1223, 2005.

LEWIS, V. E.; WILLIAMS, R. N. Mood-congruent vs. mood-statedependent learning: implications for a view of emotion. Journal of Social Behavior and Personality, v. 4, n. 2, p. 157-171, 1989.

LOEFFLER, S. N.; MYRTEK, M.; PEPER, M. Mood-congruent memory in daily life: Evidence from interactive ambulatory monitoring. Biological Psychology, v. 93, n. 2, p. 308-315, 2013.

MACCALLUM, F. et al. Specific autobiographical memory following hypnotically induced mood state. The International journal of clinical and experimental hypnosis, v. 48, n. 4, p. 361-373, 2000.

MATHEWS, A.; MACLEOD, C. Cognitive vulnerability to emotional disorders. Annual review of clinical psychology, v. 1, p. 167-95, 2005.

MAYER, J. D. et al. Toward better specification of the mood-congruency effect in recall. Journal of Experimental Social Psychology, v. 26, n. 6, p. 465-480, 1990.

MAYER, J. D.; MCCORMICK, L. J.; STRONG, S. E. Mood-Congruent Memory and Natural Mood: New Evidence. Personality and Social Psychology Bulletin, v. 21, n. 7, p. 736-746, 1995.

MECKLENBRAUKER, S.; HAGER, W. Effects of mood on memory: Experimental tests of a mood-state-dependent retrieval hypothesis and of a mood-congruity hypothesis. Psychological Research, v. 46, n. 4, p. 355-376, 1984. 
MIRANDA, R.; KIHLSTROM, J. Mood congruence in childhood and recent autobiographical memory. Cognition \& Emotion, v. 19, n. 7, p. 981-998, 2005.

NASBY, W. Moderators of mood-congruent encoding: Self-/otherreference and affirmative/nonaffirmative judgement. Cognition \& Emotion, v. 8, n. 3, p. 259-278, 1994.

NASBY, W. Moderators of Mood-congruent Encoding and Judgement: Evidence that Elated and Depressed Moods Implicate Distinct Processes. Cognition \& Emotion, v. 10, n. 4, p. 361-378, 1996.

NATALE, M.; HANTAS, M. Effect of temporary mood states on selective memory about the self. Journal of Personality and Social Psychology, v. 42 , n. 5 , p. 927-934, 1982.

NELSON, J. C.; CHARNEY, D. S. The symptoms of major depressive illness. The American journal of psychiatry, v. 138, n. 1, p. 1-13, 1981.

NOLEN-HOEKSEMA, S. Responses to depression and their effects on the duration of depressive episodes. Journal of abnormal psychology, $v$. 100, n. 4, p. 569-582, 1991.

NOLEN-HOEKSEMA, S. The role of rumination in depressive disorders and mixed anxiety/depressive symptoms. Journal of abnormal psychology, v. 109, n. 3, p. 504-511, 2000.

NUTT, R. M.; LAM, D. A comparison of mood-dependent memory in bipolar disorder and normal controls. Clinical psychology \& psychotherapy, v. 18, n. 5, p. 379-386, 2011.

PARROTT, W. G. Mood induction and instructions to sustain moods: A test of the subject compliance hypothesis of mood congruent memory. Cognition \& Emotion, v. 5, n. 1, p. 41-52, 1991.

PARROTT, W. G.; SABINI, J. Mood and memory under natural conditions: Evidence for mood incongruent recall. Journal of Personality and Social Psychology, v. 59, n. 2, p. 321-336, 1990.

PERRIG, W. J.; PERRIG, P. Mood and memory: mood-congruity effects in absence of mood. Memory \& cognition, v. 16, n. 2, p. 102-109, 1988.

RAINVILLE, P. et al. Basic emotions are associated with distinct patterns of cardiorespiratory activity. International Journal of Psychophysiology, Psychophiosology and Cognitive Neuroscience. v. 61, n. 1, p. 5-18, 2006.

RINCK, M.; GLOWALLA, U.; SCHNEIDER, K. Mood-congruent and moodincongruent learning. Memory \& cognition, v. 20, n. 1, p. 29-39, 1992.

RUSTING, C. L. Interactive effects of personality and mood on emotion- 
congruent memory and judgment. Journal of personality and social psychology, v. 77, n. 5, p. 1073-1086, 1999.

RUSTING, C. L.; DEHART, T. Retrieving positive memories to regulate negative mood: consequences for mood-congruent memory. Journal of personality and social psychology, v. 78, n. 4, p. 737-752, 2000.

SALOVEY, P.; SINGER, J. A. Mood congruency effects in recall of childhood versus recent memories. Journal of Social Behavior \& Personality, v. 4, n. 2, p. 99-120, 1989.

SINGER, J. A.; SALOVEY, P. Mood and memory: Evaluating the network theory of affect. Clinical Psychology Review, v. 8, n. 2, p. 211-251, 1988.

SNYDER, M.; WHITE, P. Moods and memories: elation, depression, and the remembering of the events of one's life. Journal of personality, v. 50, n. 2, p. $149-167,1982$.

TEASDALE, J. D. Negative thinking in depression: Cause, effect, or reciprocal relationship? Advances in Behaviour Research and Therapy, v. 5, n. 1, p. 3-25, 1983.

TEASDALE, J. D.; RUSSELL, M. L. Differential effects of induced mood on the recall of positive, negative and neutral words. The British journal of clinical psychology, v. 22 (Pt 3), p. 163-171, 1983.

TEASDALE, J. D.; TAYLOR, R.; FOGARTY, S. J. Effects of induced elation depression on the accessibility of memories of happy and unhappy experiences. Behaviour Research and Therapy, v. 18, n. 4, p. 339-346, 1980.

VAN WINGEN, G. A. et al. Neural state and trait bases of moodincongruent memory formation and retrieval in first-episode major depression. Journal of psychiatric research, v. 44, n. 8, p. 527-534, 2010.

VARNER, L. J.; ELLIS, H. C. Cognitive activity and physiological arousal: processes that mediate mood-congruent memory. Memory \& cognition, v. 26, n. 5, p. 939-950, 1998.

WATKINS, P. C. Implicit memory bias in depression. Cognition \& Emotion, v. 16, n. 3, p. 381-402, 2002.

YOUNG, S. N. et al. Tryptophan depletion causes a rapid lowering of mood in normal males. Psychopharmacology, v. 87, n. 2, p. 173-7, 1985. 


\section{ARTICLE 2}

Bertrand, E., Dourado, M. C. N., Laks, J., Morris, R. G., Landeira-Fernandez, J., \& Mograbi, D. C. (2016). Mood-congruent recollection and anosognosia in Alzheimer's disease. Cortex, 84, 55-62. http://doi.org/10.1016/j.cortex.2016.09.001

CORTEX $84(2016) 55-62$

Available online at www.sciencedirect.com

ScienceDirect

Journal homepage: www.elsevier.com/locate/cortex

Mood-congruent recollection and anosognosia in Alzheimer's disease

Elodie Bertrand ${ }^{a, *}$, Marcia C.N. Dourado ${ }^{b}$, Jerson Laks ${ }^{b, c}$,

Robin G. Morris ${ }^{d}$, Jesus Landeira-Fernandez ${ }^{a}$ and Daniel C. Mograbi ${ }^{a, d}$

${ }^{a}$ Pontifícia Universidade Católica - Rio (PUC-Rio), Department of Psychology, Rio de Janeiro, RJ, Brazil

${ }^{\mathrm{b}}$ Federal University of Rio de Janeiro (UFRJ), Institute of Psychiatry - Center for Alzheimer's Disease, Rio de Janeiro, RJ, Brazil

' Universidade do Grande Rio (Unigranrio), Post Graduation Program on Translational Biomedicine, Caxias, RJ, Brazil

${ }^{\mathrm{d}}$ King's College London, Institute of Psychiatry - Psychology \& Neuroscience, London, United Kingdom 


\section{ABSTRACT}

The aim of the study was to investigate experimentally the impact of current mood state on anosognosia or awareness of symptoms in $A D$ patients, in which mood state was manipulated by giving tasks that were either easy (success condition) or very difficult (failure condition). Twentytwo patients with mild to moderate AD participated. Four success-failure manipulation (SFM) computerized tasks were used as mood induction procedures, two based on reaction time tasks and the other on memory tasks. Level of awareness and the current mood state were assessed before and after each task, using a modified version of the Anosognosia Questionnaire for Dementia and a self-reported questionnaire respectively. For both types of task, the results indicate that the emotional state of the participants was similar before performing the tasks and that only the failure conditions induced a negative mood state. Additionally, regarding the level of awareness, there were no significant differences after the reaction time tasks but for the memory tasks, there was greater awareness of symptoms after performing the task in the failure condition. To the best of our knowledge, this study is the first exploring experimentally the impact of mood on anosognosia in AD. The results showed an improvement of awareness of symptoms after negative mood induction, but only when the task used in the SFM was memory-based.

Key words: dementia, Alzheimer's disease, awareness, anosognosia, mood 


\section{Introduction}

Anosognosia refers to a lack of awareness about deficit or condition as found in various neurological conditions, such as aphasia, hemiplegia and also dementia (MOGRABI; BROWN; MORRIS, 2009; RIES et al., 2007; STUSS, 1991; STUSS et al., 2005). Unawareness regarding the disease or cognitive impairments is a common characteristic of Alzheimer's disease (AD) (AGNEW; MORRIS, 1998; MORRIS; HANNESDOTTIR, 2004), with estimates obtained with large samples reaching almost $80 \%$ (ANTOINE et al., 2004; MOGRABI et al., 2012a; SOUSA et al., 2015). Lack of awareness has several important clinical implications (BERTRAND; LANDEIRA-FERNANDEZ; MOGRABI, 2013; SPALLETTA et al., 2012), which go from diminished treatment adherence (ARLT et al., 2008), increased engagement in high-risk situations (SELTZER et al., 1997; STARKSTEIN et al., 2007), earlier institutionalization (HORNING; MELROSE; SULTZER, 2014; STEELE et al., 1990) to increased caregiver burden (CLARE et al., 2011; DEBETTIGNIES; MAHURIN; PIROZZOLO, 1990; RYMER et al., 2002; SELTZER et al., 1997; TURRÓ-GARRIGA et al., 2013).

The relationship with mood is an important aspect of anosognosia and has been explored using three main approaches (MOGRABI; MORRIS, 2014). First, studies show mixed results when exploring awareness for different objects in dementia, with some findings suggesting that patients with $A D$ present greater unawareness for cognitive deficits relative to behavioral changes (KOTLER-COPE; CAMP, 1995) and others results indicating also an "affective anosognosia" (VERHÜLSDONK et al., 2013), that is, a lack of awareness for mood disturbance. Second, the literature suggests that people with $A D$ may present an emotional response to failure situations even in the absence of explicit awareness. For example, Mograbi, Brown, Salas and Morris (2012) showed that, in a failure situation, patients with $A D$ exhibited the same emotional reactivity as did controls, despite unawareness of their performance. Third, when exploring the relation between level of awareness of deficits and the presence of depressive symptoms, numerous studies indicate that patients with $A D$ who have a 
higher level of depression show more awareness or less anosognosia (CLARE et al., 2012a; HARWOOD; SULTZER; WHEATLEY, 2000). Two possible explanations for these results can be found in the literature. On one hand, depressed patients may show "depressive realism" or present apparently more awareness because of a negative bias when reporting problems. On the other hand, increased awareness of difficulties might lead to higher depression, through a reactive depression process. Investigating the role played by emotional factors in anosognosia for hemiplegia, Besharati, Kopelman, Avesani, Moro and Fotopoulou (2015) showed that experimentally induced negative feelings improved awareness for motor deficits in anosognosic patients with right-hemisphere lesions. However, the question of a causal link between awareness and mood and the direction of this relationship still remains.

Another way to explore this link is through the well-known relationship between mood and memory. The most robust effects of mood on memory in the literature are the phenomena of mood-dependent memory (MDM) and mood-congruent memory (MCM). The former, as part of the global phenomenon of state-dependent memory, is improved memory for material when the subject's mood is the same at the time of encoding and retrieval, this occurring independent of the material content (BOWER, 1981; EICH; METCALFE, 1989; NUTT; LAM, 2011). The latter refers to facilitated recovery of material when the emotional valence of this material is congruent with current mood (BOWER, 1981). For example, when a person is currently in a positive mood state, the retrieval of positively toned material will be easier in comparison to the retrieval of negative items. Most of the studies exploring MCM were conducted with young adults, but there are differential older adult effects. Specifically, Knight and Durbin (2015) reviewed studies with older adults and found a greater bias for recalling negative information when in a sad mood, compared to younger adults. Additionally, in a study including also AD participants, Fleming, Kim, Doo, Maguire, \& Potkin (2003) demonstrated that AD patients remembered more negative items in an immediate recall memory task than neutral and positive words; healthy younger and older adults did not 
show this bias toward negatively toned material. The authors suggested the MCM effect as an explanation for these results. However, as current mood was not assessed, the data may not fully support their conclusions. Additionally, to the best of your knowledge, there is no published study exploring specifically the MDM and/or MCM effects in AD patients.

The aim of the current study was to investigate the impact of the current mood state on awareness of symptoms in AD patients, more specifically on the recollection of memories linked to their condition. For this purpose, we induced specific mood states using two experimental success-failure manipulation paradigms, one involving a reaction time task and the other a memory task. Participants were asked to answer questions regarding their condition before and after each mood manipulation. By using this method, we intended to explore not only the impact of mood on awareness but the additional influence of the context (memory vs. reaction time) on awareness as well. We hypothesized that the induction of a negative mood state would increase the retrieval of details regarding the patient's own deficits. However, we anticipated that the type of task would affect differentially the level of anosognosia, with a more marked increase of awareness after memory tasks in comparison to reaction time tasks.

\section{Methodology}

\subsection{Participants}

Twenty-four participants with mild to moderate AD (17 females) were recruited from the Center for Alzheimer's disease and Related Disorders (CDA) of the Institute of Psychiatry of the Federal University of Rio de Janeiro (IPUB-UFRJ), Brazil. The clinical diagnosis of AD was made by a psychiatrist using clinical interviews with the patients and caregivers, cognitive screening tests, laboratory tests, and imaging. The participants were diagnosed with possible or probable AD according to Diagnostic and Statistical Manual of Mental Disorders, Fourth Edition (DSM-IV-TR) (AMERICAN PSYCHIATRIC ASSOCIATION, 2000) and National Institute 
of Neurological and Communicative Diseases and Stroke/Alzheimer's Disease and Related Disorders Association (NINCDS-ADRDA) (MCKHANN et al., 2011) criteria. The diagnostic work-up included complete blood cell count, platelet count, glycemia, triglycerides, total cholesterol and fractions, alkaline phosphatase, glutamic oxaloacetic transaminase and glutamic pyruvic transaminase, bilirubins, urea, creatinine, total proteins, calcium, free T4 levels, TSH, VDRL, dosage of B12 and folates. Cranial CT scan or MRI scan with or without spectroscopy were also applied. People with scores of 18 or above in the Mini-Mental State Examination (MMSE) (BERTOLUCCl et al., 1994) were included in the study. Exclusion criteria were history of other neurological disorder (also excluding cases with mixed $A D$ and vascular dementia); history of head injury resulting in loss of consciousness for more than an hour; history of alcohol or substance abuse (based on ICD-10 criteria); and history of diagnosed major psychiatric illness or current psychological comorbidity (for example, mood disorder). Although no patient had a diagnosis of mood disorder, upon screening two patients showed depression symptoms, with scores on the GDS-15 above the cut-off of 5 (MARC; RAUE; BRUCE, 2008). These two participants were excluded from the following analyses, which were conducted with 22 participants.

\subsection{Procedures}

In order to induce a specific mood state, two success-failure manipulation (SFM) computerized paradigms, developed by Mograbi, Brown, et al., (2012), were used, one based on reaction time tasks (Experiment 1) and the other on memory tasks (Experiment 2) (for a full description of the development of the tasks, see (MOGRABI et al., 2014b). Two parallel versions were developed for each type of task (see description below). The SFM paradigms are designed to set and maintain the difficulty level of the task at a constant level, by first establishing the ability of the participant and then adjusting automatically the difficulty of the trials based on this ability level or individual threshold according to the condition. In the 
success condition, the difficulty level was set below the participant's individual threshold, this manipulation tending to lead to a neutral mood state. In contrast, in the failure condition, the difficulty level was set above the participant individual threshold, inducing a negative mood state. Participants were not informed that levels of difficulty would be manipulated, or that a mood change was expected. Indeed, to make the procedure look more natural, each task was composed of four phases. After the four trials of the practice phase, the trials composing the next phases (titration, initial success, experimental phase) continued without any indication to the participant. The order of experiments and conditions was quasi-counterbalanced among the participants, according to the following factors: Experiment 1 or Experiment 2 first; success or failure condition first in each experiment; and version allocated for success or failure, in each experiment. More details about the procedure and the experiments can be found in Mograbi, Brown, et al. (2012).

For this study, each task was followed by a 10-minute break intended to allow the participants to return to a neutral mood state and to carry-over effects. During this time, participants were allowed to rest while data were collected with the caregivers.

\subsubsection{Experiments}

\subsubsection{Experiment 1 - Reaction time}

In version $1 \mathrm{a}$ 'car' appeared on the left side of the screen moving to the right, with the participants having to 'stop' the car as soon as it appeared by pressing the spacebar of the keyboard. In version 2 objects (e.g. ball, egg or vase) appeared to fall from the 'top' of the screen and participants had to 'catch' the object by pressing the spacebar. In both versions participants received feedback after each trial. Difficulty was manipulated by varying the object's speed. 


\subsubsection{Experiment 2 - Memory}

The two versions of the experiment were based around memory span tasks. For version 1, a set of ten identical objects (e.g. teapot, bucket) were shown on a computer screen and these were highlighted individually in a random sequence using a red square surround. Immediately after, participants had to point to the same objects in sequence. For version 2, a sequence of digits ranging from 0 to 9 was presented both auditorily and visually to the participants, who immediately repeated it back sequentially to the experimenter. In both versions participants received feedback after each trial. Difficulty was manipulated by varying the length of the sequence from one to ten objects/digits.

\subsection{Measures}

\subsubsection{Background variables}

Global cognitive functioning was assessed with the Mini-Mental State Examination (MMSE) (BERTOLUCCI et al., 1994; FOLSTEIN; FOLSTEIN; MCHUGH, 1975). To screen for levels of depression, the Geriatric Depression Scale (GDS-15) (ALMEIDA; ALMEIDA, 1999; YESAVAGE et al., 1982) was used. The GDS-15 consists of 15 yes/no questions, with each item representing a common symptom of depression in older adults and being scored as absent or present. Total scale scores vary from 0 to 15 , with higher scores indicating greater severity of depression. Apathy was measured using the Apathy Evaluation Scale (AES-S) (GUIMARÃES et al., 2009; MARIN; BIEDRZYCKI; FIRINCIOGULLARI, 1991). Items of the AES-S explore the participant's interests and daily activities, being rated on a 4-point Likert-type scale with the following categories: Not at All True, Slightly True, Somewhat True, and Very True. The total scores range from 18 to 72 points, with a higher total score indicating greater severity of apathy. In the current study, the questions of the GDS-15 and AES-S were read to the participants, in order to ensure good 
comprehension. All the background variables were collected before the application of the experimental procedures (see table 1).

Table 1 - Sample characteristics

\begin{tabular}{ll}
\hline Variable & $\begin{array}{l}\text { AD group }(\mathrm{n}=22) \\
\text { Mean (SD) }\end{array}$ \\
\hline Age & $78.1(5.6)$ \\
Gender* & $17 / 5$ \\
Years of education & $8.1(4.2)$ \\
MMSE & $21.5(3.1)$ \\
AES & $35.7(6.1)$ \\
GDS-15 & $2.5(1.2)$ \\
\hline${ }^{*}$ \# female/ male &
\end{tabular}

\subsubsection{Self-reported emotion}

A self-report scale was used to assess the participants' mood state before and after the mood induction. Participants were asked to rate four paired emotions (frustrated and satisfied, disappointed and pleased) with a 5point Likert scale: not at all (0), a little (1), moderate (2), quite a bit (3) and extremely (4). Before and after each task of the SFM participants were asked: 'I would like to know how you are feeling right now. How [emotion] are you at this moment, from 'not at all' to 'extremely'?' Further explanation was given if needed. The negative emotions in the two pairs were scored reversely and summed with the score of the positive emotions, creating a general score ranging from 0 to 16 , with higher scores indicating more positive emotion. 


\subsubsection{Anosognosia questionnaire}

In order to assess the level of anosognosia before and after the mood manipulation, the participants were asked to answer six questions selected from the Anosognosia Questionnaire-Dementia (AQ-D) (ALMEIDA; CROCCO, 2000; MIGLIORELLI et al., 1995). The AQ-D was specifically designed to measure anosognosia in dementia, covering functional changes commonly found during the course of this illness. Three items were selected from the first section of the questionnaire, which assesses performance of basic and instrumental activities of daily living and the three other questions were selected from the second section, which examines changes in mood and behavior in relation to daily activities (see table 2). Scoring for each item ranges from 0 (never experiences impairment in the activity) to 3 (always experience impairments).

Table 2 - Anosognosia questionnaire

\begin{tabular}{|c|c|c|c|c|}
\hline & Never & Sometimes & Often & Always \\
\hline $\begin{array}{l}\text { Do you have problems remembering the } \\
\text { ate? }\end{array}$ & 0 & 1 & 2 & 3 \\
\hline $\begin{array}{l}\text { Do you have problems remembering where } \\
\text { ou leave things in your home? }\end{array}$ & 0 & 1 & 2 & 3 \\
\hline $\begin{array}{l}\text { Do you have problems remembering } \\
\text { appointments? }\end{array}$ & 0 & 1 & 2 & 3 \\
\hline $\begin{array}{l}\text { 4. Are you more rigid in your decisions, with less } \\
\text { capacity to adapt to new situations? }\end{array}$ & 0 & 1 & 2 & 3 \\
\hline $\begin{array}{l}\text { 5. Are you more irritated? Do you easily lose } \\
\text { your temper? }\end{array}$ & 0 & 1 & 2 & 3 \\
\hline 6. Do you feel more depressed? & 0 & 1 & 2 & 3 \\
\hline
\end{tabular}

\subsection{Ethical issues}

The main ethical issue of the study was related to the use of a mood induction procedure. However, mood induction procedures are widely 
used in experimental research, giving rise to moods which are mild and short lived (FROST; GREEN, 1982; ISEN; GORGOGLIONE, 1983; MARTIN, 1990).

All participants provided informed consent, with caregivers also giving their agreement for the patient to take part. At the end of the session participants were debriefed about the purpose of the experiments and told about the success/failure manipulation.

The project was approved by the Federal University of Rio de Janeiro (UFRJ) / Institute of Psychiatry Ethics Committee (Research Ethics Committee number 536.634).

\subsection{Statistical analysis}

Differences in awareness of symptoms were explored with repeatedmeasures ANOVAs, with time (pre-/post-SFM) and condition (success/failure) as within-subject factors. For the analysis of the selfreported emotions, repeated-measures ANOVAs were also used, with time (pre-/post-SFM) and condition (success/failure) as within-subject factors. In both cases, planned pairwise comparisons followed the ANOVAs. When significant interactions for awareness of symptoms were found, Pearson's bivariate correlation was calculated between awareness change and actual performance. We performed the analyses separately for each experiment (reaction time and memory). 


\section{Results}

\subsection{Experiment 1 - Reaction time}

\subsubsection{Self-reported emotion}

Table 3 indicates that the emotional state of the participants was similar before performing the tasks, and that the failure condition specifically induced a negative mood state. Repeated-measures ANOVA showed a significant interaction between time and condition $(F(1,21)=5.92, p=$ $\left..024, \eta_{p}^{2}=.22\right)$. This indicates that there were significant changes in the participant's self-report of mood depending on the type of condition. Pairwise comparisons showed that the participants rated their mood lower after the memory task in the failure condition $(p=.016)$, but not in the success condition $(p=.389$ ). Additionally, after performing the task, the participants showed a trend to rate their mood as lower in the failure condition than in the success condition $(p=.078)$, but not before the task $(p=.367)$. There was no significant main effect of time $(F(1,21)=1.42, p$ $\left.=.247, \eta_{\mathrm{p}}^{2}=.06\right)$ or condition $\left(F(1,21)=.92, p=.348, \eta_{\mathrm{p}}^{2}=.04\right)$.

\section{Table 3 - Self-reported emotion before and after the SFM for} the success and failure condition in Experiment 1 (reaction time)

\begin{tabular}{lcc}
\hline & $\begin{array}{c}\text { Success task } \\
\text { Mean (SD) }\end{array}$ & $\begin{array}{l}\text { Failure task } \\
\text { Mean (SD) }\end{array}$ \\
\hline Pre-SFM & $12.09(1.69)$ & $12.36(1.56)$ \\
\hline Post-SFM & $12.36(1.89)$ & $11.64(1.87)$
\end{tabular}

\subsubsection{Awareness of symptoms}

Figure 1 indicates that doing the tasks did not have an effect on the participants' awareness of symptoms. Repeated-measures ANOVA showed no interaction between time and condition $(F(1,21)=1.72, p=$ 
$\left..204, \eta_{p}^{2}=.08\right)$ or significant main effect of time $(F(1,21)=.03, p=.862$, $\left.\eta_{\mathrm{p}}^{2}=.001\right)$ or condition $\left(F(1,21)=1.43, p=.246, \eta_{\mathrm{p}}^{2}=.06\right)$.

Figure 1 - Awareness of symptoms during experiment 1

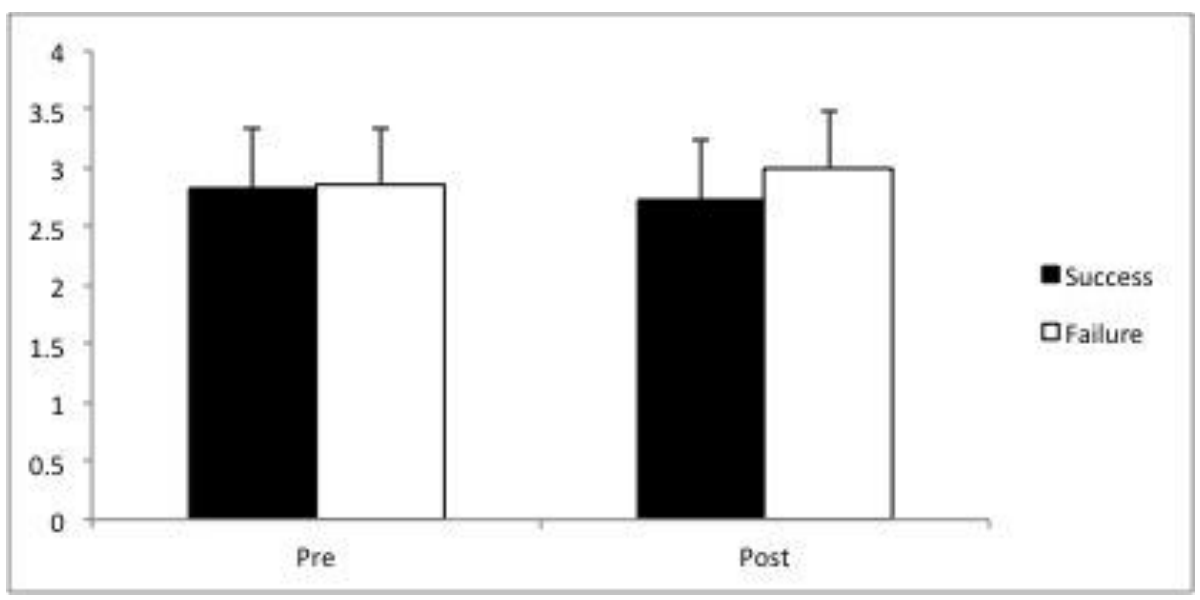

\subsection{Experiment 2 - Memory}

3.2.1. Self-reported emotion

Table 4 shows that the emotional state of the participants was similar before performing the tasks and that the failure condition specifically induced a negative mood state. There was a significant interaction effect between condition and time, $F(1,21)=10.95, p=.003, \eta_{p}{ }^{2}=.34$. Pairwise comparisons showed that the participants rated their mood lower after the memory task in the failure condition $(p=.004)$, but not in the success condition $(p=.389)$. The participants also rated their mood lower in the failure versus the success condition after performing the task $(p=.010)$, but not before the task $(p=.463)$. There was also a significant main effect of time $\left(F(1,21)=6.65, p=.018, \eta_{p}^{2}=.24\right)$, showing that mood is lower overall after performing the tasks, and a significant main effect of condition $\left(F(1,21)=5.86, p=.025, \eta_{p}^{2}=.22\right)$, showing that it is lower overall in the failure condition. 
Table 4 - Self-reported emotion before and after the SFM for the success and failure condition in Experiment 2 (memory)

\begin{tabular}{lcc}
\hline & $\begin{array}{c}\text { Success task } \\
\text { Mean (SD) }\end{array}$ & $\begin{array}{l}\text { Failure task } \\
\text { Mean (SD) }\end{array}$ \\
\hline Pre-SFM & $12.27(1.52)$ & $12.45(1.71)$ \\
\hline Post-SFM & $12.55(1.74)$ & $10.86(2.57)$ \\
\hline
\end{tabular}

\subsubsection{Awareness of symptoms}

Figure 2 shows that awareness changed according to the task condition. There was a significant interaction effect between condition and time ( $F(1$, $\left.21)=10.24, p=.004, \eta_{p}{ }^{2}=.33\right)$. Paired comparisons revealed increased awareness of deficit after performing the tasks in the failure condition ( $p=$ $.001)$, but not in the success condition $(p=.131)$. Further paired comparisons showed that the participants had a similar level of awareness before performing the task in both conditions $(p=.771)$. There was also a significant main effect of the time on ratings of anosognosia $(F(1,21)=$ $\left.5.65, p=.027, \eta_{p}^{2}=.21\right)$ and a significant main effect of the condition on ratings of anosognosia $\left(F(1,21)=10.06, p=.005, \eta_{p}^{2}=.32\right)$. Spearman rho correlations were also performed and showed a significant relationship between the change in the rating of anosognosia and the actual performance of the participants only in the failure condition $(\rho=.66, p=$ .001), and a negative association between anosognosia change and apathy $(\rho=-.46, p=.036)$. There were no significant correlations with cognition (MMSE: $\rho=-.11, p=.616$ ) and depression (GDS: $\rho=.14, p=$ $.534)$. 
Figure 2 - Awareness of symptoms during experiment 2

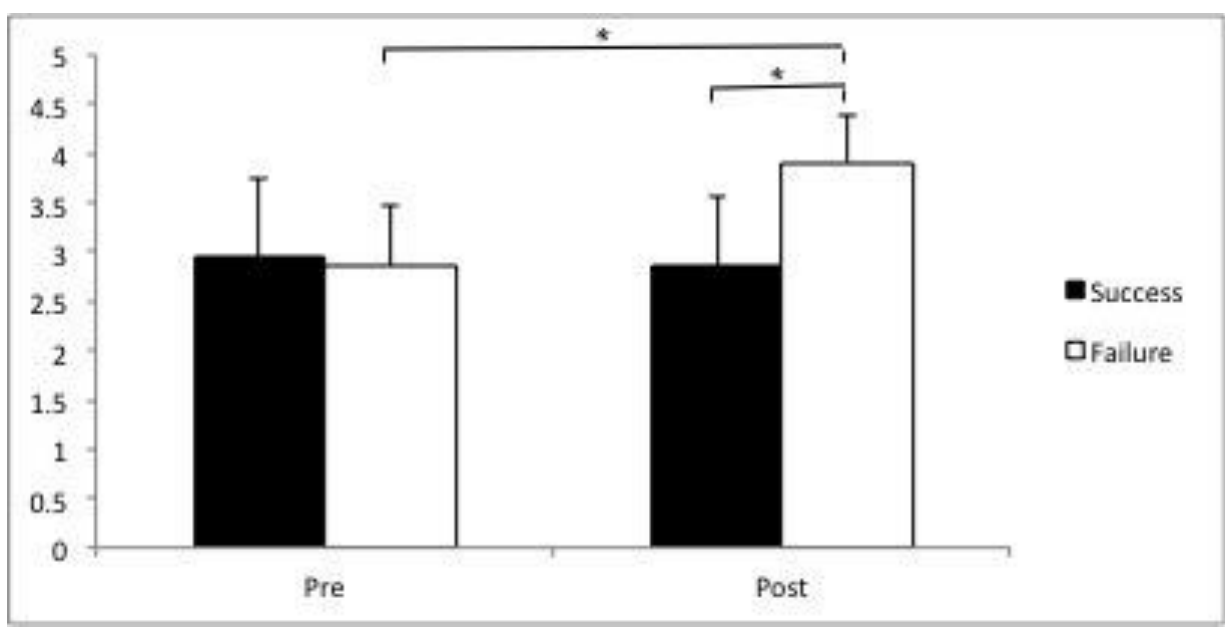

\section{Discussion}

The present study explored the effects of mood on the level of awareness regarding symptoms in AD patients. We experimentally induced neutral and negative mood states in patients with $A D$ and measured the resulting changes in the level of awareness regarding cognitive and behavioral symptoms in two experiments, with reaction time and memory tasks. In both experiments, the results showed that after performing the task in the failure condition, people with $A D$ reported a more negative mood than before performing the task, with large effect sizes for this change. As expected, performing the tasks in the success condition led to a neutral mood state. These results confirmed the efficacy of the mood induction procedure, which has already been used successfully with controls and another group of AD patients (MOGRABI et al., 2012b). In addition, the AD patients showed an increase in their apparent awareness following the negative mood induction (with a large effect size found), endorsing more symptoms on the AQ-D. Nevertheless, this improvement occurred only in the memory experiment, with the level of awareness remaining unchanged in the reaction time task experiment.

These results are partially in line with previous findings indicating that people with $A D$ who are more depressed show more apparent awareness 
(e.g., (CLARE et al., 2011; HARWOOD; SULTZER; WHEATLEY, 2000). To explain this relation, a theory suggests that depression causes only apparently more awareness because of a negative bias when reporting problems (MOGRABI; MORRIS, 2014). However, this theory does not seem to be able to fully explain the results of the present study. Indeed, patients with $A D$, despite reporting a negative mood following the mood induction procedure in both experiments, showed a greater awareness of the symptoms only when the task used in the SFM was memory-based.

An explanation for these findings might be found in the Mood Congruent/Dependent Memory theories. According to the MCM theory, the negative mood state induced by the SFM in our experiments led the participants to recall more negatively toned memories when asked about their deficits, generating a greater awareness. Following a similar idea, MDM effect might also be able to account for the results of the present study. MDM is defined as the ability to increase the recall of learned material, when the subject's emotional state is the same at the time of encoding and at the time of retrieval, regardless of the content of the material (BOWER, 1981). As shown by Mograbi et al. (2012), AD patients exhibit an implicit emotional reactivity to failure, despite a lack of explicit awareness. In other words, AD patients might be encoding events of failure when they are currently experiencing low mood. Based on the MDM theory, the $A D$ patients who were experiencing a negative mood state during our experiment, would be expected to increase the recall of events encoded when they were already in a low mood, namely events of failure. Therefore, when asked about their deficits, participants presented a greater awareness about their own difficulties.

However, the MCM and MDM phenomena do not account for the differences between the two experiments, namely that $A D$ patients improve their awareness of deficits when the negative mood induction procedure uses a memory task, but not when a reaction time task is used? An additional explanation might emerge from the Context-Dependent Memory (CDM) effect. CDM is defined as an increased recall of material when the context at encoding and retrieval is the same and the context is 
understood as external (e.g. spatial). In the case of the present study, the context can be seen as the type of task the participant is involved in. Indeed, AD patients are constantly confronted with memory failure situations, and during these situations, they might be encoding having difficulties. So, when exposed to a similar memory failure situation (in Experiment 2), they experience an increased recall of their own difficulties, leading to an improvement of their awareness.

Our findings may have important clinical implications. Firstly, the study shows again how exposure to failure reduces mood state in $A D$ (MOGRABI et al., 2012b) and this has implications for how mood might be adversely affected in everyday life. Secondly, the greater apparent awareness of deficit following failure experience in the memory condition suggests that levels of recorded anosognosia might vary according to when in a clinical session a person has been exposed to failure, perhaps involving neuropsychological assessment. The study also underlines the importance of the context, showing that only memory-based tasks produce the specific effect and this might be consistent with everyday experience where memory difficulties produce some of the most disabling effects. Finally, studies show that lack of awareness regarding the deficits in $A D$ seems to be protective from developing depression (CLARE et al., 2012a; HARWOOD; SULTZER; WHEATLEY, 2000) and, consistent with this, it is possible that shaping the environment of a person to reduce exposure to failure might help to retain mood state, whilst making then less aware of their deficit.

It is necessary to consider some limitations of the present study. Indeed, our small sample size and the large majority of women in our sample may affect generalizability of the results and further studies are needed to confirm our findings. Another limitation of the study refers to the absence of a control group. Healthy controls were not used to explore the impact of mood on the level of anosognosia, because, by definition, a healthy control group would not show the lack of awareness associated with dementia. The current study was also limited to a degree by the methodology used to assess the participants' awareness. Indeed, the 
same questions were used to assess awareness before and after all the conditions. As pointed by Marcel et al. (2004), patients with plegia following stroke may learn how to respond to awareness measures when the questions are repeated. Nevertheless, the present study was conducted with people with dementia and the order of experiments and conditions was quasi-counterbalanced among the participants. In addition, changes in awareness were observed only after the failure memory task, suggesting that the results cannot be simply explained by practice effects.

To the best of our knowledge, this is the first study exploring in an experimental design the relation between mood state and awareness in patients with AD. As most of the studies highlighted, the existence of a relation between anosognosia and mood state is now well accepted. However, the direction of this relation is still debated in the literature. One theory is that the awareness of the deficits leads to a higher negative mood state, through a reactive depression phenomenon. Another theory suggests that depression leads to report more difficulties overall. The results of the present study support the notion that negative mood leads to a greater awareness of the deficits, and the best explanatory model is to be found in the MCM and MDM/CDM phenomena. Further investigations of the relation between mood and awareness are needed with larger samples and the inclusion of other methodology, such as neuroimaging.

\section{Acknowledgments}

We thank Stephanie Cosentino for helpful comments. Elodie Bertrand receives financial support from the Capes Foundation, Ministry of Education of Brazil (Grant BEX 3489/15-9). The authors declare that there are no conflicts of interest. Daniel Mograbi received funding from FAPERJ. Jerson Laks is a Cientista do Nosso Estado, Fundação de Apoio à Pesquisa do Estado do Rio de Janeiro (FAPERJ). 


\section{REFERENCES}

AGNEW, S. K.; MORRIS, R. G. The heterogeneity of anosognosia for memory impairment in Alzheimer's disease: A review of the literature and a proposed model. Aging \& Mental Health, v. 2, n. 1, p. 7-19, 1998.

ALMEIDA, O. P.; ALMEIDA, S. A. Confiabilidade da versão brasileira da Escala de Depressão em Geriatria (GDS) versão reduzida. Arquivos de Neuro-Psiquiatria, v. 57, n. 2B, p. 421-426, 1999.

ALMEIDA, O. P.; CROCCO, E. I. Percepção dos déficits cognitivos e alterações do comportamento em pacientes com doença de Alzheimer. Arquivos de Neuro-Psiquiatria, v. 58, n. 2A, p. 292-299, 2000.

AMERICAN PSYCHIATRIC ASSOCIATION. Diagnostic and Statistical Manual of Mental Disorders: DSM-IV-TR. [s.I.] American Psychiatric Association, 2000.

ANTOINE, C. et al. Awareness of deficits and anosognosia in Alzheimer's disease. L'Encephale, v. 30, n. 6, p. 570-577, 2004.

ARLT, S. et al. Adherence to medication in patients with dementia: Predictors and strategies for improvement. Drugs and Aging, v. 25, n. 12, p. 1033-1047, 2008.

BAEZ, S.; GARCÍA, A. M.; IBANEZ, A. The Social Context Network Model in Psychiatric and Neurological Diseases. In: WÖHR, M.; KRACH, S. (Eds.). . Social Behavior from Rodents to Humans. Cham: Springer International Publishing, 2016. p. 379-396.

BERTOLUCCI, P. H. et al. [The Mini-Mental State Examination in a general population: impact of educational status]. Arquivos de neuropsiquiatria, v. 52, n. 1, p. 1-7, 1994.

BERTRAND, E.; LANDEIRA-FERNANDEZ, J.; MOGRABI, D. C. L'impact psychosocial de l'anosognosie dans la Démence de Type Alzheimer. Revista Ibero-american de Gerontologia, v. 2, p. 52-69, 2013.

BESHARATI, S. et al. Another perspective on anosognosia: Selfobservation in video replay improves motor awareness. Neuropsychological rehabilitation, v. 25, n. 3, p. 319-52, 2015.

BOWER, G. H. Mood and memory. The American psychologist, v. 36, n. 2, p. 129-148, 1981.

CLARE, L. et al. Multidimensional assessment of awareness in early-stage dementia: A cluster analytic approach. Dementia and Geriatric Cognitive Disorders, v. 31, n. 5, p. 317-327, 2011.

CLARE, L. et al. The influence of psychological, social and contextual 
factors on the expression and measurement of awareness in early-stage dementia: testing a biopsychosocial model. International journal of geriatric psychiatry, v. 27, n. 2, p. 167-77, 2012.

DEBETTIGNIES, B. H.; MAHURIN, R. K.; PIROZZOLO, F. J. Insight for impairment in independent living skills in Alzheimer's disease and multiinfarct dementia. Journal of clinical and experimental neuropsychology, v. 12, n. 2, p. 355-363, 1990.

EICH, E.; METCALFE, J. Mood dependent memory for internal versus external events. Journal of Experimental Psychology: Learning, Memory, and Cognition, v. 15, n. 3, p. 443-455, 1989.

FLEMING, K. et al. Memory for emotional stimuli in patients with Alzheimer's disease. American Journal of Alzheimer's Disease and Other Dementias, v. 18, n. 6, p. 340-342, 2003.

FOLSTEIN, M. F.; FOLSTEIN, S. E.; MCHUGH, P. R. "Mini-mental state". A practical method for grading the cognitive state of patients for the clinician. Journal of psychiatric research, v. 12, n. 3, p. 189-198, 1975.

FROST, R. O.; GREEN, M. L. Velten Mood Induction Procedure Effects Duration and Postexperimental Removal. Personality and Social Psychology Bulletin, v. 8, n. 2, p. 341-347, jun. 1982.

GUIMARÃES, H. C. et al. Brazilian caregiver version of the Apathy Scale. Dementia e Neuropsychologia, v. 3, n. 4, p. 321-326, 2009.

HARWOOD, D. G.; SULTZER, D. L.; WHEATLEY, M. V. Impaired insight in Alzheimer disease: association with cognitive deficits, psychiatric symptoms, and behavioral disturbances. Neuropsychiatry, Neuropsychology, and Behavioral Neurology, v. 13, n. 2, p. 83-88, 2000.

HORNING, S. M.; MELROSE, R.; SULTZER, D. Insight in Alzheimer's disease and its relation to psychiatric and behavioral disturbances. International Journal of Geriatric Psychiatry, v. 29, n. 1, p. 77-84, 2014.

IBAÑEZ, A.; MANES, F. Contextual social cognition and the behavioral variant of frontotemporal dementia. Neurology, v. 78, n. 17, p. 1354-62, 2012.

ISEN, A. M.; GORGOGLIONE, J. M. Some Specific Effects of Four AffectInduction Procedures. Personality and Social Psychology Bulletin, v. 9, n. 1 , p. $136-143,1983$.

KNIGHT, B. G.; DURBIN, K. Aging and the effects of emotion on cognition: Implications for psychological interventions for depression and anxiety. PsyCh journal, v. 4, n. 1, p. 11-9, 2015. 
KOTLER-COPE, S.; CAMP, C. J. Anosognosia in Alzheimer disease. Alzheimer disease and associated disorders, v. 9, n. 1, p. 52-56, 1995.

MARC, L. G.; RAUE, P. J.; BRUCE, M. L. Screening performance of the 15-item geriatric depression scale in a diverse elderly home care population. The American journal of geriatric psychiatry, v. 16, n. 11, p. 914-21, 2008.

MARCEL, A.; TEGNER, R.; NIMMOSMITH, I. Anosognosia for Plegia: Specificity, Extension, Partiality and Disunity of Bodily Unawareness. Cortex, v. 40, n. 1, p. 19-40, 2004.

MARIN, R.; BIEDRZYCKI, R.; FIRINCIOGULLARI, S. Reliability and validity of the Apathy Evaluation Scale. Psychiatry Research, v. 38, n. 2, p. 143-162, 1991.

MARTIN, M. On the induction of mood. Clinical Psychology Review, v. 10, n. 6, p. 669-697, 1990.

MCKHANN, G. M. et al. The diagnosis of dementia due to Alzheimer's disease: recommendations from the National Institute on AgingAlzheimer's Association workgroups on diagnostic guidelines for Alzheimer's disease. Alzheimer's \& dementia: the journal of the Alzheimer's Association, v. 7, n. 3, p. 263-9, 2011.

MIGLIORELLI, R. et al. Anosognosia in Alzheimer's disease: a study of associated factors. The Journal of neuropsychiatry and clinical neurosciences, v. 7, n. 3, p. 338-344, 1995.

MOGRABI, D. C. et al. Unawareness of memory impairment in dementia: a population-based study. International Psychogeriatrics, v. 24, n. 6, p. 931-939, 2012a.

MOGRABI, D. C. et al. Emotional reactivity and awareness of task performance in Alzheimer's disease. Neuropsychologia, v. 50, n. 8, p. 2075-84, 2012b.

MOGRABI, D. C. et al. The development of computerised success-failure manipulation paradigms for the experimental study of metacognition in neurological patients. Temas em Psicologia, v. 22, n. 3, p. 579-588, 2014.

MOGRABI, D. C.; BROWN, R. G.; MORRIS, R. G. Anosognosia in Alzheimer's disease - The petrified self. Consciousness and Cognition, v. 18, n. 4, p. 989-1003, 2009.

MOGRABI, D. C.; MORRIS, R. G. On the relation among mood, apathy, and anosognosia in Alzheimer's disease. Journal of the International Neuropsychological Society : JINS, v. 20, n. 1, p. 2-7, 2014. 
MORRIS, R. G.; HANNESDOTTIR, K. Loss of "awareness" in Alzheimer's Disease. In: MORRIS, R. G.; BECKER, J. T. (Eds.). . The Cognitive Neuropsychology of Alzheimer's Disease. Oxford: Oxford University Press, 2004. p. 275-296.

NUTT, R. M.; LAM, D. A comparison of mood-dependent memory in bipolar disorder and normal controls. Clinical psychology \& psychotherapy, v. 18, n. 5, p. 379-386, 2011.

RIES, M. L. et al. Anosognosia in mild cognitive impairment: Relationship to activation of cortical midline structures involved in self-appraisal. Journal of the International Neuropsychological Society: JINS, v. 13, n. 3, p. 450-461, 2007.

RYMER, S. et al. Impaired awareness, behavior disturbance, and caregiver burden in Alzheimer disease. Alzheimer disease and associated disorders, v. 16, n. 4, p. 248-253, 2002.

SELTZER, B. et al. Awareness of deficit in Alzheimer's disease: relation to caregiver burden. The Gerontologist, v. 37, n. 1, p. 20-24, 1997.

SOUSA, M. F. B. et al. Awareness of disease is different for cognitive and functional aspects in mild Alzheimer's Disease: A one-year observation study. Journal of Alzheimer's Disease, v. 43, n. 3, p. 905-913, 2015.

SPALLETTA, G. et al. Anosognosia and neuropsychiatric symptoms and disorders in mild Alzheimer disease and mild cognitive impairment. Journal of Alzheimer's disease: JAD, v. 29, n. 4, p. 761-772, 2012.

STARKSTEIN, S. E. et al. Insight and danger in Alzheimer's disease. European journal of neurology, v. 14, n. 4, p. 455-60, 2007.

STEELE, C. et al. Psychiatric symptoms and nursing home placement of patients with Alzheimer's disease. The American Journal of Psychiatry, v. 147 , n. 8 , p. $1049-1051,1990$.

STUSS, D. T. Self, awareness and the frontal lobes: A neuropsychological perspective. In: STRAUSS, J.; GOETHALS, G. R. (Eds.). . The self: Interdisciplinary approaches. [s.I.] Springer New York, 1991. p. 255277.

STUSS, D. T. et al. The frontal lobes and self-awareness. In: FEINBERG, T. E.; KEENAN, J. P. (Eds.). . The Lost Self: Pathologies of the Brain and Identity. Oxford: Oxford University Press, 2005. p. 50-64.

TURRÓ-GARRIGA, O. et al. Burden associated with the presence of anosognosia in Alzheimer's disease. International Journal of Geriatric Psychiatry, v. 28, n. 3, p. 291-297, 2013.

VERHÜLSDONK, S. et al. Anosognosia and depression in patients with 
Alzheimer's dementia. Archives of Gerontology and Geriatrics, v. 57, n. 3, p. 282-287, 2013.

YESAVAGE, J. A. et al. Development and validation of a geriatric depression screening scale: A preliminary report. Journal of Psychiatric Research, v. 17, n. 1, p. 37-49, 1982. 


\section{ARTICLE 3}

Bertrand, E., Landeira-Fernandez, J., \& Mograbi, D. C. (2016). Metacognition and perspective-taking in Alzheimer's disease: a mini-review. Metacognition and Perspective-Taking in Alzheimer's Disease: a minireview. Frontiers in Psychology, 7, 1-7. http://doi.org/10.3389/fpsyg.2016.01812

\section{Metacognition and}

Perspective-Taking in Alzheimer's Disease: A Mini-Review 


\section{ABSTRACT}

Metacognition refers to the monitoring and regulation of cognitive processes and its impairment can lead to a lack of self-awareness of deficits, or anosognosia. In the context of different neurological and psychiatric disorders (e.g., traumatic brain injury, dementia, and schizophrenia), studies have shown that patients who present impairments in metacognitive abilities may be able to recognize such difficulties in others and in themselves when exposed to material in a third-person perspective. Considering that metacognitive impairments are an important characteristic of dementia, especially in Alzheimer's Disease (AD), studies of the relationship between metacognition and perspective-taking may be relevant to improve the quality of life of people with dementia. The current paper first briefly addresses the theme of metacognition and the impact of metacognitive deficits in people with AD. The focus then turns to the relationship between metacognition and perspective-taking in different neurological and psychiatric disorders, particularly AD. This relationship is also discussed based on theoretical models, particularly the Cognitive Awareness Model (CAM). Specifically, the CAM suggests the existence of distinct memory systems for self- and other-information, an idea which is supported by neuroimaging findings. We suggest that the Default Mode Network, as it has been shown to be implicated in self vs. other processing and is affected early in AD, could explain the impact of perspective-taking on awareness of deficits in AD. Finally, we present possible clinical implications of the relationship between metacognition and perspectivetaking in AD. Indeed, we considered the possibility of improving patient's awareness through the use of a third-person perspective, which, consequently, may decrease the negative impacts of anosognosia in $A D$.

Keywords: Metacognition, anosognosia, perspective-taking, dementia, Alzheimer's Disease 


\section{Introduction}

Increases in life expectancy are now well documented worldwide. With an ageing population, the number of people who suffer from dementia is also increasing. According to Alzheimer's Disease International (2015), 46.8 million people are currently living with dementia, and studies suggest that this number will increase in the near future, with estimations of double the number of people who are affected by dementia by 2030 (WIMO; JONSSON; WINBLAD, 2006).

With the aim of promoting a better quality of life in people with dementia $(P w D)$, the theme of metacognition is particularly relevant. The awareness of deficits relies on metacognitive abilities, which are shown to be compromised in PwD (COSENTINO; STERN, 2005). In fact, a lack of awareness about behavioral and/or cognitive deficits, referred to as anosognosia, is a common characteristic of dementia (MOGRABI et al., 2012a; MORRIS; HANNESDOTTIR, 2004), with an important impact on patients and their caregivers (BERTRAND; LANDEIRA-FERNANDEZ; MOGRABI, 2013).

Within this context, this review first addresses the theme of metacognition and the impact of metacognitive deficits in PwD, especially in Alzheimer's Disease $(A D)$. The focus then turns to the relationship between metacognition and perspective-taking in $A D$. Studies that explore metacognitive abilities in different neurological and psychiatric disorders have suggested that the perspective through which information is presented may impact the patient's awareness of his own deficits. Such studies have investigated the impact of perspective-taking on metacognitive abilities from two angles: self-observation through a thirdperson perspective (e.g., observing oneself from the outside through a video) and the evaluation of another person's performance. The concept of perspective-taking is usually defined as the ability to take another person's point of view (RYSKIN et al., 2015). However, as it has already been done in the literature (BESHARATI et al., 2015; BRUGGER, 2002), in the current review, we will use the term "perspective-taking" to refer to 
the two perspectives explained above (self-observation in a third-person perspective and other-observation). The relationship between perspectivetaking and awareness is discussed based on the Cognitive Awareness Model (CAM) (AGNEW; MORRIS, 1998; HANNESDOTTIR; MORRIS, 2007; MORRIS; HANNESDOTTIR, 2004; MORRIS; MOGRABI, 2013). Finally, we present possible clinical implications of this relationship in dementia.

\section{Metacognition}

Metacognition is defined as the knowledge and reflective capacities one has concerning one's own cognitive functioning (FLAVELL, 1979). Considering the original conceptualization proposed by Flavell (1979), metacognition can be divided into metacognitive knowledge (which represents acquired knowledge about one's own and also other people's cognitive processes) and metacognitive experience (which permits the updating of metacognitive knowledge and activation of strategies during cognitive processes). Nelson and Narens (1990) proposed another influential model of metacognition that comprises two levels of analysis, meta-level and object-level, which operate in an interrelated fashion. The meta-level receives information from the object-level through a monitoring process, and the meta-level regulates the object-level through a control process. There are some parallels between this model and the conceptualization of metacognition proposed by Flavell (1979). The monitoring process can be seen as "metacognitive knowledge," and the control process can be seen as "metacognitive experience" in Flavell's description of metacognition.

The literature on metacognitive abilities indicates that deficits in metacognition and anosognosia are referred to interchangeably. However, as highlighted by Souchay (2007), the two terms rely on different theoretical frameworks. The concept of anosognosia focuses on deficits in awareness in clinical populations, and the notion of metacognition is based on the functioning of awareness in normal populations. However, 
anosognosia and metacognition are closely related concepts. Based on the metacognitive theories described above, anosognosia can be seen as a deficit at the level of metacognitive knowledge or monitoring processes. Indeed, anosognosia is defined as the diminished ability to recognize the presence or appreciate the severity of deficits (BABINSKI, 1914). In other terms, it refers to a lack of awareness about deficits or the condition and is described in cases of various neurological conditions, such as aphasia, hemiplegia, and dementia (MOGRABI; BROWN; MORRIS, 2009; RIES et al., 2007; STUSS, 1991; STUSS et al., 2005). For example, in the case of anosognosia for hemiplegia, patients would state that they are capable of moving their paralyzed limb despite contradictory evidence (ORFEl et al., 2007).

Unawareness of cognitive impairments are common characteristics of $A D$ (MORRIS; HANNESDOTTIR, 2004; MORRIS; MOGRABI, 2013). The estimates of prevalence have varied widely across studies, ranging from $23 \%$ to $81 \%$, likely because of differences in criteria and assessment methods (ANTOINE et al., 2004; MOGRABI et al., 2012a; SOUSA et al., 2015). Nevertheless, studies that explore anosognosia in PwD with large samples have consistently reported a prevalence above $30 \%$ (STARKSTEIN et al., 2006, 2007). In a large epidemiological study ( $n=$ 897), Mograbi et al. (2012) showed that $78 \%$ of PwD are unaware of their memory impairment. The multidimensional aspect of awareness also contributes to variations in the reported prevalence in dementia. In fact, there is considerable variability in the presentation and severity of anosognosia, with unawareness ranging from slight minimization to complete denial of problems (CLARE et al., 2005). Additionally, awareness can differ according to its object (e.g., memory deficits, changes in activities of daily living, and the diagnosis itself), and it is not uncommon for patients to acknowledge problems in one sphere but not in another (neuropsychological deficits vs. behavioral and psychological symptoms) (KOTLER-COPE; CAMP, 1995; VASTERLING et al., 1995a). 


\section{Relationship between metacognition and perspective-taking}

Studies that explored the impact of self-observation found improvements in awareness when patients were allowed to see themselves in a video. Through the presentation of a case-study, Fotopoulou, Rudd, Holmes and Kopelman (2009) showed that video self-observation can be used as an efficient technique to improve the awareness of motor deficits after stroke. These findings were replicated in other settings. Besharati et al. (2015) described two case-studies of patients who suffered from anosognosia for hemiplegia. At the time of the first experimental session, one patient was in an acute stage of recovery ( 15 days post-stroke), and the other patient was in the chronic stage (89 days post-stroke). Both patients presented a reinstatement of motor awareness after seeing themselves in a video, suggesting that self-observation through a third-person perspective positively influences metacognitive abilities. Similar results have been observed in the context of psychosis. For example, David, Chis Ster and Zavarei (2012) explored the efficacy of video-observation as a strategy to improve psychotic patients' awareness. One group viewed a video of themselves during an acute psychotic episode, and a second group viewed a video of an actor who played the role of someone with acute psychosis. The authors showed that both groups improved their awareness regarding psychotic symptoms after watching the video. These findings reinforced previous results that also highlighted the potential use of video self-observation as an efficient intervention to improve insight in psychotic patients (DAVIDOFF et al., 1998; VIKRAM et al., 2008).

The relationship between metacognition and perspective-taking has also been explored by studying the capacity to perceive deficits in someone else. For example, Ramachandran and Rogers-Ramachandran (1996) showed that, in the context of anosognosia for hemiplegia, patients were able to acknowledge the paralysis of others, even when they were unaware of their own paralysis. Similarly, Garrett, Singh, Amanbekova and Kamarajan (2011) demonstrated that schizophrenia patients who lacked 
awareness of their own illness were able to accurately categorize clinical vignettes as cases of medical illness, no illness, or psychiatric illness. Altogether, these findings used different methods to assess awareness to highlight the possible relationship between metacognitive processes and perspective-taking in psychiatric and neurologic diseases.

\subsection{Metacognition and perspective-taking in the context of} $A D$

In the context of $A D$, a few studies have explored the issue of perspectivetaking with regard to metacognitive abilities by asking patients with $A D$ to evaluate the performance of their relatives. The results indicated that $A D$ patients were generally accurate in predicting their caregiver's performance, despite difficulties in evaluating their own performance. These results were attributable to deficits in the patients' ability to update their knowledge of their own cognitive functioning (i.e., a monitoring deficit in the metacognitive process that is restricted to the self) (KASZNIAK; ZAK, 1996; MCGLYNN; KASZNIAK, 1991). However, in a review of the neuropsychological bases of metamemory, which is a subtype of metacognition looking specifically at the control and monitoring of memory performances, Kaszniak and Zak (1996) argued that such an interpretation of these findings may be problematic because cognitive abilities in the patients' relatives did not decline as sharply. Therefore, the patients may be able to make accurate evaluations of their caregivers' performance even when relying on out-of-date knowledge of their relatives' cognitive capacities. To resolve this issue, Duke, Seltzer, Seltzer, and Vasterling (2002) used a combination of two methods to assess awareness: predictions and post-dictions regarding performance and discrepancies between patient and informant reports. $A D$ patients and their spouses were asked to estimate each other's performance and the performance of a fictional patient who suffered from moderate cognitive impairment. The estimations were made before and after performing a verbal memory task and verbal fluency task. Before making the predictions, the participants 
were given normative data based on their own age range, their spouse's age range, and the fictional patient's age range. The results showed that AD patients overestimated themselves but made accurate predictions and post-dictions of their spouse's performance. With regard to evaluating the fictional patient, both $A D$ patients and their caregivers overestimated performance. These results, however, did not allow the determination of whether AD patients' difficulties in awareness were self-specific or global. However, by comparing the predictions and post-dictions, the authors suggested that some monitoring abilities, in an on-line fashion, might be preserved in AD patients. Indeed, the results showed that they reduced the extent of overestimating their abilities after completing the task. To date, this is the only study that has compared the ability of AD patients to evaluate the performance of a well-known person (e.g., spouse) and an unknown person (e.g., fictional patient).

Using a vignette technique as an indirect method to assess awareness, Clare et al. (2012) explored the ability of PwD (including AD, vascular dementia and mixed Alzheimer's and vascular dementia) to appreciate the deficits of a fictional person. PwD, their caregivers, and older adult controls were asked to identify and offer advice for the problems that were described in the vignettes. Vignettes were created and described a short scenario of a person who presented a typical case of advanced or earlystage dementia or a healthy older adult. The results showed that, when presented with these vignettes, the participants were able to correctly identify and offer appropriate advice for the problem that was described in the vignette. Additionally, some of the participants in the dementia group, even some who presented a limited level of awareness, identified themselves spontaneously with the situation that was presented in the vignette. These results led the authors to suggest that the vignette method (i.e., a third-person perspective method) could be useful to help PwD acknowledge their own deficits.

Based on the evaluation of a third person, Mograbi, Brown, LandeiraFernandez, and Morris (2014) investigated the attribution of difficulty for the self and for others. Patients with $A D$ were asked to judge how difficult 
a task was for them and would be for someone else their own age. Two experiments were conducted using computerized tasks. Experiment 1 used reaction time tasks, and Experiment 2 used memory tasks. The level of task difficulty was controlled, leading to one easy and one difficult task in each experiment. In both experiments, the authors showed that $A D$ patients predicted that others would perform as well as themselves, despite their cognitive deficits. This study also explored correlations with premorbid personality and showed that higher neuroticism and agreeableness were associated with the attribution of more difficulty for the self and less difficulty for others. These findings were interpreted by the authors as the poor ability of people with $A D$ to put themselves in someone else's position. The authors explained that the different findings between their results and Clare et al. (2012) were attributable to methodological differences. Indeed, in Mograbi et al. (2014), the cognitive demand of the task, where participants had to imagine themselves as someone else, was higher than in Clare et al. (2012), in which patients did have access to written vignettes.

Altogether, these results suggest that patients with $A D$ are more accurate when evaluating the performance of someone else (e.g., caregiver or fictional person) than they are for themselves. Nevertheless, the methods that were employed in these studies had distinctly different features (e.g., known vs. unknown person, vignettes vs. actual observation, prediction of performance vs. judgment of difficulty level), thus limiting synthesis of the findings. Moreover, to date, no study has explored the impact of selfevaluation through a third-person perspective, using for example video self-observation, on awareness level in AD patients. Further research is needed to better understand the impact of perspective-taking on the awareness of deficits in dementia. Additionally, possible symptoms, such as a deficit in familiarity recognition for self and other faces, should also be considered in studies investigating the impact of perspective-taking in dementia (VAN DEN STOCK et al., 2012, 2013). Finally, it is important to acknowledge the differences in the underlying mechanisms of metacognitive deficits in different types of dementia, such as AD and FTD 
(ROSEN, 2011; SALMON et al., 2008) and, therefore, to take those into account when exploring self vs. other-information processing in dementia.

\subsection{Theoretical explanation}

As suggested by Morris and Mograbi (2013), the behavioral evidence may reflect the existence of different networks that are involved in self/other appraisal. The authors included this notion in a reformulated version of the CAM (AGNEW; MORRIS, 1998; HANNESDOTTIR; MORRIS, 2007; MORRIS; HANNESDOTTIR, 2004; MORRIS; MOGRABI, 2013), which is a neurocognitive model of anosognosia, accounting for the heterogeneous presentation of disordered awareness, through domain-specific modules (see Figure 1). In fact, they proposed different memory records for selfand other-information. First, the Personal Database, which contains semanticized representations about the self, and the Autobiographical Conceptual Memory System, which contains lifetime knowledge concerning experienced events, allow the appraisal of self-evaluation. Both are relying on personal semantics, which is acquired through personal, social, and cultural experiences. Second, these memory systems are separated from the Generic Memory System, which stores other material that permits evaluations of others and is based on general semantic knowledge. 
Figure 1 - Cognitive Awareness Model (CAM)

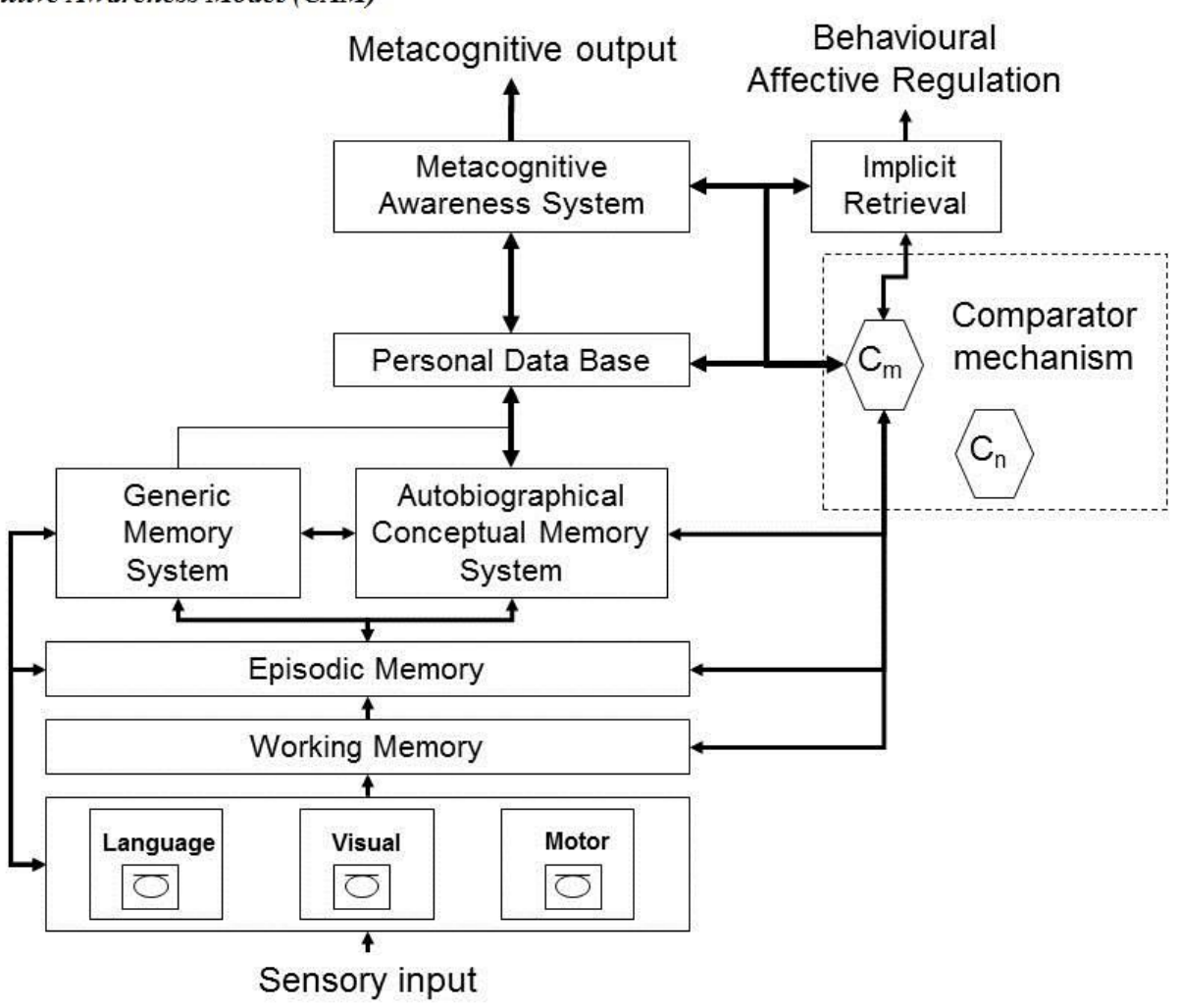

Reprinted from Cortex, Vol. 49, Issue 6, Morris, R.G., \& Mograbi, D.C., "Anosognosia, autobiographical memory and self knowledge in Alzheimer's disease", pp. 1553-1565, Copyright 2013, with permission from Elsevier.

\subsection{Neuroimaging evidence}

Recent neuroimaging evidence supports the idea of different neural bases for processing self vs. non-self information. For example, Ruby and Decety (2001, 2003, 2004) explored the neuroanatomical correlates of perspective-taking regarding different domains: motor, conceptual, and emotional. The authors showed that, for these three domains, the frontopolar, somatosensory, and inferior parietal cortices are implicated in the process of self vs. other distinction. As underscored by Ruby et al. (2009), some of these brain areas, such as the orbitofrontal cortex and temporoparietal junction, have also been shown to be related to measures of anosognosia in AD. Additionally, these brain regions are partially overlapping with those that comprise the default mode network (DMN). Indeed, the $\mathrm{DMN}$, activated when participants are not engaged in a specific cognitive task, includes the frontal, parietal and temporal regions (for review see (BUCKNER; ANDREWS-HANNA; SCHACTER, 2008). Moreover, this network has been shown to be affected early by $A D$ 
neurodegenerative process (MEVEL et al., 2011) and, as suggested by Bond et al. (2016), the impairment of the $D M N$ by $A D$ neurodegeneration could explain the differences in metacognitive abilities depending on the perspective through which the information is presented. However, to date, no neuroimaging study has specifically explored the issue of perspectivetaking (first- vs. third-person perspectives) regarding metacognitive processes in $A D$.

\subsection{Clinical implications}

The findings regarding the relationship between metacognition and perspective-taking may have important clinical implications. In fact, studies have shown that the lack of awareness is related to higher engagement in risk situations, earlier institutionalization, more difficulties with treatment adherence, and greater caregiver burden, all of which increase the financial impact on society (ARLT et al., 2008; BERTRAND; LANDEIRAFERNANDEZ; MOGRABI, 2013; HORNING; MELROSE; SULTZER, 2014; STARKSTEIN et al., 2007). Interventions that increase awareness may eventually bring important clinical benefits. Throughout this review, we highlighted the possibility of using third-person perspective paradigms to do so. This type of intervention has already been successfully used with anosognosic patients with neurological or psychiatric disorders, such as hemiplegia after stroke or schizophrenia (BESHARATI et al., 2015; DAVID; CHIS STER; ZAVAREI, 2012; FOTOPOULOU et al., 2009; VIKRAM et al., 2008). However, when using interventions to improve awareness, caution needs to be taken with the patient's emotional state. Studies have shown that awareness regarding deficits in AD may lead to negative mood changes, including depressive symptoms (CLARE et al., 2012a; HARWOOD; SULTZER; WHEATLEY, 2000). Thus, further efforts need to be made by clinicians to acknowledge changes in their patients' mood states during interventions that attempt to decrease the level of anosognosia. 


\section{Conclusion}

In summary, there is preliminary evidence suggesting that $A D$ patients might show better awareness when evaluating abilities of others or themselves in a third-person perspective. These findings are supported by the CAM, which suggests distinct memory systems for self- and otherinformation, and also by neuroimaging studies, highlighting different neural bases for self and non-self processing. The early impairment of the DMN in $A D$ could explain the relationship between metacognition and perspective-taking. Regarding possible clinical implications, we believe that improvements in patient's awareness through the use of a thirdperson perspective may decrease the negative impacts of anosognosia in AD. However, practitioners, psychologists, and other health professionals who are involved in patient's rehabilitation must be aware of the potential psychological and emotional consequences of increasing patients' awareness of their condition and impairments.

\section{Author Contributions}

EB collect the materials and resources needed for this review. EB wrote this paper, which is derived from EB's doctoral studies for which DCM and JLF are co-supervisors. DCM and JLF provided suggestions on the structure of the paper and revised each draft.

\section{Conflict of Interest Statement}

The authors declare that the research was conducted in the absence of any commercial or financial relationships that could be construed as a potential conflict of interest. 


\section{Acknowledgements}

The authors acknowledge financial support from the Capes Foundation, Ministry of Education of Brazil. 


\section{REFERENCES}

AGNEW, S. K.; MORRIS, R. G. The heterogeneity of anosognosia for memory impairment in Alzheimer's disease: A review of the literature and a proposed model. Aging \& Mental Health, v. 2, n. 1, p. 7-19, fev. 1998.

ALZHEIMER'S DISEASE INTERNATIONAL. World Alzheimer Report 2015 - The Global Impact of Dementia: An analysis of prevalence, incid ence, cost and trends. London, UK: [s.n.].

ANTOINE, C. et al. Awareness of deficits and anosognosia in Alzheimer's disease. L'Encephale, v. 30, n. 6, p. 570-577, dez. 2004.

ARLT, S. et al. Adherence to medication in patients with dementia: Predictors and strategies for improvementDrugs and Aging, 2008. Disponível em: <http://www.ncbi.nlm.nih.gov/pubmed/19021302>

BABINSKI, J. Contribution à l'étude des troubles mentaux dans I'hémiplégie organique cérébrale (anosognosie). Revue Neurologique, v. 27, p. 845-848, 1914.

BERTRAND, E.; LANDEIRA-FERNANDEZ, J.; MOGRABI, D. C. L'impact psychosocial de l'anosognosie dans la Démence de Type Alzheimer. Revista Ibero-american de Gerontologia, v. 2, p. 52-69, 2013.

BESHARATI, S. et al. Another perspective on anosognosia: Selfobservation in video replay improves motor awareness. Neuropsychological rehabilitation, v. 25, n. 3, p. 319-52, jan. 2015.

BOND, R. L. et al. Processing of Self versus Non-Self in Alzheimer's Disease. Frontiers in Human Neuroscience, v. 10, n. March, p. 97, 2016.

BRUGGER, P. Reflective mirrors: perspective-taking in autoscopic phenomena. Cognitive neuropsychiatry, v. 7, n. 3, p. 179-94, ago. 2002.

BUCKNER, R. L.; ANDREWS-HANNA, J. R.; SCHACTER, D. L. The Brain's Default Network: Anatomy, Function, and Relevance to Disease. Annals of the New York Academy of Sciences, v. 1124, n. 1, p. 1-38, 1 mar. 2008.

CLARE, L. et al. Awareness in dementia: A review of assessment methods and measures. Aging \& mental health, v. 9, n. 5, p. 394-413, set. 2005.

CLARE, L. et al. "She might have what I have got": the potential utility of vignettes as an indirect measure of awareness in early-stage dementia. Aging \& mental health, v. 16, n. 5, p. 566-75, jan. 2012a.

CLARE, L. et al. The influence of psychological, social and contextual factors on the expression and measurement of awareness in early-stage dementia: testing a biopsychosocial model. International journal of geriatric psychiatry, v. 27, n. 2, p. 167-77, fev. 2012b. 
COSENTINO, S.; STERN, Y. Metacognitive theory and assessment in dementia: do we recognize our areas of weakness? Journal of the International Neuropsychological Society: JINS, v. 11, n. 7, p. 910-9, nov. 2005.

DAVID, A. S.; CHIS STER, I.; ZAVAREI, H. Effect of video selfobservations vs. observations of others on insight in psychotic disorders. The Journal of nervous and mental disease, v. 200, n. 4, p. 358-61, maio 2012.

DAVIDOFF, S. A. et al. Effect of video self-observation on development of insight in psychotic disorders. The Journal of nervous and mental disease, v. 186, n. 11, p. 697-700, dez. 1998.

DUKE, L. M. et al. Cognitive components of deficit awareness in Alzheimer's disease. Neuropsychology, v. 16, n. 3, p. 359-69, jul. 2002.

FLAVELL, J. H. Metacognition and cognitive monitoring: A new area of cognitive-developmental inquiry. American Psychologist, v. 34, n. 10, p. 906-911, 1979.

FOTOPOULOU, A. et al. Self-observation reinstates motor awareness in anosognosia for hemiplegia. Neuropsychologia, v. 47, n. 5, p. $1256-$ 1260, abr. 2009.

GARRETT, M. et al. Lack of insight and conceptions of "mental illness" in schizophrenia, assessed in the third person through case vignettes. Psychosis, v. 3, n. 2, p. 115-125, 2 jun. 2011.

HANNESDOTTIR, K.; MORRIS, R. G. Primary and secondary anosognosia for memory impairment in patients with Alzheimer's disease. Cortex; a journal devoted to the study of the nervous system and behavior, v. 43, n. 7, p. 1020-1030, out. 2007.

HARWOOD, D. G.; SULTZER, D. L.; WHEATLEY, M. V. Impaired insight in Alzheimer disease: association with cognitive deficits, psychiatric symptoms, and behavioral disturbances. Neuropsychiatry, Neuropsychology, and Behavioral Neurology, v. 13, n. 2, p. 83-88, abr. 2000.

HORNING, S. M.; MELROSE, R.; SULTZER, D. Insight in Alzheimer's disease and its relation to psychiatric and behavioral disturbances. International Journal of Geriatric Psychiatry, v. 29, n. 1, p. 77-84, jan. 2014.

KASZNIAK, A. W.; ZAK, M. G. On the neuropsychology of metamemory: Contributions from the study of amnesia and dementia. Learning and Individual Differences, v. 8, n. 4, p. 355-381, jan. 1996.

KOTLER-COPE, S.; CAMP, C. J. Anosognosia in Alzheimer disease. Alzheimer disease and associated disorders, v. 9, n. 1, p. 52-56, 1995.

MCGLYNN, S. M.; KASZNIAK, A. W. When metacognition fails: impaired awareness of deficit in Alzheimer's disease. Journal of cognitive 
neuroscience, v. 3, n. 2, p. 183-7, 13 jan. 1991.

MEVEL, K. et al. The default mode network in healthy aging and Alzheimer's disease. International journal of Alzheimer's disease, $v$. 2011, p. 535816, 2011.

MOGRABI, D. C. et al. Unawareness of memory impairment in dementia: a population-based study. International Psychogeriatrics, v. 24, n. 6, p. 931-939, jun. 2012.

MOGRABI, D. C. et al. Metacognition and attribution of difficulty for self and others in Alzheimer's disease. Psychology \& Neuroscience, v. 7, n. 3, p. 417-424, 2014.

MOGRABI, D. C.; BROWN, R. G.; MORRIS, R. G. Anosognosia in Alzheimer's disease - The petrified selfConsciousness and Cognition, dez. 2009. Disponível em: <http://www.ncbi.nlm.nih.gov/pubmed/19683461>

MORRIS, R. G.; HANNESDOTTIR, K. Loss of "awareness" in Alzheimer's Disease. In: MORRIS, R. G.; BECKER, J. T. (Eds.). . The Cognitive Neuropsychology of Alzheimer's Disease. Oxford: Oxford University Press, 2004. p. 275-296.

MORRIS, R. G.; MOGRABI, D. C. Anosognosia, autobiographical memory and self knowledge in Alzheimer's disease. Cortex; a journal devoted to the study of the nervous system and behavior, v. 49, n. 6, p. 1553-65, jun. 2013.

NELSON, T. O.; NARENS, L. Metamemory: A Theoretical Framework and New Findings. Psychology of Learning and Motivation, v. 26, p. 125173, 1990.

ORFEI, M. D. et al. Anosognosia for hemiplegia after stroke is a multifaceted phenomenon: a systematic review of the literature. Brain : a journal of neurology, v. 130, n. Pt 12, p. 3075-90, 1 dez. 2007.

RAMACHANDRAN, V. S.; ROGERS-RAMACHANDRAN, D. Synaesthesia in Phantom Limbs Induced with Mirrors. Proceedings of the Royal Society B: Biological Sciences, v. 263, n. 1369, p. 377-386, 22 abr. 1996.

RIES, M. L. et al. Anosognosia in mild cognitive impairment: Relationship to activation of cortical midline structures involved in self-appraisal. Journal of the International Neuropsychological Society: JINS, v. 13, n. 3, p. 450-461, maio 2007.

ROSEN, H. J. Anosognosia in neurodegenerative disease. Neurocase, v. 17, n. 3, p. 231-241, 10 jun. 2011.

RUBY, P. et al. Perspective taking to assess self-personality: what's modified in Alzheimer's disease? Neurobiology of aging, v. 30, n. 10, p. 1637-51, out. 2009. 
RUBY, P.; DECETY, J. Effect of subjective perspective taking during simulation of action: a PET investigation of agency. Nature neuroscience, v. 4, n. 5, p. 546-50, maio 2001.

RUBY, P.; DECETY, J. What you believe versus what you think they believe: a neuroimaging study of conceptual perspective-taking. European Journal of Neuroscience, v. 17, n. 11, p. 2475-2480, 20 jun. 2003.

RUBY, P.; DECETY, J. How would you feel versus how do you think she would feel? A neuroimaging study of perspective-taking with social emotions. Journal of cognitive neuroscience, v. 16, n. 6, p. 988-99, jan. 2004.

RYSKIN, R. A. et al. Perspective-taking in comprehension, production, and memory: An individual differences approach. Journal of Experimental Psychology: General, v. 144, n. 5, p. 898-915, 2015.

SALMON, E. et al. A comparison of unawareness in frontotemporal dementia and Alzheimer's disease. Journal of neurology, neurosurgery, and psychiatry, v. 79, n. 2, p. 176-9, fev. 2008.

SOUCHAY, C. Metamemory in Alzheimer's disease. Cortex, v. 43, n. 7, p. 987-1003, jan. 2007.

SOUSA, M. F. B. et al. Awareness of disease is different for cognitive and functional aspects in mild Alzheimer's Disease: A one-year observation study. Journal of Alzheimer's Disease, v. 43, n. 3, p. 905-913, ago. 2015.

STARKSTEIN, S. E. et al. A diagnostic formulation for anosognosia in Alzheimer's disease. Journal of neurology, neurosurgery, and psychiatry, v. 77, n. 6, p. 719-725, jun. 2006.

STARKSTEIN, S. E. et al. Insight and danger in Alzheimer's disease. European Journal of Neurology, v. 14, n. 4, p. 455-460, 2007 a.

STARKSTEIN, S. E. et al. Insight and danger in Alzheimer's disease. European journal of neurology: the official journal of the European Federation of Neurological Societies, v. 14, n. 4, p. 455-60, abr. 2007b.

STUSS, D. T. Self, awareness and the frontal lobes: A neuropsychological perspective. In: STRAUSS, J.; GOETHALS, G. R. (Eds.). . The self: Interdisciplinary approaches. [s.I.] Springer New York, 1991. p. 255277.

STUSS, D. T. et al. The frontal lobes and self-awareness. In: FEINBERG, T. E.; KEENAN, J. P. (Eds.). . The Lost Self: Pathologies of the Brain and Identity. Oxford: Oxford University Press, 2005. p. 50-64.

VAN DEN STOCK, J. et al. A strange face in the mirror. Face-selective self-misidentification in a patient with right lateralized occipitotemporal hypo-metabolismCortex, 2012.

VAN DEN STOCK, J. et al. Face-Selective Hyper-Animacy and Hyper- 
Familiarity Misperception in a Patient With Moderate Alzheimer's Disease. The Journal of Neuropsychiatry and Clinical Neurosciences, v. 25, n. 4, p. E52-E53, jan. 2013.

VASTERLING, J. J. et al. Unawareness of deficit in Alzheimer's Disease: Domain-specific differences and disease correlates. Neuropsychiatry, Neuropsychology, and Behavioral Neurology, v. 8, n. 1, p. 26-32, 1995.

VIKRAM, S. et al. Video self-observation: a means of improving insight in psychosis. Psychiatric Bulletin, v. 32, n. 9, p. 341-344, 1 set. 2008.

WIMO, A.; JONSSON, L.; WINBLAD, B. An estimate of the worldwide prevalence and direct costs of dementia in 2003. Dementia and geriatric cognitive disorders, v. 21, n. 3, p. 175-81, jan. 2006. 


\section{ARTICLE 4}

Bertrand, E., Cosentino, S., Dourado, M. C. N., Laks, J., Landeira-Fernandez, J., Morris, R. G., \& Mograbi, D. C. Metacognition and perspective taking in Alzheimer's Disease. (In preparation) 


\section{ABSTRACT}

Impaired metacognition is common in dementia and has important clinical implications, such as diminished treatment adherence, impaired decision making capacities, increased caregiver burden. The distinction between self- and other-evaluation is an important feature of metacognition, with evidence from different clinical groups showing that metacognitive abilities can vary according to the perspective through which the information is presented. However, the few studies exploring the capacity of patients with Alzheimer's disease (AD) to evaluate another individual's performances showed mixed results. In this context, the aim of the present study was to explore further awareness for self- and other-performance in $A D$ patients. Twenty-two patients with mild to moderate $A D$ and twenty-two healthy older adults participated. Two experiments, the first with reaction time tasks and the second with memory tasks, were carried out, and in each experiment two parallel tasks were used, one in a success condition and one in a failure condition. Participants were asked to estimate their own performance, as well as the performance of another person, after performing the task. Awareness of performance was measured comparing participant estimations of performance with actual performance. For both types of task, the results indicate that, overall, participants overestimated the performance in the failure condition and underestimated the performance in the success condition. Also, they tended to overestimate more the performance of the other person compared to themselves. Additionally, for the memory tasks, the results suggest that in general the $A D$ patients tended to overestimate more the performances compared to the control subjects. This suggests that overall both $A D$ and healthy older adults present the same pattern when asked to evaluate self- and otherperformance, with a bias leading to attribution of better performance to the other person. However, for the memory tasks, the findings suggest that $A D$ patients overestimated more their performance than controls did, which is in line with previous studies highlighting a global metamemory deficit in AD. 
Key words: Alzheimer's disease, dementia, awareness, metacognition, perspective taking 


\section{Introduction}

Lack of awareness about cognitive deficits, referred to as anosognosia, is a common characteristic of dementia (MOGRABI et al., 2012a; MORRIS; HANNESDOTTIR, 2004), with an important impact on patients and their caregivers (BERTRAND; LANDEIRA-FERNANDEZ; MOGRABI, 2013). Studies have shown that unaware Alzheimer's disease (AD) patients have diminished treatment adherence (ARLT et al., 2008), engage more often in unsafe behaviors (STARKSTEIN et al., 2007) and present impaired decision making capacities (COSENTINO et al., 2011). Additionally, anosognosia has been related to increased caregiver burden and impaired caregiver's quality of life (CLARE et al., 2011; TURRÓ-GARRIGA et al., 2013).

This awareness of deficits relies on metacognitive abilities, which are defined as the knowledge and reflective capacities one has concerning one's own cognitive functioning (FLAVELL, 1979). Metacognition, which includes monitoring and control processes (NELSON; NARENS, 1990), has been shown to be compromised in AD patients (COSENTINO; STERN, 2005; ERNST et al., 2015). Indeed, when asked to predict their own performances, $A D$ patients tend to overestimate their abilities (COSENTINO et al., 2007; MOGRABI et al., 2012b). However, as pointed by Ernst et al. (ERNST et al., 2015), findings regarding metacognition in $A D$ may vary depending on the type of metacognitive tasks (feeling of knowing vs. judgment of learning) and measures (e.g. relative vs. absolute accuracy).

It has been shown in different clinical groups that awareness about ability can vary according to the perspective through which the information is presented. For example, in the context of anosognosia for hemiplegia, studies highlighted improvement in awareness into symptoms when patients were allowed to see themselves in a video (BESHARATI et al., 2015; FOTOPOULOU et al., 2009). Similar results have been observed in the context of psychosis (DAVID; CHIS STER; ZAVAREI, 2012; DAVIDOFF et al., 1998; VIKRAM et al., 2008). Additionally, findings 
suggest that unaware patients may be able to acknowledge deficits in others, something which has been observed in the case of anosognosia for hemiplegia (RAMACHANDRAN; ROGERS-RAMACHANDRAN, 1996) and psychosis (GARRETT et al., 2011)

Looking specifically at the few studies exploring the evaluation of self and other in dementia, results suggest that people with dementia (PwD) are more accurate when evaluating the performance of someone else (e.g., caregiver or fictional person) than they are for their own performance (BERTRAND; LANDEIRA-FERNANDEZ; MOGRABI, 2016). Nevertheless, different methods have been used to explore this issue. Duke, Seltzer, Seltzer, \& Vasterling (2002) asked AD patients and their spouses to estimate each other's performance and the performance of a fictional patient who suffered from moderate cognitive impairment. Before making the estimations, the participants were given normative data. The results showed that AD patients overestimated themselves, as well as the fictional patient, but made accurate estimations of their spouse's performance. To date, this is the only study that has compared the ability of AD patients to evaluate the performance of a well-known person (e.g., spouse) and an unknown person (e.g., fictional patient). However, one limitation of this study is the variation in terms of task performance between patients and spouses, which introduces biases in the results. Using a vignette technique, Clare et al. (2012) explored the ability of people with dementia to appreciate the deficits of a fictional person, who presented a typical case of advanced or early-stage dementia or a healthy aging. The results showed that the participants, even some who presented reduced levels of awareness, were able to correctly identify and offer appropriate advice for the problem that was described in the vignette. Finally, Mograbi, Brown, Landeira-Fernandez, and Morris (2014) investigated the attribution of difficulty for self and for others. Patients with AD were asked to judge how difficult a task was for them and would be for someone else their own age. The results showed that $A D$ patients predicted that others would find the task as difficult as they themselves did, despite their cognitive deficits. 
By using a computerized program which permits to maintain constant the level of performance and, therefore, to equate the difficulty levels between participants and groups, we intended to explore further awareness for selfand other-performance in $A D$ patients. For this purpose, $A D$ patients and healthy older adults were asked to estimate their own performances and the performances of their caregiver/friend on two different types of cognitive tasks (memory and reaction time). We hypothesized that people with $A D$ would appraise the performance of their caregivers differently than their own performance, which would not be the case for healthy older adults. Additionally, we anticipated that the type of task would affect the relationship between metacognition and self/other perspective, with a difference between self and other-evaluation only for the memory paradigm.

\section{Methodology}

\subsection{Participants}

All participants were aged 60 years or older. Twenty-four participants with mild to moderate $A D$ were included in the study, recruited from the Centre for Alzheimer's disease and Related Disorders (CDA) of the Institute of Psychiatry of the Federal University of Rio de Janeiro (IPUB-UFRJ), Brazil. The clinical diagnosis of $A D$ was made by a psychiatrist using clinical interviews with the patients and caregivers, cognitive screening tests, laboratory tests, and imaging. The participants were diagnosed with possible or probable $A D$ according to Diagnostic and Statistical Manual of Mental Disorders, Fourth Edition (DSM-IV-TR, (AMERICAN PSYCHIATRIC ASSOCIATION, 2000) and National Institute of Neurological and Communicative Diseases and Stroke/Alzheimer's Disease and Related Disorders Association (NINCDS-ADRDA; (MCKHANN et al., 2011) criteria. Patients with scores of 18 or above in the Mini-Mental State Examination (MMSE; (BERTOLUCCl et al., 1994) were included in the study. To provide comparison values, twenty-four control 
participants were recruited from a community centre and were screened for cognitive impairment using the MMSE.

Exclusion criteria in both groups were: current neurological disorder (other than $A D$ in the patient group, also excluding cases with mixed $A D$ and vascular dementia); history of head injury resulting in loss of consciousness for more than an hour; history of alcohol or substance abuse (based on ICD-10 criteria); history of diagnosed psychiatric disorder or current comorbidity (for example, mood disorder or psychosis), and drug treatment that could affect emotional reactions (e.g. beta-blockers). Although no patient had a diagnosis of mood disorder, upon screening two $A D$ patients and two control subjects showed depressive symptoms, with scores on the GDS-15 above the cut-off of 5 (MARC; RAUE; BRUCE, 2008). These four participants were excluded from the following analyses, which were conducted with 22 AD participants and 22 control subjects.

\subsection{Procedures}

Two success-failure manipulation (SFM) computerized paradigms, developed by Mograbi et al. (2012), were used, one based on reaction time tasks (Experiment 1) and the other on memory tasks (Experiment 2) (for a full description of the development of the tasks, see (MOGRABI et al., 2014b). Two parallel versions were developed for each type of task (see description below). The SFM paradigms are designed to set and maintain the difficulty level of the task at a constant level, by first establishing the ability of the participant and then adjusting automatically the difficulty of the trials based on this ability level or individual threshold according to the condition (success or failure). Participants were not informed that levels of difficulty would be manipulated. To make the procedure look more natural, each task was composed of four phases: practice (four instructional trials at low difficulty levels), titration (to establish a success/failure threshold for each participant by increasing the difficulty level until the participant failed), initial success (trials below the participants' threshold to acclimatize the participant to the task before the 
experimental manipulation), and experimental phase (the level of difficulty of most trials were below or above the individual's threshold depending on the condition). After the four trials of the practice phase, the trials composing the next phases continued without any indication of change to the participant. After performing each task, participants were asked to watch their caregiver, in the case of $A D$ patients, or a friend of the same age, in the case of controls, performing the same task. The order of experiments and conditions was quasi-counterbalanced among the participants, according to the following factors: Experiment 1 or Experiment 2 first; success or failure condition first in each experiment; and version allocated for success or failure, in each experiment. More details about the procedure and the experiments can be found in Mograbi et al. (2012).

\subsubsection{Experiments}

\subsubsection{Experiment 1-Reaction time}

In version 1, a 'car' appeared on the left side of the screen moving to the right, with the participants having to 'stop' the car as soon as it appeared by pressing the spacebar of the keyboard. In version 2, objects (e.g. ball, egg or vase) appeared to fall from the 'top' of the screen and participants had to 'catch' the object by pressing the spacebar. In both versions participants received feedback after each trial. Difficulty was manipulated by varying the object's speed.

\subsubsection{Experiment 2-Memory}

The two versions of the experiment were based around memory span tasks. For version 1, a set of ten identical objects (e.g. teapot, bucket) were shown on a computer screen and these were highlighted individually in a random sequence using a red square surround. Immediately after, participants had to point to the same objects in the sequence they were highlighted. For version 2, a sequence of digits ranging from 0 to 9 was 
presented both auditorily and visually to the participants, who immediately repeated it back sequentially to the experimenter. In both versions, participants received feedback after each trial. Difficulty was manipulated by varying the length of the sequence from one to ten objects/digits.

\subsection{Measures}

\subsubsection{Awareness of performance}

An Objective-Judgement Discrepancy (OJD; (AGNEW; MORRIS, 1998) method was used in which immediately after the success or failure conditions, participants were asked to rate how well they did, with ratings compared to actual performance. Because there was no apparent discontinuity to participants between titration and experimental phases in each task, performance was considered over the whole task (excluding the practice trials). Ratings were done using a $0 \%$ to $100 \%$ scale, with $0 \%$ meaning all trials were wrong and $100 \%$ all trials correct. The OJD score was obtained subtracting actual performance (expressed in terms of \% correct) from estimation of performance, with positive scores indicating overestimation of performance. Similarly, after their caregiver/friend performed the task, participants were also asked to rate how well this person did, and using the same formula an OJD score for other-evaluation was calculated.

\subsection{Ethical issues}

All participants provided informed consent, with caregivers also giving their agreement for the patient to take part. The project was approved by the Federal University of Rio de Janeiro (UFRJ)/ Institute of Psychiatry Ethics Committee (Research Ethics Committee number 536.634). 


\subsection{Statistical analysis}

The analyses were performed separately for each experiment (Experiment 1 - Reaction time tasks; Experiment 2 - Memory tasks). In order to confirm that the experimental manipulation of difficulty worked, a two-way mixed design ANOVA was conducted with performance in the tasks as the dependent variable, with condition (success / failure) as a within-subject factors and group ( $\mathrm{AD} / \mathrm{control})$ as a between-subjects factor. Differences in awareness of symptoms were explored using the OJD measures as dependent variables in three-way mixed ANOVAs, with perspective (self / other) and condition (success / failure) as within-subject factors and group (AD / control) as the between-subject factor. Planned pairwise comparisons followed the ANOVAs.

\section{Results}

There were no significant differences between the groups in age, years of education, gender ratio and level of depression (see table 1). MMSE scores were significantly lower for the AD patients.

Table 1 - Sample characteristics

\begin{tabular}{lccc}
\hline Variable & $\begin{array}{c}\text { AD group }(\mathrm{n}=22) \\
\text { Mean }(\mathrm{SD})\end{array}$ & $\begin{array}{c}\text { Control group }(\mathrm{n}=22) \\
\text { Mean }(\mathrm{SD})\end{array}$ & p-values \\
\hline Age & $78.1(5.6)$ & $75.2(6.3)$ & .118 \\
Gender* & $17 / 5$ & $18 / 4$ & .709 \\
Years of & $8.1(4.2)$ & $10.2(5.3)$ & .143 \\
education & & & $<.001$ \\
MMSE & $21.5(3.1)$ & $26.7(2.1)$ & .072 \\
GDS-15 & $2.5(1.2)$ & $1.73(1.4)$ & \\
\hline
\end{tabular}

${ }^{*}$ \# female/ male 


\subsection{Experiment 1 (Reaction Time)}

Table 2 shows that the two groups were matched on their performance in both conditions as expected from the individual manipulation of task difficulty. The ANOVA showed no interaction between group and condition $\left(F(1,42)=2.59, p=.115, \eta_{p}^{2}=.06\right)$, or significant main effect of group $(F$ $\left.(1,42)=.01, p=.906, \eta_{p}^{2}=.00\right)$. As expected, there was a main effect of condition $\left(F(1,42)=662.64, p<.001, \eta_{p}^{2}=.94\right)$ with predicted worse performance in the failure condition.

For the OJD self vs other (Table 2 and Figure 1), there was a significant main effect of condition $\left(F(1,42)=131.42, p<.001, \eta_{p}^{2}=.76\right)$. These results suggest that overall participants tended to overestimate performance in the failure condition and to underestimate it in the success condition. There was also a significant main effect of perspective $(F(1,42)$ $=5.71, p=.021, \eta_{p}^{2}=.12$ ), indicating that overall the participants tended to overestimate more the performance of a known person compared to the estimation they made of their own performance. There were no significant interactions or main effect of group $\left(F(1,42)=2.60, p=.114, \eta_{p}^{2}=.06\right)$. 
Table 2 - Performance and awareness of performance (OJD) during Experiment 1 (reaction time) for success and failure conditions in the both groups

\begin{tabular}{|c|c|c|c|c|}
\hline & \multicolumn{2}{|c|}{$A D$} & \multicolumn{2}{|c|}{ Controls } \\
\hline Variable & Self & Other & Self & Other \\
\hline & Mean (SD) & Mean (SD) & Mean (SD) & Mean (SD) \\
\hline \multicolumn{5}{|l|}{$\frac{\text { Success }}{\text { condition }}$} \\
\hline Estimation (\%) & $69.1(14.1)$ & $82.4(9.7)$ & $78.2(13.7)$ & $81.5(11.6)$ \\
\hline $\begin{array}{l}\text { Performance } \\
(\%)\end{array}$ & $78.8(10.6)$ & $83.3(5.2)$ & $82.1(6.0)$ & $82.3(6.1)$ \\
\hline OJD (\%) & $-9.8(18.0)$ & $-0.9(9.8)$ & $-3.9(12.9)$ & $-0.9(12.4)$ \\
\hline \multicolumn{5}{|l|}{$\begin{array}{l}\text { Failure } \\
\text { condition }\end{array}$} \\
\hline Estimation (\%) & $52.7(17.0)$ & $47.8(12.7)$ & $52.2(24.3)$ & $61.4(19.8)$ \\
\hline $\begin{array}{l}\text { Performance } \\
(\%)\end{array}$ & $35.7(16.1)$ & $31.3(12.5)$ & $33.1(10.8)$ & 33.6 (11.5) \\
\hline OJD (\%) & $17.1(15.4)$ & $16.5(8.7)$ & $19.0(20.6)$ & $27.7(20.5)$ \\
\hline
\end{tabular}

Figure 1 - Bar graph of the mean with standard deviation of the OJD per condition during Experiment 1 (reaction time).

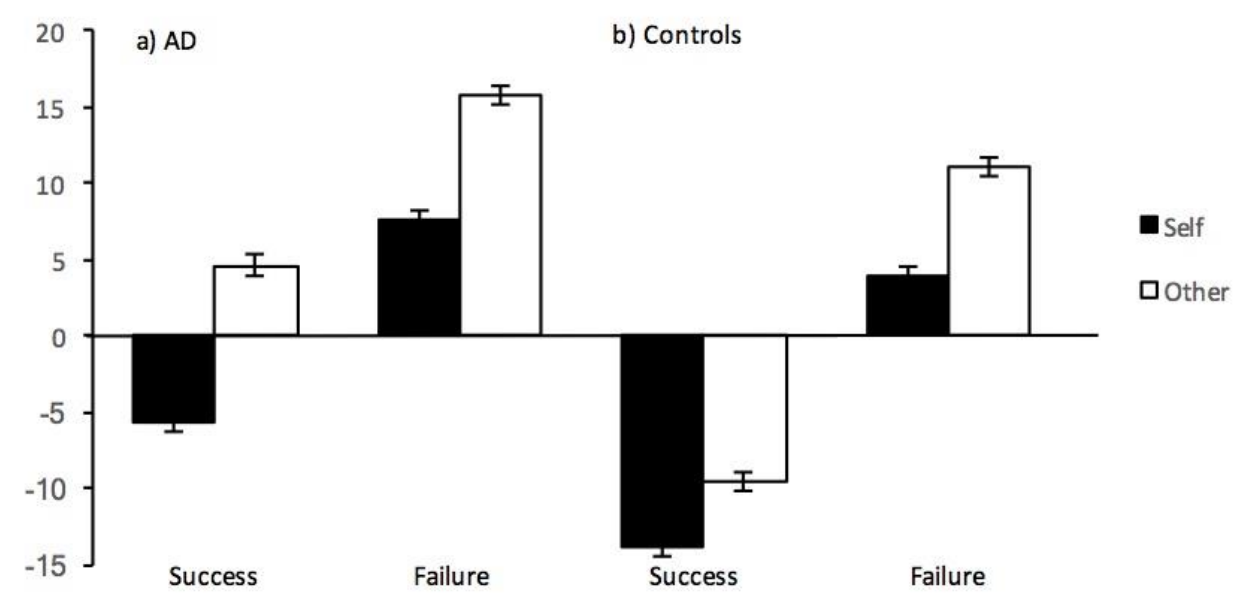




\subsection{Experiment 2 (Memory)}

Table 3 shows that the two groups were matched on their performance in both condition as expected from the individual manipulation of task difficulty. The ANOVA showed no interaction between group and condition $\left(\mathrm{F}(1,42)=1.16, \mathrm{p}=.287, \mathrm{n}_{\mathrm{p}}{ }^{2}=.03\right)$, or significant main effect of group ( $\mathrm{F}$ $\left.(1,42)=.63, p=.432, \eta_{p}^{2}=.02\right)$. As expected, there was a main effect of condition $\left(F(1,42)=547.56, p<.001, \eta_{p}^{2}=.93\right)$ with predicted worse performance in the failure condition.

For the OJD self vs other (Table 3 and Figure 2), there was a main effect of condition $\left(F(1,42)=41.14, p<.001, \eta_{p}^{2}=.50\right)$, a main effect of perspective $\left(F(1,42)=9.66, p=.003, \eta_{p}^{2}=.19\right)$ and a main effect of group $\left(F(1,42)=6.17, p=.017, n_{p}^{2}=.13\right)$. No significant interaction effects were found. These results suggest that overall the participants overestimated performance in the failure condition and underestimated it in the success condition. Also, they tended to overestimate more the performance of a known person compared to the estimation they made of their own performance. Additionally, these results indicate that overall the $A D$ patients tended to overestimate performance more than the control subjects. 
Table 3 - Performance and awareness of performance (OJD) during Experiment 2 (memory) for success and failure conditions in the both groups

\begin{tabular}{|c|c|c|c|c|}
\hline \multirow[b]{2}{*}{ Variable } & \multicolumn{2}{|c|}{$A D$} & \multicolumn{2}{|c|}{ Controls } \\
\hline & Self & Other & Self & Other \\
\hline & Mean (SD) & Mean (SD) & Mean (SD) & Mean (SD) \\
\hline \multicolumn{5}{|l|}{$\begin{array}{l}\text { Success } \\
\text { condition }\end{array}$} \\
\hline Estimation (\%) & $70.0(14.1)$ & $82.8(13.0)$ & $65.1(17.2)$ & $69.3(18.0)$ \\
\hline $\begin{array}{l}\text { Performance } \\
(\%)\end{array}$ & $75.7(8.7)$ & $78.2(7.4)$ & $79.0(6.9)$ & $78.8(6.8)$ \\
\hline OJD (\%) & $-5.7(16.5)$ & $4.6(14.2)$ & $-13.9(17.7)$ & $-9.5(16.9)$ \\
\hline \multicolumn{5}{|l|}{$\begin{array}{l}\text { Failure } \\
\text { condition }\end{array}$} \\
\hline Estimation (\%) & $42.5(12.7)$ & $54.1(14.1)$ & $38.1(24.3)$ & $45.6(21.5)$ \\
\hline $\begin{array}{l}\text { Performance } \\
(\%)\end{array}$ & $35.0(9.1)$ & $38.4(5.0)$ & $34.4(8.1)$ & $34.7(8.5)$ \\
\hline OJD (\%) & $7.5(13.8)$ & $15.7(13.8)$ & $3.8(23.4)$ & $11.0(21.4)$ \\
\hline
\end{tabular}

Figure 2 - Bar graph of the mean with standard deviation of the OJD per condition during Experiment 2 (memory). a) AD, b) Controls

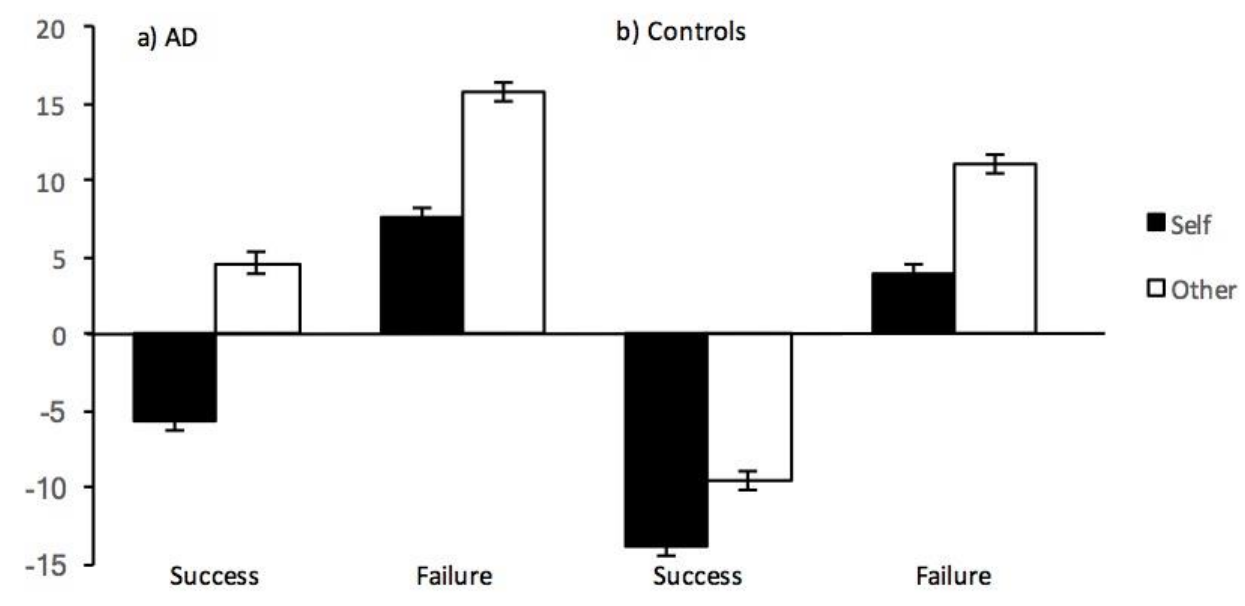




\section{Discussion}

To the best of our knowledge, the present work, which aimed to explore the relationship between metacognitive monitoring processes and the perspective through which the information is presented, is the first study to explore experimentally this relationship in patients with $A D$. To do so, $A D$ patients and healthy older adults were asked to evaluate their own performance and the performance of a well-known person (caregiver/friend) after performing different types of tasks (e.g. reaction time and memory). The results show that overall and in both types of task, the participants ( $A D$ and controls) tended to overestimate performance in the failure condition and to underestimate it in the success condition. Additionally, our findings indicate that in general both groups made a higher overestimation when evaluating a known-person compared to when they evaluated themselves. Finally, the results suggest that there is an overall difference between the $A D$ group and the control group in the memory tasks, highlighting that $A D$ patients overestimated more performances compared to healthy older adults during Experiment 2 only.

One question addressed by the present work was whether $A D$ patients and healthy controls were making evaluation of performance (self and other) in the same fashion. Our findings highlighted that, for the memory tasks, AD patients overestimated performances more than the control group. This is in line with studies showing that $A D$ patients present metamemory difficulties, with a tendency to be overconfident and make overestimation of performances (for a review see (ERNST et al., 2015). These results also highlight that the type of task has an impact on metacognitive abilities. Indeed, this main effect of group was significant only in the memory experiment. This supports the idea of awareness as a multidimensional concept, which can vary according to the object of awareness (CLARE et al., 2011; STARKSTEIN, 2014). Indeed, various studies showed domain-specific anosognosia, with awareness for memory deficits being the most frequently impaired compared to awareness for other cognitive domains, such as attention, and for psychiatric and 
behavioral symptoms (GREEN et al., 1993; KOTLER-COPE; CAMP, 1995; VASTERLING et al., 1995a).

Another question addressed in this study was whether the participants appraise the performance of a known-person differently than their own performance when groups perform at the same level. The results demonstrated that, in both types of task, participants consistently suggest that the known-person performed better than themselves. These findings are in agreement with previous studies suggesting that people with dementia are considering their own performance and another person's performance in a different fashion (CLARE et al., 2012b; DUKE et al., 2002). Additionally, in our study, we showed that this difference between self- and other-evaluation is similar in both groups. Recent neuroimaging evidence supports the idea of distinct processes for self- vs. otherevaluation, suggesting that self- and other-information processing have different neural bases. Studies showed that the frontopolar, somatosensory, and inferior parietal cortices are implicated in the process of self vs. other distinction (RUBY; DECETY, 2001, 2003, 2004). The notion of a distinction between self vs. other processing has also been included in the reformulated version of the Cognitive Awareness Model (CAM) (AGNEW; MORRIS, 1998; MORRIS; HANNESDOTTIR, 2004; MORRIS; MOGRABI, 2013). In fact, the authors proposed different memory records for self- and other-information. Self-evaluation would rely on personal semantics, which is acquired through personal, social, and cultural experiences, and represented in the Personal Database and an Autobiographical Conceptual Memory System. These memory systems are distinct from a Generic Memory System, which stores other material that permits evaluations of others and is based on general semantic knowledge.

Finally, this study also looked at the possible impact of the condition in which the task was performed (success vs. failure). Results indicate that, for both experiments, $A D$ and control groups tended to overestimate their own performance and the ones of a known-person in the failure condition and to underestimate them in success condition. These findings can be 
explained by the midpoint anchoring effect. Indeed, previous studies showed that in young and old healthy populations, there is a bias leading to answer at the midpoint of the scale when participants present a lack of discrimination in a task of performance judgments (CONNOR; DUNLOSKY; HERTZOG, 1997; MOGRABI et al., 2012b; MOULIN, 2002). In the current study, underestimation of success and overestimation of failure in both groups may be partially due to a tendency to use the midpoint of the scale.

One potential limitation of the current study must be considered. The fact that participants were asked to evaluate a well-known person (caregiver or friend) may limit the interpretation of the results. Indeed, Duke et al. (2002) suggested the possible influence of the common history with the individual for whom the estimates are being made. Further investigations of the difference between self- vs other-evaluation in $A D$ are needed with other methodology (for example, evaluation of known vs. unknown individual).

In summary, the present study underlines the multidimensional aspect of awareness, with results pointing to a difference between self- and otherevaluation and to the influence of the object in awareness. In terms of clinical implications, these findings should be taken this into account when assessing anosognosia in the clinic. Indeed, the present results indicating a different pattern for metacognition in a memory task vs in a reaction time task, suggest that awareness affects differentially distinct cognitive domains. This highlights the importance of a more extensive evaluation of the patients' capacity to appreciate the presence of deficits and symptoms regarding different domains.

\section{Acknowledgments}

Elodie Bertrand receives financial support from the Capes Foundation, Ministry of Education of Brazil. The authors declare that there are no conflicts of interest. Daniel Mograbi is a Jovem Cientista do Nosso Estado, and Jerson Laks and Jesus Landeira-Fernandez are Cientista do Nosso 
Estado, Fundação de Apoio à Pesquisa do Estado do Rio de Janeiro (FAPERJ). Jerson Laks also receives grants from the Brazilian National Council of Research (CNPq research fellowship awards - level II). 


\section{REFERENCES}

AGNEW, S. K.; MORRIS, R. G. The heterogeneity of anosognosia for memory impairment in Alzheimer's disease: A review of the literature and a proposed model. Aging \& Mental Health, v. 2, n. 1, p. 7-19, 1998.

AMERICAN PSYCHIATRIC ASSOCIATION. Diagnostic and Statistical Manual of Mental Disorders: DSM-IV-TR. [s.I.] American Psychiatric Association, 2000.

ARLT, S. et al. Adherence to medication in patients with dementia: Predictors and strategies for improvement. Drugs and Aging, v. 25, n. 12, p. 1033-1047, 2008.

BERTOLUCCI, P. H. et al. [The Mini-Mental State Examination in a general population: impact of educational status]. Arquivos de neuropsiquiatria, v. 52, n. 1, p. 1-7, 1994.

BERTRAND, E.; LANDEIRA-FERNANDEZ, J.; MOGRABI, D. C. L'impact psychosocial de l'anosognosie dans la Démence de Type Alzheimer. Revista Ibero-american de Gerontologia, v. 2, p. 52-69, 2013.

BERTRAND, E.; LANDEIRA-FERNANDEZ, J.; MOGRABI, D. C. Metacognition and perspective-taking in Alzheimer's disease: a minireview. Metacognition and Perspective-Taking in Alzheimer's Disease: a mini-review. Frontiers in Psychology, v. 7, n. November, p. 1-7, 2016.

BESHARATI, S. et al. Another perspective on anosognosia: Selfobservation in video replay improves motor awareness. Neuropsychological rehabilitation, v. 25, n. 3, p. 319-52, 2015.

CLARE, L. et al. Multidimensional assessment of awareness in early-stage dementia: A cluster analytic approach. Dementia and Geriatric Cognitive Disorders, v. 31, n. 5, p. 317-327, 2011.

CLARE, L. et al. "She might have what I have got": the potential utility of vignettes as an indirect measure of awareness in early-stage dementia. Aging \& mental health, v. 16, n. 5, p. 566-75, 2012.

CONNOR, L. T.; DUNLOSKY, J.; HERTZOG, C. Age-related differences in absolute but not relative metamemory accuracy. Psychology and aging, v. 12, n. 1, p. 50-71, 1997.

COSENTINO, S. et al. Objective metamemory testing captures awareness of deficit in Alzheimer's disease. Cortex, v. 43, n. 7, p. 1004-1019, 2007.

COSENTINO, S. et al. Memory Awareness Influences Everyday Decision Making Capacity about Medication Management in Alzheimer's Disease. International journal of Alzheimer's disease, v. 2011, p. 483897, 2011.

COSENTINO, S.; STERN, Y. Metacognitive theory and assessment in dementia: do we recognize our areas of weakness? Journal of the International Neuropsychological Society: JINS, v. 11, n. 7, p. 910-9, 
2005.

DAVID, A. S.; CHIS STER, I.; ZAVAREI, H. Effect of video selfobservations vs. observations of others on insight in psychotic disorders. The Journal of nervous and mental disease, v. 200, n. 4, p. 358-61, 2012.

DAVIDOFF, S. A. et al. Effect of video self-observation on development of insight in psychotic disorders. The Journal of nervous and mental disease, v. 186, n. 11, p. 697-700, 1998.

DUKE, L. M. et al. Cognitive components of deficit awareness in Alzheimer's disease. Neuropsychology, v. 16, n. 3, p. 359-69, 2002.

ERNST, A. et al. Anosognosia and Metacognition in Alzheimer's Disease. In: DUNLOSKY, J.; TAUBER, S. U. K. (Eds.). . The Oxford Handbook of Metamemory. New York, NY: Oxford University Press, 2015.

FLAVELL, J. H. Metacognition and cognitive monitoring: A new area of cognitive-developmental inquiry. American Psychologist, v. 34, n. 10, p. 906-911, 1979.

FOTOPOULOU, A. et al. Self-observation reinstates motor awareness in anosognosia for hemiplegia. Neuropsychologia, v. 47, n. 5, p. $1256-$ 1260, 2009.

GARRETT, M. et al. Lack of insight and conceptions of "mental illness" in schizophrenia, assessed in the third person through case vignettes. Psychosis, v. 3, n. 2, p. 115-125, 2011.

GREEN, J. et al. Variable Awareness of Deficits in Alzheimer's Disease.: Cognitive and Behavioral Neurology. Neuropsychiatry, Neuropsychology, \& Behavioral Neurology, v. 6, n. 3, p. $159-165$, 1993.

KOTLER-COPE, S.; CAMP, C. J. Anosognosia in Alzheimer disease. Alzheimer disease and associated disorders, v. 9, n. 1, p. 52-56, 1995.

MARC, L. G.; RAUE, P. J.; BRUCE, M. L. Screening performance of the 15-item geriatric depression scale in a diverse elderly home care population. The American journal of geriatric psychiatry, v. 16, n. 11, p. 914-21, 2008.

MCKHANN, G. M. et al. The diagnosis of dementia due to Alzheimer's disease: recommendations from the National Institute on AgingAlzheimer's Association workgroups on diagnostic guidelines for Alzheimer's disease. Alzheimer's \& dementia: the journal of the Alzheimer's Association, v. 7, n. 3, p. 263-9, 2011.

MOGRABI, D. C. et al. Unawareness of memory impairment in dementia: a population-based study. International Psychogeriatrics, v. 24, n. 6, p. 931-939, 2012a.

MOGRABI, D. C. et al. Emotional reactivity and awareness of task 
performance in Alzheimer's disease. Neuropsychologia, v. 50, n. 8, p. 2075-84, 2012b.

MOGRABI, D. C. et al. Metacognition and attribution of difficulty for self and others in Alzheimer's disease. Psychology \& Neuroscience, v. 7, n. 3, p. 417-424, 2014a.

MOGRABI, D. C. et al. The development of computerised success-failure manipulation paradigms for the experimental study of metacognition in neurological patients. Temas em Psicologia, v. 22, n. 3, p. 579-588, 2014b.

MORRIS, R. G.; HANNESDOTTIR, K. Loss of "awareness" in Alzheimer's Disease. In: MORRIS, R. G.; BECKER, J. T. (Eds.). . The Cognitive Neuropsychology of Alzheimer's Disease. Oxford: Oxford University Press, 2004. p. 275-296.

MORRIS, R. G.; MOGRABI, D. C. Anosognosia, autobiographical memory and self knowledge in Alzheimer's disease. Cortex; a journal devoted to the study of the nervous system and behavior, v. 49, n. 6, p. 1553-65, 2013.

MOULIN, C. Sense and sensitivity: metacognition in Alzheimer's disease. In: PERFECT, T. J.; SCHWARTZ, B. L. (Eds.). . Applied Metacognition. New York, NY: Cambridge University Press, 2002. p. 197-223.

NELSON, T. O.; NARENS, L. Metamemory: A Theoretical Framework and New Findings. Psychology of Learning and Motivation, v. 26, p. 125173, 1990.

RAMACHANDRAN, V. S.; ROGERS-RAMACHANDRAN, D. Synaesthesia in Phantom Limbs Induced with Mirrors. Proceedings of the Royal Society B: Biological Sciences, v. 263, n. 1369, p. 377-386, 1996.

RUBY, P.; DECETY, J. Effect of subjective perspective taking during simulation of action: a PET investigation of agency. Nature neuroscience, v. 4, n. 5, p. 546-50, 2001.

RUBY, P.; DECETY, J. What you believe versus what you think they believe: a neuroimaging study of conceptual perspective-taking. European Journal of Neuroscience, v. 17, n. 11, p. 2475-2480, 2003.

RUBY, P.; DECETY, J. How would you feel versus how do you think she would feel? A neuroimaging study of perspective-taking with social emotions. Journal of cognitive neuroscience, v. 16, n. 6, p. 988-99, 2004.

STARKSTEIN, S. E. et al. Insight and danger in Alzheimer's disease. European journal of neurology, v. 14, n. 4, p. 455-60, 2007.

STARKSTEIN, S. E. Anosognosia in Alzheimer's disease: Diagnosis, frequency, mechanism and clinical correlates. Cortex, Special Issue: Understanding Babinski's anosognosia: 100 years later. v. 61, p. 64-73, 2014. 
TURRÓ-GARRIGA, O. et al. Burden associated with the presence of anosognosia in Alzheimer's disease. International Journal of Geriatric Psychiatry, v. 28, n. 3, p. 291-297, 2013.

VASTERLING, J. J. et al. Unawareness of deficit in Alzheimer's Disease: Domain-specific differences and disease correlates. Neuropsychiatry, Neuropsychology, and Behavioral Neurology, v. 8, n. 1, p. 26-32, 1995.

VIKRAM, S. et al. Video self-observation: a means of improving insight in psychosis. Psychiatric Bulletin, v. 32, n. 9, p. 341-344, 2008. 


\section{General discussion}

The general objective of the present thesis was to explore different aspects of metacognition, namely the impact of current mood state and the influence of the perspective through which the information is presented, in mild to moderate Alzheimer's disease. In this context, our investigation aimed to contribute to a better understanding of metacognitive abilities and, consequently, of anosognosia in AD patients with direct relevance for clinical practice.

Thus, the first section of this work tackles the influence of the current mood state on awareness of deficits in $A D$ patients. While numerous studies pointed to a relationship between emotional factors and anosognosia (AALTEN et al., 2006; CLARE et al., 2012c; MOGRABI; MORRIS, 2014), the present work is the first to our knowledge to explore experimentally this relationship in AD. Our work showed that, when in a negative mood induced by a memory-based task in the failure condition, AD patients presented an increased apparent awareness of their deficits. We suggest that these findings could be explained by the MDM and MCM phenomena. Indeed, to be able to report deficits regarding one's own abilities, the person needs to have access to memories representing events during which he experienced difficulties. Based on the MDM and MCM theories, the access to this type of memories is facilitated when the individual is in the same emotional state at the moment of the retrieval as he was during the events and/or when the current mood state is congruent with the emotional valence of the event he is trying to retrieve. Moreover, as the results of the current work did not highlight the increase of awareness after the negative mood was induced using a reaction timebased task, an additional explanation can be found in the CDM effect, which suggest that the recall of a specific material is facilitated when the context at the moment of retrieval is similar with the context during encoding. To conclude, these findings reinforce previous evidence indicating a relationship between mood state and awareness in AD. This 
relationship between anosognosia and mood is well established, with higher awareness of deficits being related to higher level of depression (MOGRABI; MORRIS, 2014; STARKSTEIN, 2014). However, the direction of causality of this relationship is still unclear in the literature. Two hypotheses were suggested. On one hand, increased awareness of difficulties might lead to higher depression, through a reactive depression process. On the other hand, depressed patients may show "depressive realism" or present apparently more awareness because of a negative bias when reporting problems. The only longitudinal study investigating the direction of causality between depressive symptoms and anosognosia failed to find a significant effect for the baseline level of anosognosia and depressive symptoms at follow-up (VAN VLIET et al., 2013). In this context, a major finding of our work is that our results give support to the direction of this relation by supporting the hypothesis which suggests that negative mood state leads to report more deficits.

In addition to this first part, the second section of this thesis was dedicated to the exploration of another potential factor influencing metacognitive judgments, namely the perspective through which the information is presented (e.g. self vs. other-perspective). Indeed, as highlighted by Bertrand et al. (BERTRAND; LANDEIRA-FERNANDEZ; MOGRABI, 2016), studies exploring the impact of perspective taking on metacognition with different neurologic and psychiatric populations showed that patients are able to recognize deficits in others, despite lack of awareness of their own difficulties. Our findings highlight that overall both groups (AD and controls) made higher overestimation when evaluating the performance of a well-known person. However, AD patients tended to overestimate more the performance compared to controls but only in the memory experiment. These results suggest that for both $A D$ and control groups the appraisal of performance depends on the perspective. Moreover, the difference between $A D$ patients and controls only for the memory tasks points to a multifaceted concept of awareness, as suggested by previous studies (GREEN et al., 1993; KOTLER-COPE; CAMP, 1995; VASTERLING et al., 1995b). 
Overall, the present work contributes to provide new evidence supporting the CAM model (AGNEW; MORRIS, 1998; MORRIS; HANNESDOTTIR, 2004; MORRIS; MOGRABI, 2013). First, the findings on the relationship between mood and awareness highlight that $A D$ patients in a negative mood state induced by a memory-based task present a higher level of awareness of their deficits. This result could be explained by the mood-congruent, mooddependent and context-dependent phenomenon. The idea of emotional biases in memory as a partial explanation for anosognosia has already been suggested by the authors of the CAM (MOGRABI; MORRIS, 2014; MORRIS; MOGRABI, 2013). Indeed, their hypothesis was that the patient's current mood state introduces a bias in the access to memories stored in the personal data base, leading to an impaired sense of self, and consequently, leading to anosognosia. Our work provides experimental evidence to support this hypothesis. Second, the thesis also shows that $A D$ patients appraise the evaluation of self-performance differently than the evaluation of a well-known person's performance, by overestimating more the performance of the other person. By proposing different memory records for self- and other-information (respectively, the Personal Database and the Generic Memory System) in the reformulated version of the CAM, the authors introduced the notion of a distinction between self vs. other processing in anosognosia (AGNEW; MORRIS, 1998; MORRIS; HANNESDOTTIR, 2004; MORRIS; MOGRABI, 2013), and our experimental results support this idea.

Additionally, by presenting differences in results depending on the type of task used in the SFM (reaction time vs. memory) in both sections of this present work, our findings reinforce the multidimensionality of awareness, especially the hypothesis of domain-specific anosognosia. Indeed, various studies showed that awareness can vary according to its object (CLARE et al., 2011; STARKSTEIN, 2014). Furthermore, there is a growing body of evidence highlighting domain-specific anosognosia, with awareness for memory deficits being the most frequently impaired compared to awareness for other cognitive domains, such as attention, and for psychiatric and behavioral symptoms (GREEN et al., 1993; KOTLER- 
COPE; CAMP, 1995; VASTERLING et al., 1995a). This concept of domain-specific anosognosia has been included in the revised CAM, which is essentially modular. In fact, the CAM is composed of domainspecific modules, which are capable of processing information specific to modality of behavior (e.g. language, visual or motor) (MORRIS; MOGRABI, 2013).

The present work might have some important clinical implications. For example, the present evidence supporting domain-specific anosognosia should be taken into account when assessing awareness in clinical setting. Indeed, extensive evaluation of AD patients' awareness of deficits regarding distinct cognitive and behavioral domains should be recommended. Moreover, our findings also highlight that, despite a lack of explicit awareness, the mood state of people with $A D$ is affected by the exposure to failure. Consequently, in everyday life as well as during neuropsychological assessment, clinicians and caregivers should give special attention to the patient's mood state. With the aim of promoting a better quality of life, limiting the patient's exposure to failure might help to avoid depressive symptoms in AD patients, whilst making them less aware of their deficits.

Some general limitations of the present work should be acknowledged. A first one refers to the generalizability of our findings. Indeed, the current sample was composed of patients with mild to moderate $A D$, which can reduce the applicability of the findings to the case of more severe $A D$ patients. Moreover, it was required that all patients in the sample had a level of education at least equal to an alphabetization level. This characteristic of the current sample can limit the generalizability of the results to the illiterate elderly population. However, these were necessary measures, since the use of the computerized tasks in both experimental studies required it. Another factor that may have influenced the results is the willingness of the participants to explicitly discuss their level of functioning, through the endorsement of deficits on the AQ-D in Article 2 or through the objective evaluation of their own performance in Article 4. This is a general problem of most research exploring awareness and we tried to 
address this issue during the experimental phase of this project by trying to gain the participants' trust and assuring them the confidentiality of the responses.

By way of conclusion, we would like to present some future directions. First, research using different methodologies would be useful to understand better the multidimensionality of anosognosia in AD. For example, as suggested by Duke and colleagues (2002), the way the $A D$ patient is evaluating the performance of another person might be influenced by the relationship the patient has with that person. It would be interesting to replicate our experiment including the evaluation of an unknown person. Studies using a longitudinal design would also offer some interesting insights on the relationship between anosognosia and different factors, such as mood state. Longitudinal design studies may also help understanding the direction of causality of the relationship between mood and awareness of deficits in AD. Also, our findings would benefit from neuroimaging studies exploring the neural mechanisms underlying the processes of metacognition, especially the distinction between selfand other-evaluation. Indeed, previous studies already showed that selfand other-information processing rely on distinct neural network (RUBY; DECETY, 2001, 2003, 2004). 


\section{References}

AALTEN, P. et al. Awareness and behavioral problems in dementia patients: a prospective study. International psychogeriatrics / IPA, v. 18, n. 1, p. 3-17, mar. 2006.

AGNEW, S. K.; MORRIS, R. G. The heterogeneity of anosognosia for memory impairment in Alzheimer's disease: A review of the literature and a proposed model. Aging \& Mental Health, v. 2, n. 1, p. 7-19, 1998.

ALEXANDER, L.; GUENTHER, R. K. The effect of mood and demand on memory. British Journal of Psychology, v. 77, n. 3, p. 343-350, 1986.

ALMEIDA, O. P.; ALMEIDA, S. A. Confiabilidade da versão brasileira da Escala de Depressão em Geriatria (GDS) versão reduzida. Arquivos de Neuro-Psiquiatria, v. 57, n. 2B, p. 421-426, 1999.

ALMEIDA, O. P.; CROCCO, E. I. Percepção dos déficits cognitivos e alterações do comportamento em pacientes com doença de Alzheimer. Arquivos de Neuro-Psiquiatria, v. 58, n. 2A, p. 292-299, 2000.

ALZHEIMER'S ASSOCIATION. 2015 Alzheimer's disease facts and figures. Alzheimer's \& Dementia, v. 11, n. 3, p. 332-384, 2015.

ALZHEIMER'S DISEASE INTERNATIONAL. World Alzheimer Report 2015 - The Global Impact of Dementia: An analysis of prevalence, incid ence, cost and trends. London, UK: [s.n.].

AMERICAN PSYCHIATRIC ASSOCIATION. Diagnostic and Statistical Manual of Mental Disorders: DSM-IV-TR. [s.I.] American Psychiatric Association, 2000.

ANTOINE, C. et al. Awareness of deficits and anosognosia in Alzheimer's disease. L'Encephale, v. 30, n. 6, p. 570-577, 2004.

APOSTOLOVA, L. G.; THOMPSON, P. M. Mapping progressive brain structural changes in early Alzheimer's disease and mild cognitive impairment. Neuropsychologia, v. 46, n. 6, p. 1597-1612, 2008.

ARLT, S. et al. Adherence to medication in patients with dementia: Predictors and strategies for improvement. Drugs and Aging, v. 25, n. 12, p. 1033-1047, 2008.

BABINSKI, J. Contribution à l'étude des troubles mentaux dans I'hémiplégie organique cérébrale (anosognosie). Revue Neurologique, v. 27, p. 845-848, 1914.

BARRY, E. S.; NAUS, M. J.; REHM, L. P. Depression and implicit memory: Understanding mood congruent memory bias. Cognitive Therapy and Research, v. 28, n. 3, p. 387-414, 2004.

BECK, A. T. Cognitive therapy and the emotional disorders. New York: International Universities Press, 1976. 
BERTOLUCCI, P. H. et al. [The Mini-Mental State Examination in a general population: impact of educational status]. Arquivos de neuropsiquiatria, v. 52, n. 1, p. 1-7, 1994.

BERTRAND, E.; LANDEIRA-FERNANDEZ, J.; MOGRABI, D. C. L'impact psychosocial de l'anosognosie dans la Démence de Type Alzheimer. Revista Ibero-american de Gerontologia, v. 2, p. 52-69, 2013.

BERTRAND, E.; LANDEIRA-FERNANDEZ, J.; MOGRABI, D. C. Metacognition and perspective-taking in Alzheimer's disease: a minireview. Metacognition and Perspective-Taking in Alzheimer's Disease: a mini-review. Frontiers in Psychology, v. 7, n. November, p. 1-7, 2016.

BESHARATI, S. et al. Another perspective on anosognosia: Selfobservation in video replay improves motor awareness. Neuropsychological rehabilitation, v. 25, n. 3, p. 319-52, 2015.

BLACK, W.; ALMEIDA, O. P. A systematic review of the association between the Behavioral and Psychological Symptoms of Dementia and burden of care. International Psychogeriatrics, v. 16, n. 3, p. 295-315, 2004.

BLANEY, P. H. Affect and memory: a review. Psychological bulletin, v. 99, n. 2, p. 229-246, 1986.

BLAUT, A. et al. Are attentional bias and memory bias for negative words causally related? Journal of Behavior Therapy and Experimental Psychiatry, v. 44, n. 3, p. 293-299, 2013.

BODEN, J. M.; BAUMEISTER, R. F. Repressive coping: distraction using pleasant thoughts and memories. Journal of personality and social psychology, v. 73, n. 1, p. 45-62, 1997.

BOND, R. L. et al. Processing of Self versus Non-Self in Alzheimer's Disease. Frontiers in Human Neuroscience, v. 10, n. March, p. 97, 2016.

BOWER, G. H. Mood and memory. The American psychologist, v. 36, n. 2, p. 129-148, 1981.

BOWER, G. H.; GILLIGAN, S. G.; MONTEIRO, K. P. Selectivity of learning caused by affective states. Journal of Experimental Psychology: General, v. 110, n. 4, p. 451-473, 1981.

BOWER, G. H.; MAYER, J. D. In search of mood-dependent retrieval. Journal of Social Behavior and Personality, v. 4, n. 2, p. 121-156, 1989.

BOWER, G. H.; MONTEIRO, K. P.; GILLIGAN, S. G. Emotional mood as a context for learning and recall. Journal of Verbal Learning and Verbal Behavior, v. 17, n. 5, p. 573-585, 1978.

BRAAK, H.; BRAAK, E. Evolution of the neuropathology of Alzheimer's disease. Acta Neurologica Scandinavica, v. 94, n. S165, p. 3-12, 1996. 
BRADLEY, B. P.; MOGG, K.; WILLIAMS, R. Implicit and explicit memory for emotional information in non-clinical subjects. Behaviour research and therapy, v. 32, n. 1, p. 65-78, 1994.

BRUGGER, P. Reflective mirrors: perspective-taking in autoscopic phenomena. Cognitive neuropsychiatry, v. 7, n. 3, p. 179-94, 2002.

BUCKNER, R. L.; ANDREWS-HANNA, J. R.; SCHACTER, D. L. The Brain's Default Network: Anatomy, Function, and Relevance to Disease. Annals of the New York Academy of Sciences, v. 1124, n. 1, p. 1-38, 2008.

BULLINGTON, J. C. Mood congruent memory: A replication of symmetrical effects for both positive and negative moods. Journal of Social Behavior and Personality, v. 5, n. 4, p. 123-134, 1990.

BURDICK, K. E. et al. Attention and psychomotor functioning in bipolar depression. Psychiatry Research, v. 166, n. 2-3, p. 192-200, 2009.

CACIOPPO, J. T. et al. The psychophysiology of emotion. 2. ed. New York: Guilford Press, 2000.

CEREJEIRA, J.; LAGARTO, L.; MUKAETOVA-LADINSKA, E. B. Behavioral and Psychological Symptoms of Dementia. Frontiers in Neurology, v. 3, 2012.

CLARE, L. et al. Awareness in dementia: A review of assessment methods and measures. Aging \& mental health, v. 9, n. 5, p. 394-413, 2005.

CLARE, L. et al. Multidimensional assessment of awareness in early-stage dementia: A cluster analytic approach. Dementia and Geriatric Cognitive Disorders, v. 31, n. 5, p. 317-327, 2011.

CLARE, L. et al. The influence of psychological, social and contextual factors on the expression and measurement of awareness in early-stage dementia: testing a biopsychosocial model. International journal of geriatric psychiatry, v. 27, n. 2, p. 167-77, 2012a.

CLARE, L. et al. "She might have what I have got": the potential utility of vignettes as an indirect measure of awareness in early-stage dementia. Aging \& mental health, v. 16, n. 5, p. 566-75, 2012b.

CLARE, L. et al. The influence of psychological, social and contextual factors on the expression and measurement of awareness in early-stage dementia: testing a biopsychosocial model. International journal of geriatric psychiatry, v. 27, n. 2, p. 167-77, fev. 2012c.

CLARK, D. M.; TEASDALE, J. D. Constraints on the effects of mood on memory. Journal of Personality and Social Psychology, v. 48, n. 6, p. 1595-1608, 1985.

COLLETTE, F.; VAN DER LINDEN, M. Executive functions in Alzheimer's disease. In: MORRIS, R. G.; BECKER, J. T. (Eds.). . Cognitive neuropsychology of Alzheimer's disease. 2nd. ed. New York: Oxford 
University Press, 2004. p. 103-120.

COLLETTE, F.; VAN DER LINDEN, M.; SALMON, E. Executive Dysfunction in Alzheimer's Disease. Cortex, v. 35, n. 1, p. 57-72, 1999.

CONNOR, L. T.; DUNLOSKY, J.; HERTZOG, C. Age-related differences in absolute but not relative metamemory accuracy. Psychology and aging, v. 12, n. 1, p. 50-71, 1997.

COSENTINO, S. et al. Objective metamemory testing captures awareness of deficit in Alzheimer's disease. Cortex, v. 43, n. 7, p. 1004-1019, 2007.

COSENTINO, S. et al. Memory Awareness Influences Everyday Decision Making Capacity about Medication Management in Alzheimer's Disease. International journal of Alzheimer's disease, v. 2011, p. 483897, 2011.

COSENTINO, S.; STERN, Y. Metacognitive theory and assessment in dementia: do we recognize our areas of weakness? Journal of the International Neuropsychological Society : JINS, v. 11, n. 7, p. 910-9, 2005.

DARLEY, C. F. et al. The nature of storage deficits and state-dependent retrieval under marihuana. Psychopharmacologia, v. 37, n. 4, p. 139149, 1974.

DAVID, A. S.; CHIS STER, I.; ZAVAREI, H. Effect of video selfobservations vs. observations of others on insight in psychotic disorders. The Journal of nervous and mental disease, v. 200, n. 4, p. 358-61, 2012.

DAVIDOFF, S. A. et al. Effect of video self-observation on development of insight in psychotic disorders. The Journal of nervous and mental disease, v. 186, n. 11, p. 697-700, 1998.

DEBETTIGNIES, B. H.; MAHURIN, R. K.; PIROZZOLO, F. J. Insight for impairment in independent living skills in Alzheimer's disease and multiinfarct dementia. Journal of clinical and experimental neuropsychology, v. 12, n. 2, p. 355-363, 1990.

DUKA, T.; WEISSENBORN, R.; DIENES, Z. State-dependent effects of alcohol on recollective experience, familiarity and awareness of memories.

Psychopharmacology, v. 153, n. 3, p. 295-306, 2001.

DUKE, L. M. et al. Cognitive components of deficit awareness in Alzheimer's disease. Neuropsychology, v. 16, n. 3, p. 359-69, 2002.

$\mathrm{EICH}, \mathrm{E}$. et al. Cognition and Emotion. New York: Oxford University Press, 2000.

EICH, E.; MACAULAY, D. Are real moods required to reveal moodcongruent and mood-dependent memory? Psychological science: a journal of the American Psychological Society / APS, v. 11, n. 3, p. 244-248, 2000. 
EICH, E.; METCALFE, J. Mood dependent memory for internal versus external events. Journal of Experimental Psychology: Learning, Memory, and Cognition, v. 15, n. 3, p. 443-455, 1989.

$\mathrm{EICH}, \mathrm{J}$. E. The cue-dependent nature of state-dependent retrieval. Memory \& Cognition, v. 8, n. 2, p. 157-173, 1980.

EKMAN, P.; LEVENSON, R. W.; FRIESEN, W. V. Autonomic nervous system activity distinguishes among emotions. Science, v. 221, n. 4616, p. 1208-1210, 1983.

ELLIS, H. C.; MOORE, B. A. M. Mood and Memory. In: DALGLEISH, T.; POWER, M. J. (Eds.). . Handbook of Cognition and Emotion. Chichester, UK: John Wiley \& Sons, Ltd, 1999. p. 191-210.

ELLWART, T.; RINCK, M.; BECKER, E. S. Selective memory and memory deficits in depressed inpatients. Depression and anxiety, v. 17, n. 4, p. 197-206, 2003.

ERGIS, A.; PIOLINO, P.; MURE, C. Mémoire explicite et implicite pour des stimuli émotionnels dans la dépression du sujet âgé et la maladie d'Alzheimer. Psychologie \& NeuroPsychiatrie du vieillissement, v. 1, n. 4, p. 265-271, 2003.

ERNST, A. et al. Anosognosia and Metacognition in Alzheimer's Disease. In: DUNLOSKY, J.; TAUBER, S. U. K. (Eds.). . The Oxford Handbook of Metamemory. New York, NY: Oxford University Press, 2015.

FEAST, A. et al. A systematic review of the relationship between behavioral and psychological symptoms (BPSD) and caregiver well-being. International Psychogeriatrics, p. 1-14, 2016.

FERNÁNDEZ-MARTÍNEZ, $M$. et al. Prevalence of neuropsychiatric symptoms in Alzheimer's disease and vascular dementia. Current Alzheimer research, v. 5, n. 1, p. 61-69, 2008.

FEYERS, D. et al. Neural networks involved in self-judgement in young and elderly adults. Neurolmage, v. 53, n. 1, p. 341-347, 2010.

FIEDLER, K. et al. Is Mood Congruency an Effect of Genuine Memory or Response Bias? Journal of Experimental Social Psychology, v. 37, n. 3, p. 201-214, 2001.

FIEDLER, K.; PAMPE, H.; SCHERF, U. Mood and memory for tightly organized social information. European Journal of Social Psychology, v. 16, n. 2, p. 149-164, 1986.

FIEDLER, K.; STROEHM, W. What kind of mood influences what kind of memory: the role of arousal and information structure. Memory \& cognition, v. 14, n. 2, p. 181-188, 1986.

FITZGERALD, D. A. et al. How mood challenges emotional memory formation: An fMRI investigation. Neurolmage, v. 56, n. 3, p. 1783-1790, 2011. 
FLAVELL, J. H. Metacognition and cognitive monitoring: A new area of cognitive-developmental inquiry. American Psychologist, v. 34, n. 10, p. 906-911, 1979.

FLEMING, K. et al. Memory for emotional stimuli in patients with Alzheimer's disease. American Journal of Alzheimer's Disease and Other Dementias, v. 18, n. 6, p. 340-342, 2003.

FOLSTEIN, M. F.; FOLSTEIN, S. E.; MCHUGH, P. R. "Mini-mental state". A practical method for grading the cognitive state of patients for the clinician. Journal of psychiatric research, v. 12, n. 3, p. 189-198, 1975.

FOTOPOULOU, A. et al. Self-observation reinstates motor awareness in anosognosia for hemiplegia. Neuropsychologia, v. 47, n. 5, p. $1256-$ 1260, 2009.

FROST, R. O.; GREEN, M. L. Velten Mood Induction Procedure Effects Duration and Postexperimental Removal. Personality and Social Psychology Bulletin, v. 8, n. 2, p. 341-347, jun. 1982.

GARRETT, M. et al. Lack of insight and conceptions of "mental illness" in schizophrenia, assessed in the third person through case vignettes.

Psychosis, v. 3, n. 2, p. 115-125, 2011.

GILLIGAN, S. G.; BOWER, G. H. Reminding and mood-congruent memory. Bulletin of the Psychonomic Society, v. 21, n. 6, p. 431-434, 1983.

GREEN, J. et al. Variable Awareness of Deficits in Alzheimer's Disease.: Cognitive and Behavioral Neurology. Neuropsychiatry, Neuropsychology, \& Behavioral Neurology, v. 6, n. 3, p. $159-165$, 1993.

GUIMARÃES, H. C. et al. Brazilian caregiver version of the Apathy Scale. Dementia e Neuropsychologia, v. 3, n. 4, p. 321-326, 2009.

HANNESDOTTIR, K.; MORRIS, R. G. Primary and secondary anosognosia for memory impairment in patients with Alzheimer's disease. Cortex, v. 43, n. 7, p. 1020-1030, 2007.

HARWOOD, D. G.; SULTZER, D. L.; WHEATLEY, M. V. Impaired insight in Alzheimer disease: association with cognitive deficits, psychiatric symptoms, and behavioral disturbances. Neuropsychiatry, Neuropsychology, and Behavioral Neurology, v. 13 , n. 2, p. 83-88, 2000.

HIGGINS, J. P.; GREEN, S. (EDS.). Cochrane Handbook for Systematic Reviews of Interventions. Chichester, UK: John Wiley \& Sons, Ltd, 2008.

HORNING, S. M.; MELROSE, R.; SULTZER, D. Insight in Alzheimer's disease and its relation to psychiatric and behavioral disturbances. International Journal of Geriatric Psychiatry, v. 29, n. 1, p. 77-84, 2014. 
HURT, C. S. et al. Insight, cognition and quality of life in Alzheimer's disease. Journal of Neurology, Neurosurgery \& Psychiatry, v. 81, n. 3, p. 331-336, 2010.

ISEN, A. M. Toward understanding the role of affect in cognition. In: SCRULL, T. K.; WYER, R. S. (Eds.). . Handbook of social cognition. Hillsdale, NJ: Lawrence Erlbaum Associates, Inc, 1984. v. 3p. 179-236.

ISEN, A. M. Asymmetry of happiness and sadness in effects on memory in normal college students: Comment on Hasher, Rose, Zacks, Sanft, and Doren. Journal of Experimental Psychology: General, v. 114, n. 3, p. 388-391, 1985.

ISEN, A. M.; GORGOGLIONE, J. M. Some Specific Effects of Four AffectInduction Procedures. Personality and Social Psychology Bulletin, v. 9, n. 1 , p. $136-143,1983$.

ISEN, A M. et al. Affect, accessibility of material in memory, and behavior: a cognitive loop? Journal of personality and social psychology, v. 36, n. 1, p. 1-12, 1978.

JOHNSON, W. B. Euphoric and Depressed Moods in Normal Subjects*. Journal of Personality, v. 6, n. 2, p. 79-98, 1937.

KASZNIAK, A. W.; ZAK, M. G. On the neuropsychology of metamemory: Contributions from the study of amnesia and dementia. Learning and Individual Differences, v. 8, n. 4, p. 355-381, 1996.

KIEFER, M. et al. Mood states modulate activity in semantic brain areas during emotional word encoding. Cerebral Cortex, v. 17, n. 7, p. 1516-30, 2007.

KLAASSEN, T. et al. Mood congruent memory bias induced by tryptophan depletion. Psychological medicine, v. 32, n. 1, p. 167-172, 2002.

KNIGHT, B. G.; DURBIN, K. Aging and the effects of emotion on cognition: Implications for psychological interventions for depression and anxiety. PsyCh journal, v. 4, n. 1, p. 11-9, 2015.

KOTLER-COPE, S.; CAMP, C. J. Anosognosia in Alzheimer disease. Alzheimer disease and associated disorders, v. 9, n. 1, p. 52-56, 1995.

LEWIS, P. A. et al. Brain mechanisms for mood congruent memory facilitation. Neurolmage, v. 25, n. 4, p. 1214-1223, 2005.

LEWIS, V. E.; WILLIAMS, R. N. Mood-congruent vs. mood-statedependent learning: implications for a view of emotion. Journal of Social Behavior and Personality, v. 4, n. 2, p. 157-171, 1989.

LOEFFLER, S. N.; MYRTEK, M.; PEPER, M. Mood-congruent memory in daily life: Evidence from interactive ambulatory monitoring. Biological Psychology, v. 93, n. 2, p. 308-315, 2013.

LOEWENSTEIN, D. Assessment of Alzheimer's Disease. In: RAVDIN, L. 
D.; KATZEN, H. L. (Eds.). . Handbook on the Neuropsychology of Aging and Dementia. New York, NY: Springer New York, 2013. p. 271280.

LOPEZ, O. L. et al. Awareness of cognitive deficits and anosognosia in probable Alzheimer's disease. European neurology, v. 34, n. 5, p. 277282, 1994.

MACCALLUM, F. et al. Specific autobiographical memory following hypnotically induced mood state. The International journal of clinical and experimental hypnosis, v. 48, n. 4, p. 361-373, 2000.

MANGONE, C. A. et al. Impaired Insight in Alzheimer's Disease. Journal of Geriatric Psychiatry and Neurology, v. 4, n. 4, p. 189-193, 1991.

MARC, L. G.; RAUE, P. J.; BRUCE, M. L. Screening performance of the 15-item geriatric depression scale in a diverse elderly home care population. The American journal of geriatric psychiatry, v. 16, n. 11, p. 914-21, 2008.

MARCEL, A.; TEGNER, R.; NIMMOSMITH, I. Anosognosia for Plegia: Specificity, Extension, Partiality and Disunity of Bodily Unawareness. Cortex, v. 40, n. 1, p. 19-40, 2004.

MARIN, R.; BIEDRZYCKI, R.; FIRINCIOGULLARI, S. Reliability and validity of the Apathy Evaluation Scale. Psychiatry Research, v. 38, n. 2, p. 143-162, 1991.

MARTIN, M. On the induction of mood. Clinical Psychology Review, v. 10, n. 6, p. 669-697, 1990.

MARTYR, A. et al. Dissociation between implicit and explicit manifestations of awareness in early stage dementia: evidence from the emotional Stroop effect for dementia-related words. International journal of geriatric psychiatry, v. 26, n. 1, p. 92-9, 2011.

MATHEWS, A.; MACLEOD, C. Cognitive vulnerability to emotional disorders. Annual review of clinical psychology, v. 1, p. 167-95, 2005.

MAYER, J. D. et al. Toward better specification of the mood-congruency effect in recall. Journal of Experimental Social Psychology, v. 26, n. 6, p. 465-480, 1990.

MAYER, J. D.; MCCORMICK, L. J.; STRONG, S. E. Mood-Congruent Memory and Natural Mood: New Evidence. Personality and Social Psychology Bulletin, v. 21, n. 7, p. 736-746, 1995.

MCGLYNN, S. M.; KASZNIAK, A. W. When metacognition fails: impaired awareness of deficit in Alzheimer's disease. Journal of cognitive neuroscience, v. 3, n. 2, p. 183-7, 1991.

MCGLYNN, S. M.; SCHACTER, D. L. Unawareness of deficits in neuropsychological syndromes. Journal of Clinical and Experimental Neuropsychology, v. 11, n. 2, p. 143-205, 1989. 
MCKHANN, G. M. et al. The diagnosis of dementia due to Alzheimer's disease: recommendations from the National Institute on AgingAlzheimer's Association workgroups on diagnostic guidelines for Alzheimer's disease. Alzheimer's \& dementia: the journal of the Alzheimer's Association, v. 7, n. 3, p. 263-9, 2011.

MECKLENBRAUKER, S.; HAGER, W. Effects of mood on memory: Experimental tests of a mood-state-dependent retrieval hypothesis and of a mood-congruity hypothesis. Psychological Research, v. 46, n. 4, p. 355-376, 1984.

MEVEL, K. et al. The default mode network in healthy aging and Alzheimer's disease. International journal of Alzheimer's disease, $v$. 2011, p. 535816, 2011.

MIGLIORELLI, R. et al. Anosognosia in Alzheimer's disease: a study of associated factors. The Journal of neuropsychiatry and clinical neurosciences, v. 7, n. 3, p. 338-344, 1995.

MIRANDA, R.; KIHLSTROM, J. Mood congruence in childhood and recent autobiographical memory. Cognition \& Emotion, v. 19, n. 7, p. 981-998, 2005.

MOGRABI, D. C. et al. Unawareness of memory impairment in dementia: a population-based study. International Psychogeriatrics, v. 24, n. 6, p. 931-939, 2012a.

MOGRABI, D. C. et al. Emotional reactivity and awareness of task performance in Alzheimer's disease. Neuropsychologia, v. 50, n. 8, p. 2075-84, 2012b.

MOGRABI, D. C. et al. Metacognition and attribution of difficulty for self and others in Alzheimer's disease. Psychology \& Neuroscience, v. 7, n. 3, p. 417-424, 2014a.

MOGRABI, D. C. et al. The development of computerised success-failure manipulation paradigms for the experimental study of metacognition in neurological patients. Temas em Psicologia, v. 22, n. 3, p. 579-588, 2014b.

MOGRABI, D. C. et al. Neuropsychological and behavioral disturbance correlates of unawareness of memory impairment in dementia: a population-based study. Journal of geriatric psychiatry and neurology, v. 28, n. 1, p. 3-11, 2015.

MOGRABI, D. C.; BROWN, R. G.; MORRIS, R. G. Anosognosia in Alzheimer's disease - The petrified self. Consciousness and Cognition, v. 18, n. 4, p. 989-1003, 2009.

MOGRABI, D. C.; MORRIS, R. G. Implicit Awareness in Anosognosia: Clinical Observations, Experimental Evidence, and Theoretical Implications. Cognitive Neuroscience, v. 4, n. 3-4, p. 181-209, 2013.

MOGRABI, D. C.; MORRIS, R. G. On the relation among mood, apathy, 
and anosognosia in Alzheimer's disease. Journal of the International Neuropsychological Society : JINS, v. 20, n. 1, p. 2-7, 2014.

MORRIS, R. G.; HANNESDOTTIR, K. Loss of "awareness" in Alzheimer's Disease. In: MORRIS, R. G.; BECKER, J. T. (Eds.). . The Cognitive Neuropsychology of Alzheimer's Disease. Oxford: Oxford University Press, 2004. p. 275-296.

MORRIS, R. G.; MOGRABI, D. C. Anosognosia, autobiographical memory and self knowledge in Alzheimer's disease. Cortex; a journal devoted to the study of the nervous system and behavior, v. 49, n. 6, p. 1553-65, 2013.

MOULIN, C. Sense and sensitivity: metacognition in Alzheimer's disease. In: PERFECT, T. J.; SCHWARTZ, B. L. (Eds.). . Applied Metacognition. New York, NY: Cambridge University Press, 2002. p. 197-223.

NASBY, W. Moderators of mood-congruent encoding: Self-/otherreference and affirmative/nonaffirmative judgement. Cognition \& Emotion, v. 8, n. 3, p. 259-278, 1994.

NASBY, W. Moderators of Mood-congruent Encoding and Judgement: Evidence that Elated and Depressed Moods Implicate Distinct Processes. Cognition \& Emotion, v. 10, n. 4, p. 361-378, 1996.

NATALE, M.; HANTAS, M. Effect of temporary mood states on selective memory about the self. Journal of Personality and Social Psychology, v. 42, n. 5, p. 927-934, 1982.

NELSON, J. C.; CHARNEY, D. S. The symptoms of major depressive illness. The American journal of psychiatry, v. 138, n. 1, p. 1-13, 1981.

NELSON, T. O.; NARENS, L. Metamemory: A Theoretical Framework and New Findings. Psychology of Learning and Motivation, v. 26, p. 125173, 1990.

NOLEN-HOEKSEMA, S. Responses to depression and their effects on the duration of depressive episodes. Journal of abnormal psychology, $v$. 100, n. 4, p. 569-582, 1991.

NOLEN-HOEKSEMA, S. The role of rumination in depressive disorders and mixed anxiety/depressive symptoms. Journal of abnormal psychology, v. 109, n. 3, p. 504-511, 2000.

NUTT, R. M.; LAM, D. A comparison of mood-dependent memory in bipolar disorder and normal controls. Clinical psychology \& psychotherapy, v. 18, n. 5, p. 379-386, 2011.

ORFEI, M. D. et al. Anosognosia for hemiplegia after stroke is a multifaceted phenomenon: a systematic review of the literature. Brain : a journal of neurology, v. 130, n. Pt 12, p. 3075-90, 2007.

PARROTT, W. G. Mood induction and instructions to sustain moods: A test of the subject compliance hypothesis of mood congruent memory. 
Cognition \& Emotion, v. 5, n. 1, p. 41-52, 1991.

PARROTT, W. G.; SABINI, J. Mood and memory under natural conditions: Evidence for mood incongruent recall. Journal of Personality and Social Psychology, v. 59, n. 2, p. 321-336, 1990.

PERRIG, W. J.; PERRIG, P. Mood and memory: mood-congruity effects in absence of mood. Memory \& cognition, v. 16, n. 2, p. 102-109, 1988.

RAINVILLE, P. et al. Basic emotions are associated with distinct patterns of cardiorespiratory activity. International Journal of Psychophysiology, Psychophiosology and Cognitive Neuroscience. v. 61, n. 1, p. 5-18, 2006.

RAMACHANDRAN, V. S.; ROGERS-RAMACHANDRAN, D. Synaesthesia in Phantom Limbs Induced with Mirrors. Proceedings of the Royal Society B: Biological Sciences, v. 263, n. 1369, p. 377-386, 1996.

RIES, M. L. et al. Anosognosia in mild cognitive impairment: Relationship to activation of cortical midline structures involved in self-appraisal. Journal of the International Neuropsychological Society: JINS, v. 13, n. 3, p. 450-461, 2007.

RINCK, M.; GLOWALLA, U.; SCHNEIDER, K. Mood-congruent and moodincongruent learning. Memory \& cognition, v. 20, n. 1, p. 29-39, 1992.

ROSEN, H. J. Anosognosia in neurodegenerative disease. Neurocase, v. 17, n. 3, p. 231-241, 2011.

RUBY, P. et al. Perspective taking to assess self-personality: what's modified in Alzheimer's disease? Neurobiology of aging, v. 30, n. 10, p. 1637-51, 2009.

RUBY, P.; DECETY, J. Effect of subjective perspective taking during simulation of action: a PET investigation of agency. Nature neuroscience, v. 4, n. 5, p. 546-50, 2001.

RUBY, P.; DECETY, J. What you believe versus what you think they believe: a neuroimaging study of conceptual perspective-taking. European Journal of Neuroscience, v. 17, n. 11, p. 2475-2480, 2003.

RUBY, P.; DECETY, J. How would you feel versus how do you think she would feel? A neuroimaging study of perspective-taking with social emotions. Journal of cognitive neuroscience, v. 16, n. 6, p. 988-99, 2004.

RUSTING, C. L. Interactive effects of personality and mood on emotioncongruent memory and judgment. Journal of personality and social psychology, v. 77, n. 5, p. 1073-1086, 1999.

RUSTING, C. L.; DEHART, T. Retrieving positive memories to regulate negative mood: consequences for mood-congruent memory. Journal of personality and social psychology, v. 78, n. 4, p. 737-752, 2000.

RYMER, S. et al. Impaired awareness, behavior disturbance, and 
caregiver burden in Alzheimer disease. Alzheimer disease and associated disorders, v. 16, n. 4, p. 248-253, 2002.

RYSKIN, R. A. et al. Perspective-taking in comprehension, production, and memory: An individual differences approach. Journal of Experimental Psychology: General, v. 144, n. 5, p. 898-915, 2015.

SALMON, E. et al. A comparison of unawareness in frontotemporal dementia and Alzheimer's disease. Journal of neurology, neurosurgery, and psychiatry, v. 79, n. 2, p. 176-9, 2008.

SALOVEY, P.; SINGER, J. A. Mood congruency effects in recall of childhood versus recent memories. Journal of Social Behavior \& Personality, v. 4, n. 2, p. 99-120, 1989.

SCARMEAS, N. et al. Disruptive behavior as a predictor in Alzheimer disease. Archives of neurology, v. 64, n. 12, p. 1755-61, 2007.

SCHALLER, S. et al. The main cost drivers in dementia: a systematic review. International Journal of Geriatric Psychiatry, v. 30, n. 2, p. 111-129, 2015.

SELTZER, B. et al. Awareness of deficit in Alzheimer's disease: relation to caregiver burden. The Gerontologist, v. 37, n. 1, p. 20-24, 1997.

SHAJI, S.; BOSE, S.; KURIAKOSE, S. Behavioral and psychological symptoms of dementia: A study of symptomatology. Indian journal of psychiatry, v. 51, n. 1, p. 38-41, 2009.

SINGER, J. A.; SALOVEY, P. Mood and memory: Evaluating the network theory of affect. Clinical Psychology Review, v. 8, n. 2, p. 211-251, 1988.

SNYDER, M.; WHITE, P. Moods and memories: elation, depression, and the remembering of the events of one's life. Journal of personality, v. 50, n. 2, p. $149-167,1982$.

SOUCHAY, C. Metamemory in Alzheimer's disease. Cortex, v. 43, n. 7, p. 987-1003, 2007.

SOUSA, M. F. B. et al. Awareness of disease is different for cognitive and functional aspects in mild Alzheimer's Disease: A one-year observation study. Journal of Alzheimer's Disease, v. 43, n. 3, p. 905-913, 2015.

SPALLETTA, G. et al. Anosognosia and neuropsychiatric symptoms and disorders in mild Alzheimer disease and mild cognitive impairment. Journal of Alzheimer's disease: JAD, v. 29, n. 4, p. 761-772, 2012.

STARKSTEIN, S. E. et al. Prospective longitudinal study of depression and anosognosia in Alzheimer's disease. The British journal of psychiatry : the journal of mental science, v. 171, p. 47-52, 1997.

STARKSTEIN, S. E. et al. A diagnostic formulation for anosognosia in Alzheimer's disease. Journal of neurology, neurosurgery, and 
psychiatry, v. 77, n. 6, p. 719-725, 2006.

STARKSTEIN, S. E. et al. Insight and danger in Alzheimer's disease. European journal of neurology, v. 14, n. 4, p. 455-60, 2007.

STARKSTEIN, S. E. Anosognosia in Alzheimer's disease: Diagnosis, frequency, mechanism and clinical correlates. Cortex, Special Issue: Understanding Babinski's anosognosia: 100 years later. v. 61 , p. 64-73, 2014.

STEELE, C. et al. Psychiatric symptoms and nursing home placement of patients with Alzheimer's disease. The American Journal of Psychiatry, v. 147 , n. 8 , p. 1049-1051, 1990.

STEFANACCI, R. G. The costs of Alzheimer's disease and the value of effective therapies. The American Journal of Managed Care, v. 17 Suppl 1, p. S356-362, 2011.

STUSS, D. T. Self, awareness and the frontal lobes: A neuropsychological perspective. In: STRAUSS, J.; GOETHALS, G. R. (Eds.). . The self: Interdisciplinary approaches. [s.I.] Springer New York, 1991. p. 255277.

STUSS, D. T. et al. The frontal lobes and self-awareness. In: FEINBERG, T. E.; KEENAN, J. P. (Eds.). . The Lost Self: Pathologies of the Brain and Identity. Oxford: Oxford University Press, 2005. p. 50-64.

TEASDALE, J. D. Negative thinking in depression: Cause, effect, or reciprocal relationship? Advances in Behaviour Research and Therapy, v. 5, n. 1, p. 3-25, 1983.

TEASDALE, J. D.; RUSSELL, M. L. Differential effects of induced mood on the recall of positive, negative and neutral words. The British journal of clinical psychology, v. 22 (Pt 3), p. 163-171, 1983.

TEASDALE, J. D.; TAYLOR, R.; FOGARTY, S. J. Effects of induced elation depression on the accessibility of memories of happy and unhappy experiences. Behaviour Research and Therapy, v. 18, n. 4, p. 339-346, 1980.

TURRÓ-GARRIGA, O. et al. Burden associated with the presence of anosognosia in Alzheimer's disease. International Journal of Geriatric Psychiatry, v. 28, n. 3, p. 291-297, 2013.

VAN DEN STOCK, J. et al. A strange face in the mirror. Face-selective self-misidentification in a patient with right lateralized occipito-temporal hypo-metabolism. Cortex, v. 48, n. 8, p. 1088-1090, 2012.

VAN DEN STOCK, J. et al. Face-Selective Hyper-Animacy and HyperFamiliarity Misperception in a Patient With Moderate Alzheimer's Disease. The Journal of Neuropsychiatry and Clinical Neurosciences, v. 25, n. 4, p. E52-E53, 2013.

VAN DER LINDE, R. M. et al. Grouping of behavioural and psychological 
symptoms of dementia. International journal of geriatric psychiatry, v. 29, n. 6, p. 562-8, 2014.

VAN DER MEER, L. et al. Self-reflection and the brain: A theoretical review and meta-analysis of neuroimaging studies with implications for schizophrenia. Neuroscience \& Biobehavioral Reviews, v. 34, n. 6, p. 935-946, 2010.

VAN VLIET, D. et al. Awareness and Its Association With Affective Symptoms in Young-onset and Late-onset Alzheimer Disease. Alzheimer Disease \& Associated Disorders, v. 27, n. 3, p. 265-271, 2013.

VAN WINGEN, G. A. et al. Neural state and trait bases of moodincongruent memory formation and retrieval in first-episode major depression. Journal of psychiatric research, v. 44, n. 8, p. 527-534, 2010.

VARNER, L. J.; ELLIS, H. C. Cognitive activity and physiological arousal: processes that mediate mood-congruent memory. Memory \& cognition, v. 26, n. 5, p. 939-950, 1998.

VASTERLING, J. J. et al. Unawareness of deficit in Alzheimer's Disease: Domain-specific differences and disease correlates. Neuropsychiatry, Neuropsychology, and Behavioral Neurology, v. 8, n. 1, p. 26-32, 1995a.

VASTERLING, J. J. et al. Unawareness of deficit in Alzheimer's Disease: Domain-specific differences and disease correlates. Neuropsychiatry, Neuropsychology, and Behavioral Neurology, v. 8, n. 1, p. 26-32, 1995b.

VERHÜLSDONK, S. et al. Anosognosia and depression in patients with Alzheimer's dementia. Archives of Gerontology and Geriatrics, v. 57, n. 3, p. 282-287, 2013.

VIKRAM, S. et al. Video self-observation: a means of improving insight in psychosis. Psychiatric Bulletin, v. 32, n. 9, p. 341-344, 2008.

WATKINS, P. C. Implicit memory bias in depression. Cognition \& Emotion, v. 16, n. 3, p. 381-402, 2002.

WIMO, A. et al. The worldwide economic impact of dementia 2010. Alzheimer's and Dementia, v. 9, n. 1, p. 1-11, 2013.

WIMO, A.; JONSSON, L.; WINBLAD, B. An estimate of the worldwide prevalence and direct costs of dementia in 2003. Dementia and geriatric cognitive disorders, v. 21, n. 3, p. 175-81, 2006.

YESAVAGE, J. A. et al. Development and validation of a geriatric depression screening scale: A preliminary report. Journal of Psychiatric Research, v. 17, n. 1, p. 37-49, 1982.

YOUNG, S. N. et al. Tryptophan depletion causes a rapid lowering of mood in normal males. Psychopharmacology, v. 87, n. 2, p. 173-7, 
1985.

ZANETTI, O. et al. Insight in dementia: when does it occur? Evidence for a nonlinear relationship between insight and cognitive status. The journals of gerontology. Series B, Psychological sciences and social sciences, v. 54, n. 2, p. P100-6, 1999.

ZHAO, Q.-F. et al. The prevalence of neuropsychiatric symptoms in Alzheimer's disease: Systematic review and meta-analysis. Journal of Affective Disorders, v. 190, p. 264-271, 2016.

ZHU, C. W. et al. Health-care use and cost in dementia caregivers: Longitudinal results from the Predictors Caregiver Study. Alzheimer's \& Dementia, v. 11, n. 4, p. 444-454, 2015. 